MONIQUE ANTUNES DE SOUZA CHELMINSKI BARRETO

ANÁLISE DO ZUMBIDO E DA AUDIÇÃO EM PORTADORES DE PERDA AUDITIVA NEUROSSENSORIAL SÚBITA IDIOPÁTICA SUBMETIDOS À CORTICOTERAPIA 


\author{
UNIVERSIDADE DE BRASÍLIA \\ FACULDADE DE CIÊNCIAS DA SAÚDE \\ PROGRAMA DE PÓS-GRADUAÇÃO EM CIÊNCIAS DA SAÚDE
}

MONIQUE ANTUNES DE SOUZA CHELMINSKI BARRETO

\title{
ANÁLISE DO ZUMBIDO E DA AUDIÇÃO EM PORTADORES DE PERDA AUDITIVA NEUROSSENSORIAL SÚBITA IDIOPÁTICA SUBMETIDOS À CORTICOTERAPIA
}

Tese apresentada como requisito parcial para a obtenção do Título de Doutor em Ciências da Saúde pelo Programa de Pós-Graduação em Ciências da Saúde da Universidade de Brasília

Orientador: Prof. Dr. Fayez Bahmad Júnior

Co-orientador: Prof. Dr. Carlos Augusto Costa Pires de Oliveira

BRASÍLIA 
MONIQUE ANTUNES DE SOUZA CHELMINSKI BARRETO

ANÁLISE DO ZUMBIDO E DA AUDIÇÃO EM PORTADORES DE PERDA AUDITIVA NEUROSSENSORIAL SÚBITA IDIOPÁTICA SUBMETIDOS À CORTICOTERAPIA

Aprovada em 1 
BANCA EXAMINADORA

$1^{\circ}$ Membro (presidente) Professor Dr. Fayez Bahmad Júnior Universidade de Brasília

$2^{\circ}$ Membro: Professor Dr. Carlos Augusto Costa Pires de Oliveira Universidade de Brasília

$3^{\circ}$ Membro: Professora Dra. Isabella Monteiro de Castro Silva Universidade de Brasília

$4^{\circ}$ Membro: Professor Dr. Lucas Moura Viana

Centro Universitário Planalto do Distrito Federal

$5^{\circ}$ Membro: Professora Dra. Marlene Escher Boger

Centro Universitário Planalto do Distrito Federal

Suplente: Dra. Vanessa Furtado de Almeida

Pesquisadora colaboradora do Programa de Pós-Graduação em Ciências da Saúde 


\title{
Ficha catalográfica
}

\author{
Barreto, Monique Antunes de Souza Chelminski \\ Análise do zumbido e da audição em portadores de perda auditiva neurossensorial súbita idiopática \\ submetidos à corticoterapia/ Monique Antunes de Souza Chelminski Barreto - Brasília: UnB / \\ Faculdade de Ciências da Saúde, 2016. \\ $104 \mathrm{f}$ \\ Orientador: Fayez Bahmad Júnior \\ Tese (Doutorado) - UnB / Faculdade de Ciências da Saúde / Programa de Pós-Graduação em \\ Ciências da Saúde, 2016. \\ Referências: f. 86-97 \\ 1. Zumbido. 2. Perda auditiva neurossensorial súbita. 3. Corticoide. - Tese. I. Bahmad Júnior, \\ Fayez. II. Universidade de Brasília, Faculdade de Ciências da Saúde, Programa de Pós-Graduação \\ em Ciências da Saúde. II. Título.
}


A Deus que colocou em minha vida pessoas maravilhosas como meu esposo Marcelo e meu filho Lucas Pietro pelo incentivo, motivação, paciência e sobretudo pelo amor incondicional.

Aos "meus meninos" com amor. 


\section{AGRADECIMENTOS}

Agradecimentos especiais ao meu orientador Dr. Fayez Bahmad Júnior, que me incentivou a seguir adiante, reforçando a importância da pesquisa como motor propulsor dos avanços em saúde. Agradeço por compartilhar seus conhecimentos, sempre que possível, bem como pelo apoio e amizade.

Aos pacientes que voluntariamente contribuíram para esta pesquisa, a minha imensa gratidão.

À minha mãe Maria Lêda e todos os amigos que mesmo distante apoiaram e incentivaram a continuidade deste projeto que além de projeto científico, se tornou projeto de vida.

Ao Dr. Carlos Augusto Costa Pires de Oliveira pelo incentivo e carinho com que trata seus alunos e por aceitar participar de banca examinadora desta tese. Obrigada por me ensinar sempre!

Ao Dr. Lucas Moura Viana, Dra. Marlene Escher Boger, Dra. Isabella Monteiro e Dra. Vanessa Furtado de Almeida, pela gentileza de terem aceitado participar da banca examinadora desta tese e agradeço pelos ensinamentos constantes!

Agradeço aos amigos e colegas do Hospital Materno Infantil de Brasília (HMIB), aos colegas professores, alunos e ex-alunos do Centro Universitário Planalto do Distrito Federal (UNIPLAN) pelo incentivo e apoio constante durante a realização deste projeto.

Agradeço ainda à amiga e colega Alleluia Lima Losno Ledesma pelo apoio incondicional e amizade em todos os momentos.

Agradeço à Universidade de Brasília e ao corpo docente que com esmero, conhecimento científico, apoio e orientação me possibilitaram a realização do curso de Doutorado em Ciências da Saúde.

Deixo também o meu agradecimento aos amores de minha vida, meu filho Lucas Pietro e meu esposo Marcelo, que mesmo diante da minha ausência constante, me apoiaram em todos os momentos em que estive realizando este trabalho, incentivando, colaborando, me proporcionando sempre muito amor e carinho. 


\section{RESUMO}

Introdução: O zumbido é um distúrbio complexo de audição e está presente em até $80 \%$ dos pacientes portadores de perda auditiva neurossensorial súbita, tornando-se inclusive, sua principal queixa. Objetivo: Analisar o zumbido e a audição em portadores de perda auditiva neurossensorial súbita idiopática submetidos à corticoterapia. Método: Estudo analítico, observacional, prospectivo e longitudinal com 23 sujeitos (Grupo Via Oral e Grupo Resgate - corticoide intratimpânico), avaliados pelo Tinnitus Handicap Inventory (THI), Escala Analógico-Visual (EAV), Audiometria Tonal Limiar e Emissões Otoacústicas Evocadas por Produto de Distorção, antes e após três meses de tratamento. Resultados: O incômodo com o zumbido medido por meio da EAV, no Grupo Via Oral foi de 7,69 no pré tratamento e 5,30 no pós tratamento. Para o Grupo Resgate, estes valores foram de 8,30 (pré) e 5,81 (pós). No THI, a nota da gravidade do zumbido no pré tratamento para o Grupo Via Oral foi 64,77 (pré) e 45,90 (pós) e para o Grupo Resgate foi 72, 20 (pré) e 47,73 (pós). Na Audiometria, no Grupo Via Oral a média tetratonal era 74,23dB e reduziu para 59,69dB. No Grupo Resgate era 86,50dB e reduziu para 51,91dB. Ocorreu melhora tanto na amplitude quanto na relação sinal/ruído das Emissões Otoacústicas Evocadas por Produto de Distorção nas quatro frequências avaliadas $(2 \mathrm{KHz}, 3 \mathrm{KHz}, 4 \mathrm{KHz}$ e $5 \mathrm{KHz})$. Os resultados mostraram uma diminuição no incômodo, na gravidade do zumbido, diminuição dos limiares auditivos e melhora na amplitude e relação sinal/ruído das emissões otoacústicas evocadas em ambos os grupos, com diferenças significativas ao comparar pré e pós tratamento, mas não diferença estatisticamente significante entre os grupos. Conclusão: Ocorreu melhora significativa do zumbido e da audição em ambos os grupos, demonstrando a eficácia de ambos tratamentos para portadores de perda auditiva neurossensorial súbita idiopática e zumbido. O tratamento com corticoide por via intratimpânica demonstrou ser uma alternativa eficaz.

Palavras-chave: zumbido; perda auditiva súbita; tratamento; intratimpânico; corticoide. 


\section{SUMMARY}

Introduction: Tinnitus is a hearing complex disorder and is present in up to $80 \%$ of patients with sudden sensorineural hearing loss, becoming even their main complaint. Objective: To analyse the tinnitus and hearing in patients with idiopathic sudden sensorineural hearing loss treated with steroids. Method: analytical, observational, prospective, longitudinal study with 23 subjects (Oral Group and Rescue Group - corticosteroids via intratympanic), evaluated by the Tinnitus Handicap Inventory (THI), Visual Analogic Scale (VAS), pure tone audiometry and evoked otoacoustic emissions distortion product, before and after three months of treatment. Results: The annoyance caused by tinnitus, measured by VAS, in Oral Group was 7.69 at pre-treatment and 5.30 at post treatment. To the Rescue group, these values were 8.30 (pre) and 5.81 (post). At THI, the score for the Oral Group was 64.77 (pre) and 45.90 (post) and for the Rescue Group was 72.20 (pre) and 47.73 (post).At pure tone audiometry, for Oral Group, the tetratonal average was reduced from $74,23 \mathrm{~dB}$ to $59,69 \mathrm{~dB}$. For Rescue Group it was reduced from $86,50 \mathrm{~dB}$ to $51,91 \mathrm{~dB}$. There was an improvement in both the amplitude and the signal/noise ratio of Evoked Otoacoustic Emissions Distortion Product in the four evaluated frequencies ( $2 \mathrm{KHz}, 3 \mathrm{KHz}, 4 \mathrm{KHz}$ and $5 \mathrm{KHz}$ ). The results showed a decrease in tinnitus severety and annoyance, decreased hearing thresholds and improved amplitude and signal/noise ratio of Evoked Otoacoustic Emissions in both groups, with significant differences when comparing pre and post treatment, but no statistically significant difference between groups. Conclusion: There was a significant improvement of tinnitus and hearing in both groups, demonstrating the efficacy of corticosteroids for idiopathic sudden sensorineural hearing loss and tinnitus. Treatment with corticosteroids via intratympanic shown to be an effective alternative.

Key words: tinnitus; sudden sensorineural hearing loss; treatment; intratympanic; steroid. 
NORMATIZAÇÃO ADOTADA

Normas para a redação de teses e dissertações do Programa de Pós-Graduação em Ciências da Saúde-Faculdade de Ciências da Saúde-Universidade de Brasília 


\section{LISTA DE ABREVIATURAS E SIGLAS}

ATL- Audiometria tonal Limiar

AAO-HNS- American Academy of Otolaryngology-Head and Neck Surgery

AASI- Aparelho de Amplificação Sonora Individual

CEP- Comitê de Ética em Pesquisa

CCE- Células Ciliadas Externas

dB- decibel

dBNA- decibel nível audição

dBNPS- decibel nível de pressão sonora

EAV- Escala Analógico-Visual

EOAs- Emissões Otoacústicas

EOAE- Emissões Otoacústicas Evocadas

EOAEPD- Emissões Otoacústicas Evocadas por Produto de Distorção

EMTr- Estimulação Magnética Transcraniana

F1- Tom primário 1

F2- Tom primário 2

GVO- Grupo Via Oral

GR- Grupo Resgate

Hz- Hertz

IT-METIL- metilpredinisolona intratimpânica

IT-DEX- dexametasona intratimpânica

IC- Implante Coclear

IPRF- Índice Percentual de Reconhecimento de Fala

KHz- Kilohertz

L1- Intensidade do Tom Primário 1

L2- Intensidade do Tom Primário 2

LDF- Limiar de Detecção de Fala

LRF- Limiar de Reconhecimento de Fala

n-quantidade de pacientes

OD- Orelha Direita

OE- Orelha Esquerda

OHB- Oxigenoterapia Hiperbárica

PANSS- Perda Auditiva Neurossensorial Súbita

PANSSI- Perda Auditiva Neurossensorial Súbita Idiopática

PEATE- Potencial Evocado Auditivo de Tronco Encefáico

QGZ- Questionário de Gravidade do Zumbido

S/R-Sinal/Ruído

THI-Tinnitus Handicap Inventory

TRT-Tinnitus Retrainig Therapy

$>=$ - Maior ou Igual

$<=-$ Menor ou Igual 


\section{LISTA DE FIGURAS}

Figura 1 - Esquema representando o modelo neurofisiológico do zumbido (Jastreboff, 1990).

Figura 2 - Ilustração da técnica de aplicação intratimpânica. 33

Figura 3 - Sonda para evocar e registrar as EOAEPD

Figura 4 - Impresso demonstrativo dos registros das EOAEPD .55

Figura 5 - Distribuição das notas de incômodo atribuídas pelos pacientes do GVO na EAV pré e pós tratamento. 60

Figura 6 - Distribuição das notas de incômodo atribuídas pelos pacientes do GR na EAV pré e pós tratamento. 61

Figura 7 - Percentual de diminuição do incômodo com o zumbido em ambos os grupos, na EAV pré e pós tratamento. 61

Figura 8 - Distribuição das notas atribuídas pelos pacientes no THI, pré e pós tratamento, no GVO. 64

Figura 9 - Distribuição das notas atribuídas pelos pacientes no THI, pré e pós tratamento, no GR. .65

Figura 10 - Comparação entre EAV, pré e pós tratamento 66

Figura 11 - Comparação entre THI, pré e pós tratamento 66

Figura 12 - Classificação do zumbido, segundo McCombe (2001), no pré e pós tratamento no GVO. .67 
Figura 13 - Classificação do zumbido, segundo McCombe (2001), no pré e pós

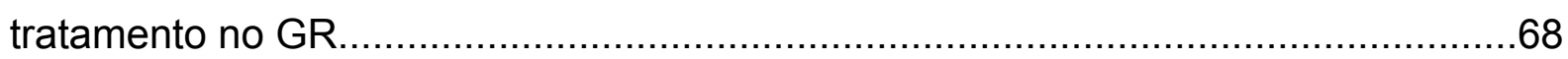

Figura 14 - Médias tetratonal, pré e pós tratamento, em ambos os grupos. .70

Figura 15 - Taxa de recuperação auditiva na Audiometria Tonal Limiar, em ambos os grupos. .70

Figura 16 - Distribuição das medidas de amplitude $(\mathrm{dB})$, pré e pós tratamento, em ambos os grupos. .73

Figura 17 - Distribuição das medidas da relação Sinal/Ruído $(\mathrm{dB})$, pré e pós tratamento, em ambos os grupos. .75 


\section{LISTA DE TABELAS}

Tabela 1 - Características gerais dos grupos, segundo idade, orelha acometida,

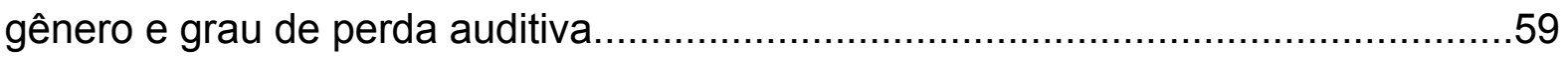

Tabela 2 - Resultados na EAV no pré e pós tratamento, em ambos os grupos.......59

Tabela 3 - Resultados no THI no pré e pós tratamento, em ambos os grupos.........63

Tabela 4 - Resultados da média tetratonal obtida na Audiometria Tonal Limiar, em

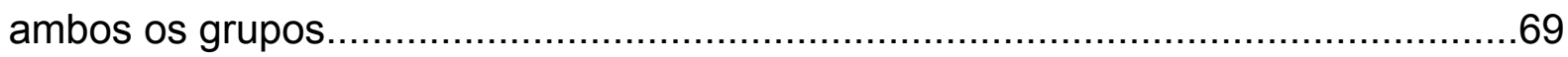

Tabela 5 - Resultados da amplitude das EOAEPD, em ambos os grupos. .72

Tabela 6 - Resultados da relação Sinal/Ruído das EOAEPD, em ambos os grupos. 


\section{SUMÁRIO}

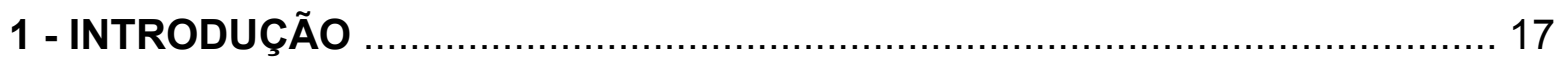

2 - REVISÃO DE LITERATURA

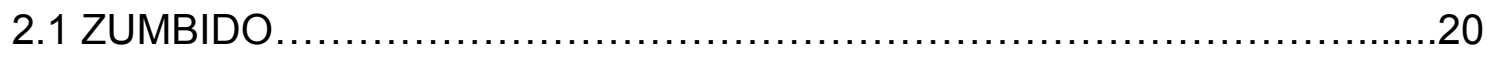

2.1.1 Tratamento com Corticoide Intratimpânico para o Zumbido......... 26

2.2 PERDA AUDITIVA NEUROSSENSORIAL SÚBITA ........................ 29

2.2.1 Tratamento com Corticoide na Perda Auditiva Neurossensorial Súbita. 33

2.3 ZUMBIDO E PERDA AUDITIVA NEUROSSENSORIAL SÚBITA 39

2.4 AVALIAÇÃO AUDIOLÓGICA NA PERDA AUDITIVA NEUROSSENSORIAL SÚBITA 42

2.4.1 Audiometria Tonal Limiar.......................................... 42

2.4.2 Emissões Otoacústicas Evocadas............................................ 43

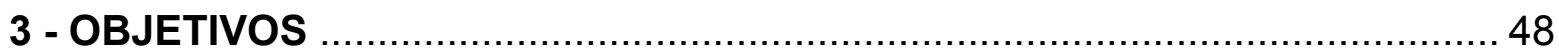

4 - MÉTODO

4.1 DESENHO E TIPO DE ESTUDO ….................................... 49

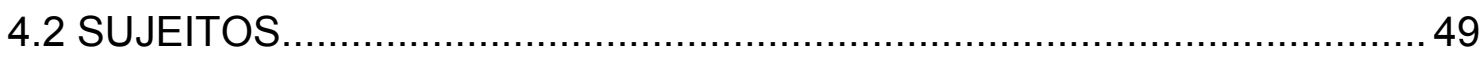

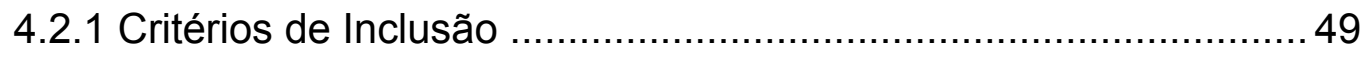

4.2.2 Critérios de Exclusão .......................................................... 49

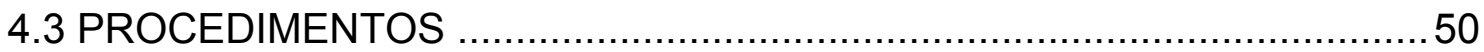

4.3.1 Avaliação Clínica, Laboratorial e de Imagem ........................ 50

4.3.2 Termo de Consentimento Livre e Esclarecido e Anamnese...........50

4.3.3 Escala Analógico-Visual e Tinnitus Handicap Inventory............ 51

4.3.4 Medidas de Imitância Acústica ............................................ 51

4.3.5 Aferição de Limiares Tonais ................................................ 51

4.3.6 Limiar de Reconhecimento de Fala, Limiar de Detecção de Fala e Índice Percentual de Reconhecimento de Fala...........................53

4.3.7 Aferição da Amplitude e Relação Sinal/Ruído (S/R) das Emissões Otoacústicas Evocadas por Produto de Distorção...........54 


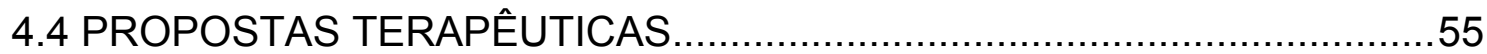

4.5 REAVALIAÇÃO DA PERCEPÇÃO DO ZUMBIDO E DOS ACHADOS

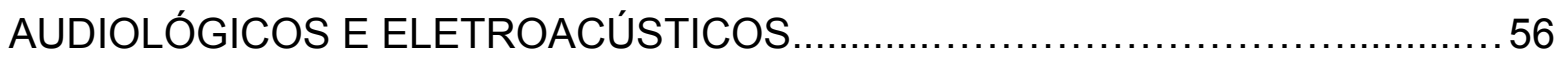

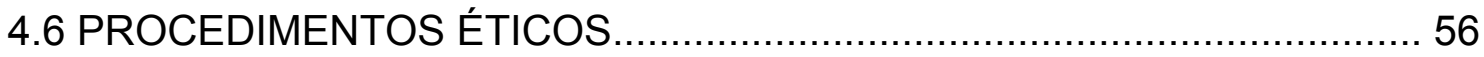

4.7 ANÁLISE DOS RESULTADOS ....................................................... 56

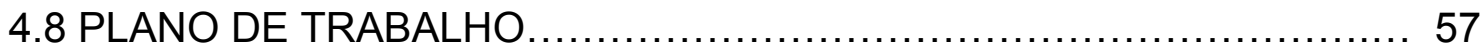

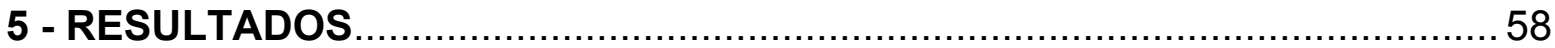

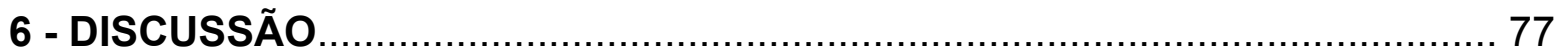

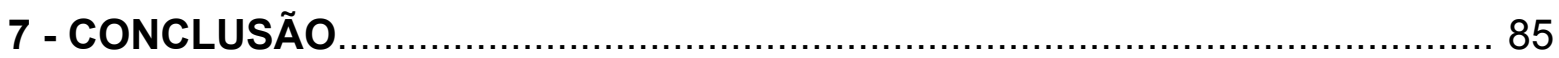

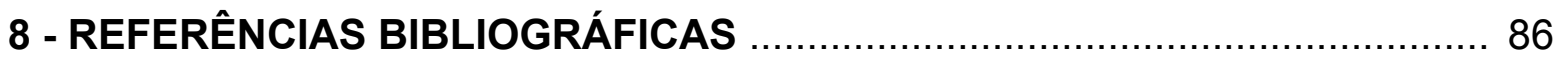

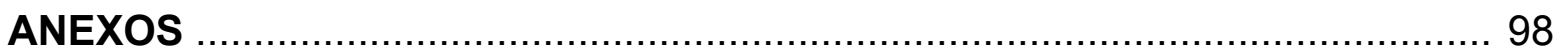

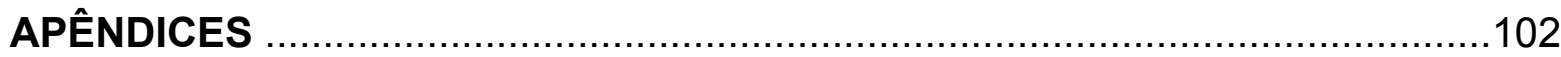




\section{INTRODUÇÃO}

O zumbido é definido como uma sensação auditiva sem um estímulo externo, podendo ser leve, moderado ou severo, conforme sua gravidade (1). O zumbido severo é considerado o terceiro pior problema que pode acometer o ser humano (2) podendo piorar significativamente a qualidade de vida das pessoas afetadas, diminuindo a concentração, o sono, o raciocínio, a memória, o equilíbrio emocional e a vida social (3). Trata-se de um sintoma e não de uma doença (4) e tem prevalência estimada em adultos entre 6 e $20 \%$ da população (5).

As informações contrastantes da literatura sobre zumbido podem ser consequência da avaliação de pacientes com zumbido de diversas etiologias, com afecções diferentes ao longo das vias auditivas, assim como do uso de diversas técnicas e parâmetros de análise. Portanto, uma avaliação precisa do zumbido exige uma população homogênea, uma doença conhecida, aspectos comuns relacionados ao zumbido bem como o estado geral de saúde (6).

A literatura demonstra que sujeitos com zumbido muito semelhantes na frequência, intensidade, lateralização, constância e tempo de instalação podem ter reações completamente diferentes ao sintoma (1). Assim, além dos aspectos médicos e audiológicos, as reações psicológicas e as consequências psicossociais do zumbido têm sido considerados fatores fundamentais para a compreensão do incômodo referido por estes pacientes (7).

O zumbido pode estar presente em doenças auditivas cocleares e/ou retrococleares, sendo comumente associado a algum dano no sistema auditivo periférico (3), podendo causar um incômodo muito intenso em cerca de $20 \%$ das pessoas (8). Importante ressaltar que dependendo de sua duração, o zumbido pode ser classificado em agudo e crônico, sendo o primeiro transitório e o segundo com duração superior a seis meses (9).

Como descrito anteriormente, o zumbido pode estar presente em diversas patologias auditivas, entre elas, na Perda Auditiva Neurossensorial Súbita (PANSS) que se caracteriza por uma perda auditiva de aparecimento abrupto e geralmente sem causa conhecida, podendo ocorrer comprometimento da orelha interna, oitavo par craniano e/ou vias auditivas centrais, de intensidade e frequências 
diferentes, variando de leve sensação de plenitude auricular até perda total da audição e sendo acompanhada de zumbido em aproximadamente $80 \%$ dos casos $(10,11)$.

A PANSS é uma afecção de etiologia multifatorial (10) e, em cerca de $80 \%$ dos casos, a etiologia permanece desconhecida mesmo após uma completa avaliação otológica. Estes casos são classificados como Perda Auditiva Neurossensorial Súbita Idiopática (PANSSI) (11). Diversos autores reforçam a necessidade de uma avaliação detalhada do zumbido e da Perda Auditiva Neurossensorial Súbita por meio da Audiometria Tonal Limiar, audiometria vocal e aplicação de questionários e instrumentos que possibilitem verificar a gravidade do zumbido e seu impacto na qualidade de vida $(4,7,12-15)$.

Atualmente, pesquisadores e clínicos estão demonstrando a importância da inclusão de testes objetivos, ou seja, sem a necessidade de resposta do paciente, a fim de monitorar a evolução do caso e verificar a eficácia do tratamento proposto $(16,17)$. Testes objetivos como o teste de Emissões Otoacústicas Evocadas (EOAE) podem acrescentar dados que demonstrem a eficácia do tratamento que foi eleito para cada paciente. Ou seja, tais dados poderão contribuir tanto para a comunidade científica quanto para a prática clínica, acrescentando-se dados quantitativos e qualitativos para o manejo mais adequado diante destas alterações.

Devido à possibilidade das emissões otoacústicas (EOAs) demonstrarem o estado do funcionamento das Células Ciliadas Externas (CCE), este teste vem sendo adotado como procedimento de investigação auditiva em diversas situações clínicas: na triagem auditiva neonatal; no diagnóstico diferencial da perda auditiva neurossensorial; durante administração de ototóxicos e no monitoramento da audição em diferentes alterações auditivas (18).

Estudos multicêntricos demonstraram a eficácia do tratamento com corticoide intratimpânico de forma primária ou corticoide por via oral para a Perda Auditiva Neurossensorial Súbita $(13,14)$. Atualmente na Europa e na Ásia têm se intensificado os estudos avaliando a eficácia da aplicação de corticoide intratimpânico como terapia para o zumbido em perdas auditivas neurossensoriais, principalmente como terapia de resgate, iniciada após falha da corticoterapia sistêmica, incluindo as Perdas Auditivas Neurossensoriais Súbitas (19-21) ou ainda como terapia primária para o zumbido (22) sendo que alguns pesquisadores avaliam 
a eficácia desta proposta terapêutica para o zumbido crônico e outros, recentemente, para o zumbido agudo $(22,23)$. No Brasil, não há publicações sobre a correlação entre o incômodo, a gravidade do zumbido e os achados auditivos e eletroacústicos em portadores de Perda Auditiva Neurossensorial Súbita Idiopática (PANSSI) submetidos a corticoterapia intratimpânica de resgate com metilprednisolona, bem como não há pesquisas comparando os resultados em pacientes submetidos a dois modelos de tratamento.

Assim, tendo em vista a importância da atualização do tema para audiologistas e otorrinolaringologistas, pretende-se analisar o zumbido e a audição em portadores de Perda Auditiva Neurossensorial Súbita Idiopática submetidos à corticoterapia. 


\section{REVISÃO DE LITERATURA}

Nesse capítulo, serão apresentadas considerações e resultados de obras científicas que constituem o referencial teórico do presente estudo. A revisão bibliográfica não obedece criteriosamente à cronologia das citações, tendo sido priorizado o encadeamento das ideias no texto.

\subsection{ZUMBIDO}

Também conhecido como tinnitus, tinido ou acúfeno, manifesta-se como uma sensação auditiva endógena, ilusória, apresentando-se como um som que é percebido na ausência de estímulos sonoros externos, denominado por muitos autores como ringing of the ears (24). Esta sensação auditiva é referida geralmente como apitos, assobios, abelhas, chiados, estalos, chuva, entre outros, podendo ser uni ou bilateral, de forma contínua ou intermitente, constante, mono ou politonal (25) e possui intensidade variável. Em sua forma mais severa pode ser altamente desconfortável, sendo considerado um sintoma patológico ou sequela de alguma agressão sofrida pelo sistema auditivo (26).

Em 2004, foi relatada que a incidência do zumbido era de 1 a $32 \%$ da população, estimando-se cerca de 35 a 50 milhões de pessoas nos Estados Unidos da América e aumentando na população idosa, chegando a até $15 \%$ na faixa etária acima dos 65 anos (27).

Em estudo recente realizado na cidade de São Paulo, a prevalência de zumbido observada foi de $22 \%$, acometendo mais mulheres $(26 \%)$ do que homens $(17 \%)$ e observou-se um crescimento progressivo da prevalência com o aumento da idade. Cerca de $1 / 3$ dos casos (32\%) referiu zumbido constante. A maioria dos sujeitos $(64 \%)$ declarou se sentir incomodada com o zumbido. Neste quesito, o percentual de mulheres foi significantemente maior $(73 \%)$ que o de homens $(50 \%)$. Em relação ao incômodo, os percentuais observados foram: incômodo leve (11\%), moderado (55\%) e severo (34\%). O incômodo médio aferido pela Escala AnalógicoVisual (EAV) apontou zumbido moderado com nota de 6,3 pontos. Os autores concluíram que o zumbido na cidade de São Paulo mostrou-se mais prevalente do que o previamente estimado (28). 
O zumbido está, na maioria dos casos associado a perda auditiva, o que provoca um significativo impacto adicional na vida dos sujeitos, justificando assim a importância de reconhecer, avaliar e, se possível, mensurar a importância da participação dos chamados "aspectos psicológicos" como fatores de piora das consequências trazidas pelo sintoma zumbido e seu eventual impacto nos resultados do tratamento (29). Muitos autores concordam que uma somatória de causas simultâneas e sequenciais podem ocasionar o zumbido, tais como trauma acústico, drogas ototóxicas, perda auditiva, problemas vasculares ou metabólicos, tumores, Doença de Ménière e fístula perilinfática, entre outros. Dentre estas, acredita-se que $90 \%$ das ocorrências sejam geradas por alterações da orelha interna (30).

Citam-se como hipóteses para a etiologia do zumbido: aumento da descarga elétrica espontânea a partir das células ciliadas auditivas (excitação anormal); diminuição da descarga elétrica espontânea a partir das células ciliadas auditivas e mudanças de componentes químicos em fluidos linfáticos na orelha interna e outros. No entanto, nenhuma dessas hipóteses é universalmente aceita (31).

O zumbido pode ser de leve a incapacitante, afetando a qualidade de vida do sujeito mesmo quando há melhora nos limiares auditivos. A percepção do zumbido varia entre os indivíduos e as limitações causadas por este podem estar relacionadas a fatores psicológicos, alterações de humor e de condições psiquiátricas sendo a perda auditiva é um fator importante para o aparecimento do zumbido (32).

Um dos tópicos mais questionados nos estudos clínicos sobre zumbido é o método de mensuração do mesmo, sendo que a Escala Analógico-Visual (EAV) e o Tinnitus Handicap Inventory (THI) são frequentemente utilizados para este fim (33).

A Escala Analógico-Visual (EAV) é de fácil aplicação, porém pode ser influenciada por aspectos culturais, intelectuais e psicológicos (29). Em relação ao THI, seu principal objetivo é ser um método com as seguintes características: resumido, adequado à prática clínica diária; de fácil aplicação e interpretação; que aborde vários aspectos do zumbido na qualidade de vida do paciente; com validade e confiabilidade. No instrumento são avaliados três itens principais: reações funcionais ao zumbido como dificuldade de concentração e tendências anti-sociais; reações emocionais ao zumbido como raiva, frustração, irritabilidade e depressão e reações catastróficas ao zumbido como desespero, sensação de impotência, sensação de 
"doença grave" e perda de controle (34). McCombe et al. (2001) sugeriu que a análise dos pontos no THI possibilite classificar o zumbido em desprezível, leve, moderado, severo e catastrófico (35).

A validação do THI para o português brasileiro foi realizada em 2005 por Ferreira et al., sendo também denominado Questionário de Gravidade do Zumbido (QGZ). Os autores descreveram que no follow up, pode-se lançar mão do Tinnitus Handicap Inventory (THI) com o objetivo de verificar o grau de comprometimento que o zumbido acarreta na vida dos sujeitos acometidos, podendo inclusive verificar a eficácia da conduta terapêutica escolhida (36).

Foi evidenciada a correlação entre os escores da EAV e do THI em 43 pacientes com zumbido ainda que o THI tenha sido considerado um método mais completo de mensuração, especialmente no que tange aos aspectos psicológicos e cotidianos do zumbido. Tendo em vista tal correlação entre os dois métodos (EAV e THI), foi sugerido que ambos sejam utilizados tanto em estudos quanto na prática clínica, tornando os resultados mais confiáveis (29).

Ao analisar a correlação entre o grau de incômodo causado pelo zumbido (EAV) e o grau da perda auditiva, por meio de uma análise retrospectiva, não houve correlação entre o grau de incômodo do zumbido com o grau da perda auditiva, idade, gênero, presença de tontura, dor de garganta, dor de cabeça, alterações da articulação temporomandibular, uso de cafeína ou uso excessivo de carboidratos. $O$ incômodo foi ligeiramente maior em pacientes sem perda auditiva e em mulheres e foi ressaltado que a tontura, dor de garganta, dor de cabeça e abuso de cafeína são queixas frequentes em pacientes com zumbido (32).

Em relação ao tratamento, tendo em vista que o zumbido pode estar correlacionado a várias etiologias, também são propostas diversas modalidades terapêuticas como Tinnitus Retraining Therapy (TRT), Oxigenoterapia Hiperbárica (OHB), adaptação de Aparelho de Amplificação Sonora Individual (AASI), Estimulação Magnética Transcraniana (EMTr), adaptação de Implante Coclear (IC) e a terapia com corticoide intratimpânico. No tratamento do zumbido na Tinnitus Retraining Therapy (TRT), são realizadas sessões intensivas de orientação dirigida e enriquecimento sonoro por cerca de 12 meses, sendo que a continuidade do tratamento é fundamental para o seu sucesso. Propostas de tratamento em grupo associando a TRT ao tratamento cognitivo comportamental também se mostrou 
eficaz em um tempo médio de 8 semanas, enquanto a TRT necessita de no mínimo 12 meses para evolução das queixas relacionadas ao zumbido (7).

A TRT é um tratamento estruturado e apoiado no aconselhamento sobre o modelo neurofisiológico do zumbido (Figura 1) e no enriquecimento sonoro com sons neutros. O tipo de enriquecimento sonoro é determinado de acordo com a categoria do paciente, que depende do impacto do zumbido na qualidade de vida e da coexistência de perda auditiva e intolerância a sons (1).

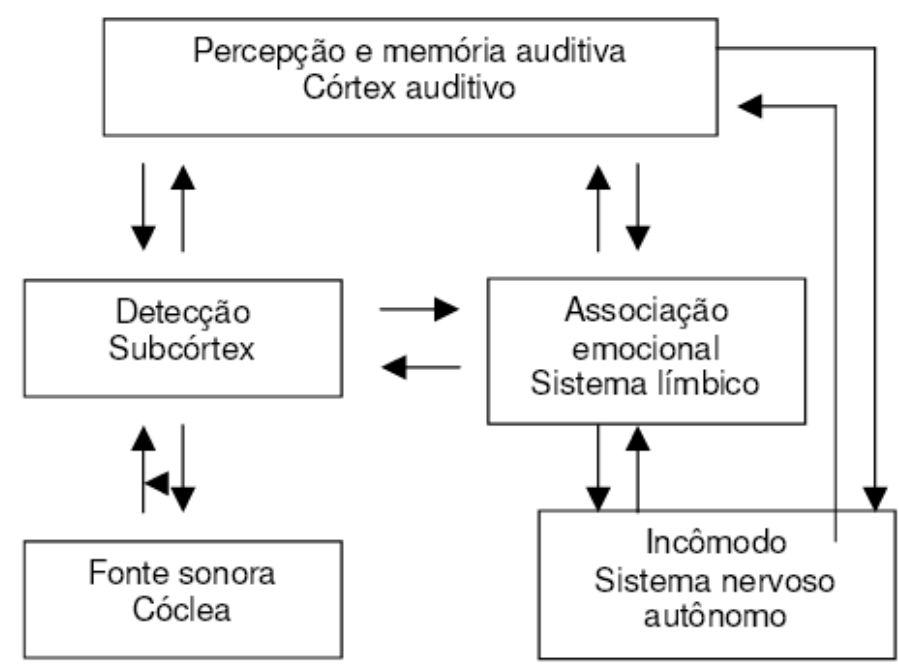

Figura 1. Modelo neurofisiológico do zumbido (Jastreboff, 1990)

Já no que diz respeito ao tratamento com AASI, McNeil et al. (2012) realizaram um estudo retrospectivo com 70 pacientes adultos, com perda auditiva de grau leve a severo e zumbido crônico. Os pacientes receberam próteses auditivas e foram reavaliados após três meses de uso por meio de questionário subjetivo. Conforme os resultados, 26 pacientes referiram mascaramento total do zumbido com a prótese auditiva, 28 referiram mascaramento parcial e 16 referiram que o mascaramento não ocorreu. Foi possível concluir que o uso da prótese auditiva, nestes sujeitos, melhorou a audibilidade e a reação ao zumbido (37).

Em 2012, na Espanha, o Implante Coclear (IC) foi estudado como um método de tratamento viável na perda auditiva neurossensorial súbita de grau severoprofundo associada ao zumbido incapacitante diante da ineficácia de outras tentativas de tratamento. Neste estudo, 10 pacientes adultos com PANSS unilateral de grau severo-profundo associada ao zumbido e audição normal ou perda auditiva 
de grau leve-moderado na orelha contralateral, foram acompanhados por meio da Audiometria Tonal Limiar (ATL) e audiometria vocal e em relação ao zumbido foi realizada Acufenometria, o THI e a EAV. Dos 10 pacientes acompanhados após a ativação do IC, 2 não apresentaram mais queixas em relação ao zumbido; 7 referiram melhora e apenas 1 referiu não ter percebido diferença após a ativação do Implante Coclear. Em relação ao THI ocorreu mudança de 72 pontos para 14,3 pontos ao final de 3 meses (mudança do grau de incapacidade severa para ausência de incapacidade $(n=8)$, incapacidade leve $(n=1)$ e apenas um paciente declarou não ter havido melhora). Na EAV, foram observados resultados semelhantes, tendo em vista que a pontuação mudou de 7,9 pontos para 2,7 pontos (38).

Ainda em relação ao tratamento do zumbido associado ao IC, foram avaliados os efeitos a longo prazo em pacientes com zumbido severo e incapacitante e perda auditiva neurossensorial profunda, unilateral. Foi um estudo prospectivo multicêntrico em cinco centros auditivos espanhóis com dezesseis (16) pacientes com pontuação maior que 58 pontos no Tinnitus Handicap Inventory (THI). A maioria dos pacientes recebeu um IC em até 2 anos após a sua perda auditiva. Foi possível concluir que o IC pode ser utilizado com sucesso no tratamento de pacientes com perda auditiva acompanhada de zumbido severo e estes resultados suportam a hipótese de que mecanismos fisiopatológicos após a perda auditiva neurossensorial periférica são, pelo menos parcialmente reversíveis quando a audição é restaurada com um IC (39).

Em estudo retrospectivo com 40 casos de PANSS atendidos no período de 4 anos em um hospital em Pamplona, na Espanha, foram analisadas as características em relação a orelha acometida e o tipo de curva audiométrica. Os pacientes que foram atendidos precocemente (entre o terceiro e quarto dia após o episódio de PANSS) receberam tratamento intravenoso (metilprednisolona) acrescido de pentoxifilina, aspirina por 48 horas, famciclovir e pantoprazol. Quando não ocorria melhora, os pacientes eram então submetidos a oxigenoterapia hiperbárica $(\mathrm{OHB})$. No referido hospital, a terapia intratimpânica na PANSS é aplicada em casos muito específicos, não tendo sido aplicada nestes 40 sujeitos. Os pacientes que tiveram curva audiométrica ascendente ou plana apresentaram melhor porcentagem de recuperação, sendo que do grupo total, $32,5 \% \quad(n=13)$ apresentaram melhora completa e 67,5\% ( $n=27)$ melhora parcial ou sem melhora. Em relação a orelha acometida, não foi encontrada diferença significativa e foram 
citados como casos com melhor prognóstico aqueles que foram medicados com metilprednisolona intravenosa, famciclovir e aspirina e com pior prognóstico aqueles com curva audiométrica descendente (40).

Em estudo de revisão, foram analisados 11 estudos abordando o tratamento intratimpânico para o zumbido ou para patologias da orelha interna e seus efeitos para o controle, diminuição ou remissão do zumbido periférico, sendo consideradas as seguintes drogas terapêuticas aplicadas de forma intratimpânica: lidocaína, dexametasona, metilprednisolona, carbamazepina e mais recentemente AM-101. O autor salienta que o interesse pelo tratamento intratimpânico para desordens da orelha interna, incluindo o zumbido, teve um incremento significativo nas duas últimas décadas (41).

Em 2014, Suckfuell et al. publicaram estudo em que 25 centros de referência europeus participaram e tiveram como objetivo avaliar a eficácia e segurança do AM-111 em 210 pacientes com perda auditiva neurossensorial aguda. O AM-111 contém o péptido sintético D-JNKI-1 (D-stereoisomer of c-Jun N-Terminal Kinase Inhibitor 1), um inibidor da JNK quinase acoplado a um transportador intracelular e é formulado de um gel biocompatível e biodegradável. Foram estudos prospectivos, duplo-cego, randomizados, controlados por placebo. A faixa etária dos pacientes foi de 18 a 61 anos e estes pacientes tiveram trauma acústico agudo ou PANSS. Foi aplicada uma dose única de AM-111 (0,4 ou 2,0 mg/ml) ou placebo intratimpânico e opcionalmente, prednisolona oral se a melhora da audição fosse inferior a $10 \mathrm{~dB}$ no sétimo dia de acompanhamento. A eficácia foi avaliada pela melhora auditiva e melhora do zumbido. O estudo não conseguiu demonstrar um benefício do tratamento para toda a população do estudo porque os casos de perda auditiva leve a moderada mostrou recuperação espontânea. Nas perdas em que os limiares eram $>=60 \mathrm{~dB}$, a AM-111 0,4 mg/ml mostrou melhora estatisticamente significativa e clinicamente relevante e persistente na audição e maior remissão do zumbido em comparação com placebo. Os autores sugeriram mais estudos com o uso da droga em sujeitos com perda severa a profunda e zumbido (42).

Em relação a Estimulação Magnética Transcraniana (EMTr) para o zumbido crônico, Folmer et al. (2015) randomizaram sessenta e quatro $(n=64)$ sujeitos para receber EMTr ativa ou placebo. Os participantes receberam 2000 pulsos por sessão de EMTr ou placebo a uma taxa de 1-Hz EMTr diária em 10 dias consecutivos e 18 dos 32 participantes (56\%) no grupo EMTr e 7 dos 32 participantes (22\%) no grupo 
EMTr placebo responderam bem ao tratamento. A diferença entre os grupos foi estatisticamente significativa (43).

Como referido anteriormente, na Europa e na Ásia tem sido realizadas pesquisas verificando a eficácia do tratamento intratimpânico para o zumbido, como por exemplo, a aplicação intratimpânica de AM-111 para o zumbido agudo. No Brasil, ainda são escassas as pesquisas com tal objetivo, podendo ser citado o estudo de Araújo et al. (2005) (44) que avaliou por meio da EAV, a eficácia do tratamento intratimpânico de resgate para o zumbido predominantemente coclear, crônico e severo em 35 pacientes. Destes, 21 sujeitos foram tratados com dexametasona intratimpânica (IT-DEX) e 14 receberam injeção intratimpânica de solução salina. Importante ressaltar que somente dois (2) sujeitos apresentavam diagnóstico de PANSS. Não foi encontrada diferença significante entre os grupos e concluiu-se que a corticoterapia intratimpânica não foi eficaz para tratar o zumbido crônico.

\subsubsection{Tratamento com Corticoide Intratimpânico para o Zumbido}

Sakata et al. (1996), no Japão, aplicou dexametasona intratimpânica (IT-DEX) como terapia de resgate para tratar o zumbido coclear em diversas patologias otológicas, incluindo sujeitos com perda auditiva neurossensorial súbita e descreveu bons resultados avaliados por meio da EAV em 71\% (33\% recuperação completa e $38 \%$ recuperação parcial) dos sujeitos e ressaltou que a terapia intratimpânica pode ter sido eficaz para a maioria dos seus casos porque o mecanismo de ação deste tratamento envolve diversas ações de corticoides, melhorando o efeito metabólico, aliviando o efeito de edema e podendo eliminar a excitação anormal de células ciliadas auditivas que poderiam ser a causa do zumbido (45).

Em estudo com corticoide intratimpânico na tentativa de controle do zumbido em 10 pacientes (um destes pacientes era portador de PANSS), Shulman e Goldstein (2000) verificaram que em 70\% (n=7) dos pacientes ocorreu alívio do zumbido. No entanto, no paciente com PANSS, não foi verificada diferença. $A$ duração do alívio do zumbido em 7 dos 10 pacientes foi de horas em um dos 7 pacientes; dias em outro dos 7; e 1 ano ou mais, em cinco dos 7 pacientes. Neste estudo, a terapia intratimpânica com corticoide resultou no alívio do zumbido de curto e de longo prazo na maioria dos pacientes (46). 
Cesarini et al. (2002) apresentaram achados de sua experiência clínica com a dexametasona intratimpânica (IT-DEX) para o controle do zumbido em 50 pacientes (20 mulheres, 30 homens, com idade média de 49,6, variando de 24 a 71 anos) que sofriam de zumbido subjetivo. Todos realizaram avaliação auditiva e os seus efeitos a curto prazo foram avaliados 2 semanas após a última injeção. Em 34\% ( $n=17)$ dos 50 pacientes, o zumbido desapareceu; em $40 \%(n=20)$ ocorreu uma diminuição significativa do sintoma; e em 26\% ( $n=13)$ não apresentaram qualquer melhora. Os autores consideraram o tratamento eficaz para o controle do zumbido, desde que o tratamento ocorra em até 3 meses do início dos sintomas (47).

$\mathrm{Na}$ China, em um estudo prospectivo que comparou a carbamazepina oral (que é um medicamento utilizado rotineiramente para tratar o zumbido) e o tratamento de resgate (metilpredinisolona intratimpânica IT-METIL ou dexametasona intratimpânica IT-DEX) em setenta e nove pacientes com zumbido subjetivo que não responderam a um mínimo de quatro semanas de terapia sistêmica foram divididos em grupo de estudo e grupo controle. O grupo de estudo foi dividido ainda em dois subgrupos. Os participantes do grupo de estudo receberam 0,5 $\mathrm{ml}$ de metilprednisolona intratimpânica (grupo de estudo 1) ou dexametasona (grupo de estudo 2). Os pacientes do grupo controle receberam carbamazepina. Os resultados foram analisados após 6 meses e não houve diferenças estatisticamente significativa entre os três grupos, pois a injecção de corticoide intratimpânico teve efeitos positivos semelhantes aos da carbamazepina oral para o zumbido subjetivo. Os autores ressaltaram portanto, que pode ser considerada uma alternativa de tratamento para o zumbido subjetivo, mas não a única (48).

Yoshida et al. (2012), no Japão, foram os primeiros pesquisadores que avaliaram a efetividade da terapia intratimpânica com dexametasona para o zumbido severo e crônico, exclusivamente em pacientes com PANSS unilateral e idiopática. Foram tratados 37 pacientes com IT-DEX e comparados com um grupo sem tratamento $(n=14)$. No grupo de estudo $(n=37)$, foi observada melhora significativa do zumbido por meio da Escala Analógico-Visual (EAV) naqueles que tinham realizado o tratamento em uma média de 8 meses após a ocorrência da PANSS. Em contrapartida, não foi observada melhora significativa do zumbido naqueles que realizaram o tratamento IT-DEX cerca de 15 meses após a ocorrência da enfermidade. Não foi observada melhora auditiva nos 51 pacientes acompanhados, possivelmente devido ao tempo transcorrido entre o tempo de ocorrência e a 
aplicação da IT-DEX. Dos 37 pacientes, 15 (41\%) tiveram melhora do zumbido, independente da orelha acometida e do gênero, sendo que em média, a idade destes sujeitos que apresentaram melhora foi de 58,46 anos e com perda auditiva neurossensorial de grau moderado $(64 \mathrm{~dB})$, baseado na média tritonal $(500 \mathrm{~Hz}$, $1000 \mathrm{~Hz}$ e $2000 \mathrm{~Hz}$ ). Desta forma, foi observada correlação entre a duração do zumbido e a efetividade do tratamento proposto (49).

Em estudo retrospectivo com 114 pacientes com perda auditiva neurossensorial de grau leve a moderado de diversas etiologias, tratados com ITDEX para o zumbido agudo com duração dos sintomas por 3 meses ou menos, An et al. (2014) avaliaram o pré e o pós tratamento por meio do THI e descreveram que a pontuação foi significativamente reduzida em 3 meses, bem como a taxa de recuperação foi significativamente maior em pacientes com sintomas que duravam 2 semanas ou menos em comparação com aqueles que tinham zumbido há mais de um mês, tendo sido significativamente associada com a duração do zumbido agudo. Já a ATL foi realizada 3 meses após o tratamento somente em 43 pacientes e foi observada diferença significativa no pré e pós tratamento em todos as frequências analisadas $(250 \mathrm{~Hz}$ à $8000 \mathrm{~Hz})(50)$. 


\subsection{PERDA AUDITIVA NEUROSSENSORIAL SÚBITA (PANSS)}

A Perda Auditiva Neurossensorial Súbita (PANSS) se caracteriza como uma perda auditiva de aparecimento abrupto, geralmente unilateral e sem causa conhecida. Pode ocorrer comprometimento da orelha interna e/ou vias auditivas centrais, de intensidade e frequência variável, podendo variar de leve sensação de plenitude auricular até perda total da audição, sendo acompanhada de zumbido em aproximadamente $80 \%$ dos casos. Quanto ao zumbido, na PANSS, este pode variar de intensidade, podendo ceder ou persistir mais que a perda auditiva $(10,11)$.

A PANSS é caracterizada como uma perda auditiva maior do que 30dBNA em pelo menos três frequências contínuas, que se desenvolve em até 72 horas e ainda hoje é um desafio diagnóstico e terapêutico (51). Teorias propostas sobre a sua etiologia incluem infecção viral coclear, oclusão vascular e ruptura de membranas $(52,53)$.

A sensação de diminuição da audição pode variar de discreta a muito intensa e pode ocorrer recuperação espontânea em cerca de $25 \%$ dos casos. O comportamento evolutivo da PANSS é bastante inconsistente, com curas espontâneas, totais ou parciais, podendo deixar sequelas auditivas irreversíveis (54).

É uma emergência em otologia, representando aproximadamente $1 \%$ de todas as perdas auditivas neurossensoriais e acomete principalmente a quarta década de vida, atingindo 5 a 20 pessoas em cada 100 mil indivíduos/ano e estimase que há aproximadamente 4 mil novos casos por ano nos Estados Unidos da América e 15 mil em todo o mundo, com igual distribuição em relação ao sexo (12, 15).

Desde que foi descrita pela primeira vez, inúmeras etiologias têm sido descritas: infecciosa, traumática, neoplásica, imunológica, ototóxica, vascular ou isquêmica, neurológica, dentre outras. Dentre os fatores associados, estão os distúrbios metabólicos que são mais frequentes entre cócleo-vestibulopatas do que na população geral. Contudo, em apenas 10 a $15 \%$ dos casos a causa pode ser determinada (54).

As possíveis causas cocleares da Perda Auditiva Neurossensorial Súbita são: a) causas inflamatórias: virais (parotidite, rubéola, sarampo, varicela, herpes, influenza, citomegalovírus), bactérias (sífilis, mycoplasma pneumoniae), toxoplasmose; b) traumáticas: fratura de osso temporal, barotrauma, contusão 
labiríntica, otocirugia, fístula perilinfática; c) vasculares: hipertensão arterial, insuficiência vertebrobasilar; d) hematológicas: anemia, embolismos, coagulopatias, leucemia, mieloma; e) enfermidades autoinmunes: lupus eritematoso sistêmico, artrite reumatóide, policondrite recidivante; f) Hidropsia endolinfática incluindo a Doença de Ménière; g) enfermidades metabólicas: insuficiência renal, diabetes, hiperlipidemia, hipotiroidismo; h) ototoxicidade: diuréticos, antinflamatórios cisplatina, eritromicina, contraceptivos orais e como possíveis causas retrococleares e do sistema nervoso central: meningite, esclerose múltipla, esclerose lateral amiotrófica (ELA), Ataxia de Friederich, neurinoma do VIII par craniano, neuropatia carcinomatosa e surdez central isquêmica (55).

Em 2007, Nascentes et al. relataram um caso de schwannoma vestibular, também conhecido como neuroma ou neurinoma do acústico como causa de PANSS e zumbido unilateral em que a melhora dos sintomas se deu através de tratamento clínico com prednisolona e pentoxifilina. Os autores ressaltaram a importância de pesquisar a etiologia nos casos de PANSS para a boa condução do caso e orientação terapêutica, bem como a importância dos exames complementares tanto para o diagnóstico quanto para o acompanhamento (56).

Ainda em relação a etiologia da PANSS, as três hipóteses mais defendidas são: a) infecciosa (agentes virais: infecções virais, como herpes, rubéola, varicelazoster, citomegalovírus, influenza $\mathrm{B}$, vírus da caxumba, sarampo, adenovírus e imunodeficiência humana (HIV), sendo que o tratamento indicado são os antivirais); b) vascular (isquemia endococlear, oclusão da artéria auditiva interna, hemorragia intralabiríntica, trombose, embolia, vasoespasmo, aumento da viscosidade do sangue, a talassemia e diabetes, que ocasionam a degradação de circulação coclear e degeneração do órgão de Corti), sendo que o tratamento indicado são os vasodilatadores e c) imunológico (existência de anticorpos específicos e nãoespecíficos dirigidos contra epítopos antigênicos da orelha interna), sendo tratado com corticoide. Outros fatores etiológicos considerados são as anormalidades anatômicas da orelha interna, como as hidropsias labirínticas ou colapso; a fístula perilinfática; hidropsia endolinfática, incluindo a Doença de Ménière; doenças ósseas ou da cápsula ótica (40).

Piñones et al. (2015) também acrescentam que a PANSS pode ser devido a ativação anormal da via de stress celular dentro do ouvido interno, resultando na 
produção de citoquinas inflamatórias e outras proteínas relacionadas com o stress que podem perturbar o equilíbrio homeostático da orelha interna (57).

A tendência atual é considerar a Perda Auditiva Neurossensorial Súbita como uma afecção de etiologia multifatorial (10) e, em muitas situações, a etiologia permanece desconhecida e constitui um grande desafio, mesmo após uma completa avaliação otológica. Estes casos são classificados como Perda Auditiva Neurossensorial Súbita Idiopática (PANSSI) (11).

A PANSSI é, ainda, um tema controverso e obscuro em diversos aspectos, principalmente quanto aos aspectos etiológicos e fisiopatogênicos. Compromete orelha direita e esquerda em semelhante proporção, assim como em relação ao sexo. Portanto, a etiopatogenia da PANSSI, como o próprio nome diz (idiopática), não é ainda esclarecida, tornando o assunto ainda bastante controverso. A baixa incidência da PANSSI, o difícil acesso à orelha interna para melhores esclarecimentos quanto aos estudos diagnósticos e a fisiopatogenia desconhecida dificultam maiores conclusões quanto à própria origem desta manifestação clínica (58).

Com o objetivo de traçar os fatores clínicos, etiológicos e evolutivos da audição na PANSS, foi ressaltada a importância de que se faça uma pesquisa objetiva da etiologia, bem como ficou demonstrado que o início da terapia na primeira semana de instalação da PANSS foi o único fator relacionado a um melhor resultado auditivo. De 40 pacientes, 100\% apresentaram a queixa de zumbido no início do quadro (11).

Diferentes fatores são analisados na literatura como parâmetros de prognóstico na recuperação da PANSS, sendo os principais: a) Tempo decorrido entre o início da PANSS e o estabelecimento do diagnóstico (início do tratamento) em todos os casos com boa recuperação auditiva, o diagnóstico e o tratamento foram estabelecidos nos primeiros 14 dias; b) Tipo de curva audiométrica tonal perdas auditivas em frequências graves tiveram melhor recuperação que perdas auditivas em frequências agudas; c) Severidade da perda auditiva inicial considerando-se o limiar auditivo, na audiometria tonal, na média das frequências de $500 \mathrm{~Hz}, 1000 \mathrm{~Hz}$ e $2000 \mathrm{~Hz}$, considerando que, quanto maior este limiar, pior a recuperação auditiva e d) Presença de tonturas severas - este sintoma foi relacionado a piores recuperações auditivas $(10,59,60)$. 
Em 2012, pela primeira vez, a American Academy of Otolaryngology-Head and Neck Surgery (AAO-HNS) publicou um guia para a prática clínica sobre a PANSS e definiu a audiometria tonal limiar como exame essencial diante da suspeita desta enfermidade, bem como salientou que a realização de exames auditivos subjetivos e objetivos são importantes no monitoramento auditivo (15).

Atualmente, os tratamentos propostos mais aceitos universalmente e com eficácia comprovada são baseados na corticoterapia oral e/ou corticoterapia intratimpânica como terapia de resgate $(13,53,54)$ ou primária (13), enquanto a taxa de recuperação espontânea ou com o uso de placebo é controversa e sempre inferior aos resultados dos pacientes tratados com os diversos medicamentos propostos (61).

Em 2012, foi conduzido por Halpin et al., na Universidade de Harvard, um estudo multicêntrico, com o objetivo de relatar as características da população pré e pós tratamento e a estabilidade dos resultados audiológicos. Foi um ensaio clínico com 250 pacientes divididos em dois grupos (corticoterapia via oral ou corticoterapia intratimpânica primária). A perda auditiva era unilateral e a média dos limiares auditivos $\geq 50 \mathrm{dBNA}$, nas frequências de $500 \mathrm{~Hz}, 1000 \mathrm{~Hz}, 2000 \mathrm{~Hz}$ e $4000 \mathrm{~Hz}$ (média tetratonal). Os autores constataram que ocorreram mudanças significativas nos primeiros dois meses de acompanhamento após o início do tratamento, os quais se mantiveram estáveis pelo tempo de acompanhamento total (6 meses). Foram observados ainda melhores resultados nas baixas frequências em ambos os grupos de tratamento. Neste estudo, foi realizado o monitoramento auditivo por meio da Audiometria Tonal Limiar (14).

A evolução natural da PANSS é imprecisa e a recuperação da função auditiva está associada a múltiplos fatores tais como tempo entre início dos sintomas e início do tratamento, grau da perda auditiva, presença de vertigem associada e idade do paciente. No Brasil não se tem uma boa referência epidemiológica quanto à real incidência da PANSS devido à dificuldade em avaliar, com segurança, a incidência desta doença. A baixa situação cultural e socioeconômica, assim como a possibilidade de recuperação espontânea antes da procura de ajuda médica ou o descaso frente aos leves sintomas, contribuem para isso (58). 
2.2.1 Tratamento com Corticoide na Perda Auditiva Neurossensorial Súbita (PANSS)

Os corticoides são, provavelmente, as drogas mais utilizadas isoladamente ou em associação com outras formas de terapia, para o tratamento da PANSS. Esta ampla utilização dos corticoides se fundamenta nas propriedades antinflamatórias desta medicação (10).

Wilson et al. (1980) avaliaram a eficácia de corticoides por via oral na PANSS e, desde então, este tem sido o tratamento mais amplamente utilizado, pois apresenta uma eficácia independentemente da etiologia envolvida em razão de suas propriedades antinflamatórias (62).

A farmacoterapia intratimpânica foi primeiramente usada por Schuknecht, em 1956 (63), para tratamento de vertigem incapacitante na Síndrome de Ménière e, desde então, múltiplos agentes têm sido utilizados por esta via para tratamento de diversas doenças da orelha interna. A via intratimpânica tem basicamente duas vantagens: permite uma maior concentração da droga administrada na perilinfa e minimiza os possíveis efeitos adversos do medicamento quando administrado sistemicamente (Figura 2).

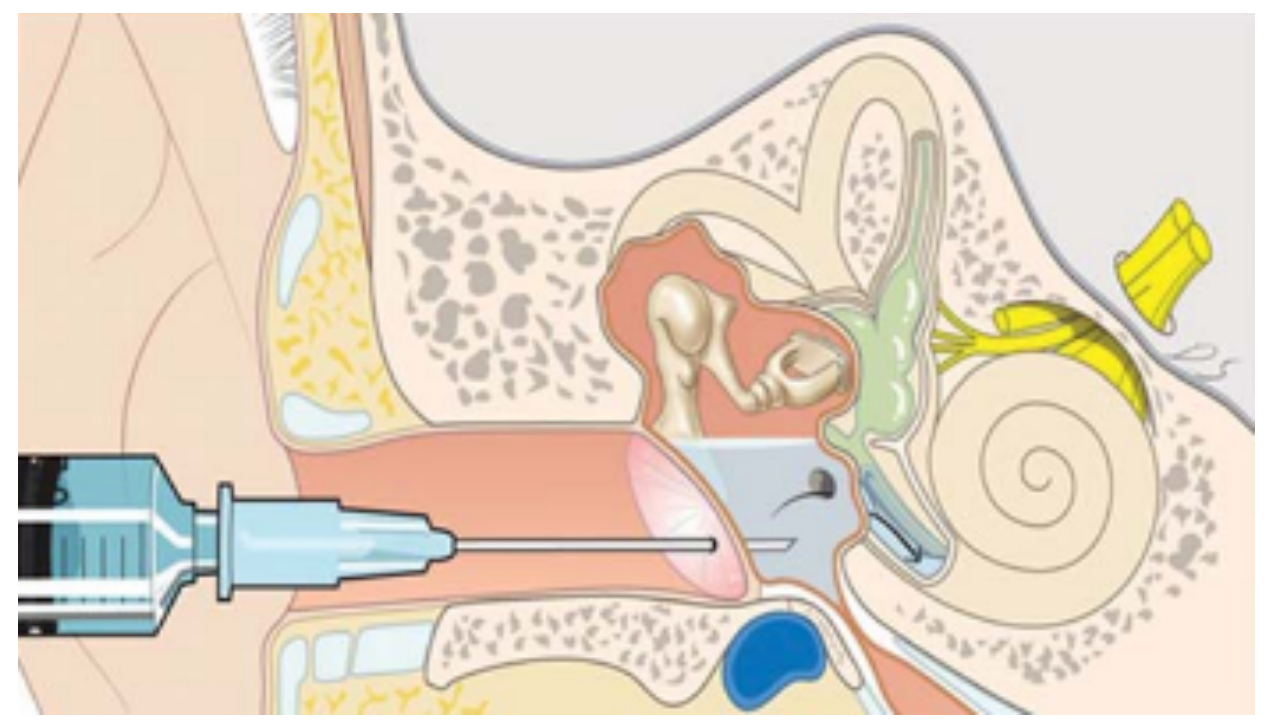

Figura 2. Ilustração da técnica de aplicação intratimpânica

Fonte: http://onlinelibrary.wiley.com/doi/10.1002/lary.24482/pdf 
Corticoides administrados intratimpanicamente podem alcançar altas concentrações na perilinfa, maiores que quando administrados por via intravenosa ou oral. Na corticoterapia intratimpânica há uma distribuição da droga diretamente na orelha interna, o que pode oferecer o potencial de uma terapia órgão-específica, administrada diretamente sobre a membrana da janela redonda e alcançando altas concentrações da droga, evitando todos os efeitos adversos da terapia com corticoide sistêmico (64-66).

O primeiro relato do uso da corticoterapia intratimpânica para PANSS foi realizado por Silverstein em 1996 que salientou que a corticoterapia intratimpânica aumenta o fluxo sanguíneo coclear, previne a toxicidade por aminoglicosídeo e melhora a homeostase iônica necessária para a adequada função coclear e apresenta um efeito protetor da estria vascular após a otite média (67).

O fato que estimulou o uso da corticoterapia intratimpânica sem o uso de corticoterapia sistêmica foi a existência de um grupo de pacientes que não toleraria os efeitos sistêmicos de altas doses de corticoterapia sistêmica, como pacientes diabéticos ou portadores de hipertensão arterial sistêmica de difícil controle $(68,69)$.

Há controvérsias no tipo de corticoide utilizado para injeção intratimpânica, sendo basicamente duas opções: metilprednisolona ou dexametasona. Em relação a metilpredinisolona, Parnes et al. 1999, em estudo pré-clínico, demonstraram que a metilprednisolona (METIL) apresentou melhor atividade na orelha interna quando comparada com a dexametasona (DEX) (70).

Conforme Raymundo et al. (2010) o uso da corticoterapia intratimpânica originou três protocolos principais para o tratamento da PANSS: Terapia Primária, como tratamento inicial ou primário sem o uso de corticoterapia sistêmica; Terapia Adjuvante ou Combinada, realizada concomitantemente com a corticoterapia sistêmica e Terapia de Resgate, iniciada após falha da corticoterapia sistêmica. Quanto as vantagens da terapia intratimpânica, os autores ressaltaram que o procedimento é realizado de forma ambulatorial, com anestesia local, facilmente administrado logo após o diagnóstico, relativamente sem dor, com possibilidade de uso em pacientes com contra-indicação ao uso de corticoides sistêmicos como imunocomprometidos (HIV), tuberculosos e diabéticos e que altas concentrações da droga podem ser administradas diretamente na orelha acometida (53).

Quanto ao prognóstico da PANSS, este muitas vezes depende de sua gravidade. Assim, um paciente com uma perda auditiva profunda teria um 
prognóstico particularmente ruim. De 27 pacientes com PANSS de grau profundo, 14 foram tratados com prednisolona sistêmica e 13 foram tratados adicionalmente com metilprednisolona intratimpânica. Do primeiro grupo, 3 pacientes tiveram boa recuperação da audição e 5 tiveram uma recuperação parcial. O ganho médio de audição na faixa de frequências de $500 \mathrm{~Hz}$ à $4000 \mathrm{~Hz}$ foi de $15 \mathrm{dBNA}$. Já no grupo que foi tratado adicionalmente com corticoide intratimpânico, 2 relataram uma boa recuperação da audição e 2 tiveram uma recuperação parcial. O ganho médio de audição foi de 11dBNA. Neste estudo, os autores concluíram que ocorreu melhora auditiva nos pacientes tratados com corticoterapia de resgate, mas não estatisticamente significativa em comparação com os pacientes tratados com a terapia padrão (71).

Em 2006, Xenellis et al. acompanharam dezenove (19) pacientes que receberam metilprednisolona intratimpânica como terapia de resgate após falha do tratamento convencional para PANSS com corticoide intravenoso e observaram melhora no audiograma em nove (9) destes pacientes. Em um grupo controle no mesmo período de tempo não foi demonstrada melhora em nenhum paciente, sendo este valor estatisticamente significante (72).

Em 2010, foi analisada a segurança e eficácia do corticoide intratimpânico como terapia de resgate em 14 pacientes com idades entre 25 e 72 anos após falha da corticoterapia oral, por meio da Audiometria Tonal Limiar (ATL), Impedanciometria, Índice Percentual de Reconhecimento de Fala (IPRF), avaliação laboratorial e ressonância magnética nuclear. Dos 14 pacientes, 85,7\% apresentaram zumbido como sintoma associado. Foram administrados $40 \mathrm{mg} / \mathrm{ml}$ de metilpredinisolona intratimpânica através de três injeções com intervalo de 48 horas entre elas, como terapia de resgate e o protocolo da corticoterapia por via oral a que os pacientes tinham sido submetidos foi de $1 \mathrm{mg} / \mathrm{Kg} /$ dia por 10 dias de predinisolona. Foi utilizado como critério para considerar a intervenção terapêutica bem sucedida, a melhora de 20 dBNA nas frequências de $500 \mathrm{~Hz}, 1000 \mathrm{~Hz}$ e $2000 \mathrm{~Hz}$. Dos 14 pacientes tratados por meio da terapia de resgate, houve uma taxa de recuperação em 10 pacientes. (53).

Em estudo que comparou a eficácia da corticoterapia intratimpânica primária e corticoterapia via oral nos casos de PANSS, foram acompanhados 250 pacientes (121 fizeram uso de predinisolona via oral e 129 receberam quatro injeções de 
metilpredinisolona intratimpânica) e foram encontrados resultados similares entre os dois grupos, considerando-se os dois métodos de tratamento eficazes (13).

Em estudo prospectivo realizado na Turquia em 2011, foram comparados os resultados auditivos em 26 pacientes tratados com corticoide sistêmico apenas intravenoso ou combinado com intratimpânico (terapia combinada), sendo 5 injeções de $0,5 \mathrm{ml}$ de $125 \mathrm{mg} / \mathrm{ml}$ e foi concluído que a combinação foi mais eficaz para a recuperação auditiva. O ganho médio na média tritonal dos pacientes submetidos a corticoterapia sistêmica foi de 5dBNA no $5^{\circ}$ dia, 7,5dBNA em 10 dias, e 8,8dBNA no $15^{\circ}$ dia, enquanto a média obtida no grupo de terapia combinada foi $7,5 \mathrm{dBNA}$, 13,8dBNA e 20,0dBNA, respectivamente. Os autores constataram que em ambos os grupos houve melhora e ocorreu diferença estatisticamente significativamente entre os grupos. Os resultados sugerem que a adição de metilprednisolona intratimpânica à terapia sistêmica aumentou a probabilidade de recuperação da audição em pacientes com PANSS (73).

Em análise retrospectiva de pacientes com PANSS tratados com três injecções de metilprednisolona intratimpânica, a taxa de resposta significativamente aumentada foi encontrada em pacientes cinco semanas após a primeira dose por meio da audiometria tonal. O estudo teve o objetivo de rever a experiência com corticoides intratimpânicos, enfatizando o momento ideal para realizar 0 acompanhamento por meio da ATL. A melhora foi definida como uma média tonal maior ou igual a 20dBNA. Os autores concluíram que a recuperação na PANSS após a injeção de metilprednisolona na orelha média ocorre com maior frequência 5 semanas após o início do tratamento, o que pode ser atribuído à história natural da PANSS ou o efeito prolongado de corticoides na orelha interna (74).

Em relação aos fatores associados e que aspectos terapêuticos influenciaram no prognóstico de pacientes com PANSS, Artal et al. (2012) descreveram como fatores associados: antecedentes cardiovasculares, diabetes, uso de cigarro e dislipidemia e consideraram como efetivos positivos no tratamento, o uso de aciclovir e com uma menor probabilidade de recuperação, o tratamento com oxigenoterapia hiperbárica, a curva audiométrica descendente e a presença de vertigem (40).

Na Grécia, em 2013, pesquisadores investigaram a eficácia da dexametasona intratimpânica (3 aplicações de IT-DEX) combinada com prednisolona sistêmica em pacientes com PANSS e inicialmente não encontraram diferença estatisticamente significativa ao comparar com o grupo controle, que recebeu o tratamento somente 
por via oral. Após uma nova análise, excluindo os sujeitos com perda auditiva de grau profundo, constataram que dos sujeitos submetidos a terapia combinada, 31 $(67,39 \%)$ apresentaram maiores benefícios auditivos em comparação com o grupo controle em que $24(52,17 \%)$ apresentaram melhora. Os pacientes foram acompanhados por 3 meses e os fatores evidenciados como sendo preditivos de um prognóstico ruim foram o grau da perda auditiva (grau profundo), os sintomas vestibulares associados e o início de tratamento tardio. Os autores consideraram como critério para considerar o sucesso do tratamento, a melhora de 10dBNA na média tritonal e demonstraram que os pacientes que foram submetidos a terapia combinada, tiveram um ganho médio de 23,12dBNA enquanto os pacientes do grupo controle, tiveram um ganho médio de 16,87dBNA, bem como salientaram que o tratamento combinado pode ser eficaz principalmente nos sujeitos com perda auditiva variando entre o grau moderado a severo (75).

Em relação a eficácia da dexametasona intratimpânica (IT-DEX) como tratamento de resgate (realizado cerca de 24 dias após o início dos sintomas), por meio da ATL, foi constatada melhora de cerca de 10dBNA após a corticoterapia por via oral e de mais $10 \mathrm{dBNA}$ após a corticoterapia de resgate (total de $20 \mathrm{~dB}$ ). Do total de 46 pacientes, 36 participaram do grupo de estudo e 10 se recusaram a receber a terapia de resgate, sendo considerado grupo controle. Estes não obtiveram melhora além dos cerca de 10dBNA obtidos após a corticoterapia por via oral (61).

Yang et al. (2013) compararam a injeção de corticoide Intratimpânico, oxigenoterapia hiperbárica e a terapia combinada (corticoide intratimpânico associado a oxigenoterapia hiperbárica) como terapia de resgate na PANSS em 103 pacientes. Destes, 35 receberam corticoide intratimpânico, 22 realizaram a oxigenoterapia hiperbárica, 19 receberam corticoide e oxigenoterapia hiperbárica e 27 não receberam tratamento (grupo controle). A melhora auditiva foi avaliada por meio da ATL e do IPRF. Os três grupos de estudo obtiveram melhores respostas do que o grupo controle e os pacientes que receberam a terapia combinada apresentaram melhores resultados tanto na audiometria quanto no IPRF, principalmente nas frequências baixas, em relação aos que receberam as terapias isoladas (76).

Em revisão sistemática realizada em 2013, com o objetivo de verificar a eficácia dos corticoides para PANSSI foi referido que ainda não há consenso sobre a eficácia dos corticoides no tratamento da PANSSI, bem como foi ressaltado que 
devem ser determinados se: a) melhora a audição (primário) e b) reduz o zumbido (secundário). Como em outros estudos, os autores reforçaram a dificuldade de comparar resultados devido a heterogeneidade das populações estudadas e as diferenças nas formulações de corticoides, doses e a duração do tratamento (77).

Ainda em 2013, Baysal et al. avaliaram a eficácia do corticoide oral em 30 sujeitos versus corticoterapia intratimpânica (IT-DEX) combinada com medicação por via oral em 39 sujeitos. O ganho auditivo no grupo via oral foi $20,97 \mathrm{~dB}$ e no grupo de terapia combinada foi $19,36 \mathrm{~dB}$. Neste estudo, ambas terapias tiveram o mesmo efeito sobre a restauração da audição (78).

Já Gundogan et al. (2013) que também compararam a eficácia do corticoide por via oral com terapia combinada (IT-METIL) descreveram que a terapia combinada apresentou melhores resultados (79).

$\mathrm{Na}$ Espanha, em 2015, foi avaliada a eficácia e segurança da metilprednisolona intratimpânica (IT-METIL) na perda auditiva neurossensorial súbita em 17 pacientes que haviam recebido corticoide por via oral ou intravenoso e 4 que receberam IT-METIL como terapia primária. Os autores concluíram que a terapia intratimpânica foi uma opção de tratamento, principalmente em casos refratários ao tratamento por via oral. Foi realizada comparação pré e pós tratamento por meio de Audiometria Tonal Limiar e EAV. A média de idade dos pacientes foi 46 anos (27 a 85 anos) e foi considerado como melhora um aumento $>=10 \mathrm{~dB}$ na audiometria tonal, sendo que foram comparadas as frequências de $250 \mathrm{~Hz}$ à $8000 \mathrm{~Hz}$ de forma individual. O valor médio para o zumbido na EAV pré e pós tratamento foi de 7,8 (zumbido severo) e 2,9 (zumbido leve), respectivamente, com diferença significante. Dos 21 pacientes, $14(66,7 \%)$ apresentaram uma média na ATL maior que $10 \mathrm{~dB}$ nos limiares auditivos $250-500-1000-2000-4000 \mathrm{~Hz}$. No pré tratamento os valores foram em média $59,0 \mathrm{~dB}$ e no pós tratamento $40,4 \mathrm{~dB}$, tendo ocorrido uma melhora de $18,75 \mathrm{~dB}$, sendo significante. Finalmente, os autores referem que o principal mecanismo de ação dos corticoides na função coclear tem sido atribuída à atividade antinflamatória e o tratamento por meio da injeção de corticoide intratimpânico é uma conduta eficaz, segura e bem tolerada, podendo ser recomendada principalmente como terapia de resgate na PANSS (57).

É possível analisar publicações de 2005 a 2011 que aplicaram a terapia intratimpânica de resgate na PANSS com corticoide (IT-METIL ou IT-DEX) e obtiveram melhora auditiva na maioria dos sujeitos acompanhados. Destes estudos, 
o número de sujeitos variou $(8 ; 14 ; 23 ; 33 ; 36 ; 49$ e 66 sujeitos), sendo alguns estudos multicêntricos. Também a forma de avaliar a melhora auditiva variou desde o cálculo da média tritonal $(500 \mathrm{~Hz}, 1000 \mathrm{~Hz}$ e $2000 \mathrm{~Hz})$; média tetratonal $(500 \mathrm{~Hz}$, $1000 \mathrm{~Hz}, 2000 \mathrm{~Hz}$ e $3000 \mathrm{~Hz}$ ou $500 \mathrm{~Hz}, 1000 \mathrm{~Hz}, 2000 \mathrm{~Hz}$ e $4000 \mathrm{~Hz}$ ) bem como o cálculo baseado em todas as frequências $(250 \mathrm{~Hz}, 500 \mathrm{~Hz}, 1000 \mathrm{~Hz}, 2000 \mathrm{~Hz}, 3000 \mathrm{~Hz}$, $4000 \mathrm{~Hz}, 6000 \mathrm{~Hz}$ e $8000 \mathrm{~Hz})$ analisadas $(48,53,80-85)$, o que reforça o aspecto levantado em revisões sistemáticas ao referir a utilização de diferentes protocolos de tratamento no que diz respeito ao corticoide eleito, a dosagem, ao número de aplicações, bem como ao método de análise para avaliar a melhora em relação a audição $(86,87)$.

\subsection{ZUMBIDO E PERDA AUDITIVA NEUROSSENSORIAL SÚBITA (PANSS)}

Em 2001, Ben-David et al. avaliaram os possíveis fatores prognósticos de recuperação em 67 pacientes com PANSSI tratados com corticoides (prednisolona), expansores de plasma (dextrano intravenoso) e vasodilatadores (papaverina). A recuperação clínica foi estimada pela diferença entre os resultados audiométricos na admissão e 10 dias depois e foram correlacionados os vários fatores prognósticos. Apenas dois fatores tiveram associação significativa com a melhora da audição: o zumbido e a configuração da curva audiométrica ascendente na admissão do paciente (88).

A sensação de plenitude auricular ocorre frequentemente em pacientes com perda auditiva neurossensorial súbita; o mesmo é verdadeiro para o zumbido. Em 171 orelhas de pacientes internados com PANSS unilateral, os resultados mostraram que o zumbido foi associado principalmente com limiares auditivos piores nas altas frequências, onde a perda auditiva foi relativamente grave enquanto a sensação de plenitude auricular foi mais associada a perda auditiva nas baixas frequências e onde a perda auditiva foi relativamente suave. Desta forma, foi possível concluir que o zumbido provavelmente se origina na região onde as células ciliadas são prejudicadas; em contraste, a origem da plenitude auricular pode ser algum fator funcional, em vez de uma lesão orgânica da cóclea (45).

Hikita-Watanabe (2010), realizaram estudo com 50 pacientes tratados com administração sistêmica de corticoides com o objetivo de verificar o zumbido como fator prognóstico na PANSS. O grupo "zumbido raro" teve um pior prognóstico para 
ouvir que o "zumbido muitas vezes", embora o grupo "curta duração" teve melhor prognóstico do que o grupo "duração mais longa", indicando que o zumbido em si não pode ser um sinal de mau prognóstico auditivo, mas pode ser um som essencial para o início do reparo de um sistema auditivo danificado (89).

Em 2011, Carlsson et al. analisaram os efeitos do nível de audição, a recuperação auditiva, o zumbido e a vertigem na qualidade de vida após a PANSS, bem como as consequências psicossociais e os benefícios da reabilitação e foi observado que o zumbido e a vertigem remanescentes após a PANSS foram fortes preditores de efeitos negativos sobre a qualidade de vida, bem como os autores ressaltaram que estes pacientes demandam uma abordagem de reabilitação multidisciplinar para conseguirem lidar com as complexas questões que podem surgir após a PANSS (90).

Em estudo publicado em 2012, foi verificado que de nove pacientes com PANSS e zumbido submetidos a corticoterapia intratimpânica de resgate, sete apresentaram melhora significativa em relação ao incômodo causado pelo zumbido. Neste estudo, levantou-se a hipótese de que a corticoterapia não tenha sido totalmente eficaz em relação a mudanças significativas nos limiares audiométricos, provavelmente devido as comorbidades associadas a PANSS, bem como o tempo decorrido entre o início dos sintomas e o início do tratamento (91).

Em relação ao zumbido residual após o tratamento na PANSS, foram acompanhados 44 pacientes submetidos a corticoterapia via oral por 2 semanas e vitamina B12 por 6 meses, bem como drogas vasoativas. Foram examinadas variáveis como sexo, lateralidade e idade, juntamente com as mudanças no nível e a pontuação do zumbido para determinar os fatores prognósticos do zumbido residual após o último dia de tratamento. Foi aplicado um questionário de escore do zumbido antes, 6 meses e 24 meses após o tratamento e a pontuação em relação ao zumbido foi significativamente melhor 6 meses após o início do tratamento, em comparação com antes do tratamento, mas não foi significativamente diferente entre os 6 e os 24 meses após o início do tratamento (92).

Wang et al. (2014), na China, encontraram correlação entre a pontuação no THI e na EAV em 44 pacientes com PANSS e zumbido, antes e após o tratamento, (ambos os instrumentos tiveram valores absolutos reduzidos significativamente após o tratamento), sendo tal resultado correlacionado com o efeito da melhora dos 
limiares auditivos e concluíram que tais pontuações são úteis para avaliação do zumbido em pacientes com PANSS e zumbido (19).

No Brasil, foram obtidos resultados semelhantes em 43 pacientes com zumbido e diversas etiologias prováveis para a perda auditiva. Estes, já haviam apresentado correlação entre estes dois instrumentos, ressaltando que o THI apresenta dados mais específicos em comparação com a EAV, sendo importante, aplicar os dois instrumentos (29).

Em estudo retrospectivo com 50 pacientes com PANSS e zumbido que realizaram tratamento por via oral e de resgate (4 injeções de corticoide intratimpânico), a avaliação da melhora do zumbido foi realizada por meio do Global Tinnitus Impact (GTI), em que os pacientes opinavam se estavam satisfeitos ou insatisfeitos em relação a redução do zumbido, em uma escala de 0 a 10 . A idade média dos sujeitos foi de 49,9 anos (16 a 73 anos) e foi possível demonstrar que a proporção de satisfeitos em relação ao zumbido foi de acordo com a melhor recuperação auditiva. Um importante achado neste estudo foi uma correlação significativa entre o grau de recuperação auditiva final e a melhora subjetiva do zumbido após o tratamento, ao passo que não houve correlação entre o grau de perda auditiva inicial e a pontuação no GTI após o tratamento, sugerindo que a melhora auditiva pode ser um fator prognóstico para melhora do zumbido, mas não necessariamente, a presença do zumbido como fator prognóstico para a recuperação da audição. A recuperação auditiva dos pacientes com PANSS de grau leve, moderado e severo foi em torno de $70 \%, 30 \%$ e $10 \%$, respectivamente e o tratamento ideal e bem sucedido da PANSS pode ser um fator importante na obtenção do controle favorável a longo prazo do zumbido (20).

Em relação as características da PANSS em 105 pacientes, 30 apresentaram perda auditiva de grau leve, 13 de grau moderado, 28 de grau severo e 34 de grau profundo. Em relação as frequências afetadas na audiometria, 53 apresentaram perda auditiva em todas as frequências; 13 em baixas frequências e 39 em frequências médias e altas e ocorreu diferença estatisticamente significativa entre os pacientes com a perda nas baixas frequências, frequências médias e altas frequências. Os autores ressaltaram que existem diferenças individuais de características clínicas entre os pacientes com zumbido e PANSS (93).

Ainda em 2015, Lavigne, Lavigne e Saliba realizaram revisão sistemática (1946-2014) de pesquisas que tiveram o objetivo de determinar a eficácia de 
corticoides intratimpânicos no gerenciamento das seguintes doenças da orelha interna: zumbido, Doença de Ménière, Perda Auditiva Induzida por Ruído (PAIR) e PANSS. Os autores ressaltaram o fato da heterogeneidade de protocolos de tratamento e acompanhamento nos estudos por eles analisados e que a corticoterapia intratimpância no tratamento do zumbido não demonstrou eficácia, devendo ser considerada como um adjuvante na PANSS e PAIR (94).

\subsection{AVALIAÇÃO AUDIOLÓGICA NA PERDA AUDITIVA NEUROSSENSORIAL SÚBITA (PANSS)}

\subsubsection{Audiometria Tonal Limiar (ATL)}

A Audiometria Tonal Limiar, a Imitanciometria, as Emissões Otoacústicas Evocadas (EOAE) e os Potenciais Evocados Auditivos de Tronco Encefálico (PEATE) são descritos como exames úteis para o diagnóstico de PANSS e para o monitoramento auditivo ideal. Deve-se usar a audiometria de tom puro para determinar o limiar auditivo ao longo de um ampla faixa de frequências (de $250 \mathrm{~Hz}$ a $8000 \mathrm{~Hz}$ ). Dependendo do tipo de curva audiométrica, definir se a perda é condutiva, neurossensorial ou mista. Se for encontrada uma perda auditiva neurossensorial, deve-se buscar a causa da PANSS na cóclea. Este tipo de perda auditiva de origem na orelha interna é característico da PANSS. As causas potenciais incluem trauma acústico, ototóxicos, infecção e outros. A PANSS devido a uma perturbação da via auditiva é rara e uma causa possível é o neurinoma do acústico ou Schwannoma do nervo vestibular que comprime o nervo auditivo à medida que cresce. Outras doenças como a esclerose múltipla ou acidente vascular cerebral isquêmico pode afetar a via auditiva e a capacidade do paciente para compreender a fala é pior do que se supõe pelos resultados obtidos na audiometria (95).

Conforme Bittar et al. (2007), há relação entre o grau da perda auditiva e a capacidade de recuperação na PANSS. Nas perdas auditivas inferiores a 40dBNA, parece haver uma recuperação melhor, não ocorrendo o mesmo nas perdas auditivas severas e profundas e a preservação de resposta em frequências altas parece ser um elemento favorável (54).

Para prescrever o melhor tratamento, deve-se utilizar diversos métodos de avaliação como as emissões otoacústicas evocadas, a vectoeletronistagmografia 
(VENG) e os potencias evocados miogênicos/vestibular evoked myogenic potentials (VEMP) que auxiliariam na determinação do diagnóstico topográfico. Para os autores, a presença de EOAs indicam que os mecanismos condutores da orelha (orelha externa, membrana timpânica e cadeia ossicular) estão funcionando corretamente e, portanto, em qualquer tipo de perda auditiva, a avaliação das emissões otoacústicas é um complemento valioso (96).

Dentre os critérios geralmente utilizados nos estudos para avaliar a eficácia das diferentes modalidades terapêuticas, destacam-se dois: média de tom puro em três frequências consecutivas, geralmente $500 \mathrm{~Hz}, 1000 \mathrm{~Hz}$ e $2000 \mathrm{~Hz}$ ou média tetratonal $(500 \mathrm{~Hz}, 1000 \mathrm{~Hz}, 2000 \mathrm{~Hz}$ e $4000 \mathrm{~Hz})$ e melhora de $20 \%$ no índice percentual de reconhecimento de fala $(\operatorname{IPRF})(13,14,53)$.

\subsubsection{Emissões Otoacústicas Evocadas (EOAE)}

Devido ao fato das Emissões Otoacústicas (EOAs) serem captadas no meato acústico externo é essencial a verificação das condições fisiológicas da orelha média, antes da realização do teste de EOAs; pois patologias neste local, podem interferir na condução do estímulo para a cóclea e na passagem das EOAs para o meato acústico externo, ou seja, as adequadas condições da orelha média são um pré-requisito para o exame, já que qualquer alteração poderá diminuir ou até abolir a ocorrência das EOAs $(97,98)$.

Os dois tipos de EOAs conforme ocorrem na ausência ou presença de estimulação sonora são as emissões otoacústicas espontâneas e evocadas, sendo que dentre as Emissões Otoacústicas Evocadas (EOAE) podemos classificar três tipos: Transientes ( $T$ ), Produto de Distorção (PD) e Estímulo-Frequência (EF). As Emissões Otoacústicas Evocadas por Produto de Distorção (EOAEPD) ocorrem em resposta a um estímulo acústico constituído por dois tons primários, formados por duas frequências próximas (F1 e F2) (Figura 3). Possuem, então, a característica de estimular a cóclea em regiões específicas e por isto são muito utilizadas para diagnóstico de danos cocleares (18). 


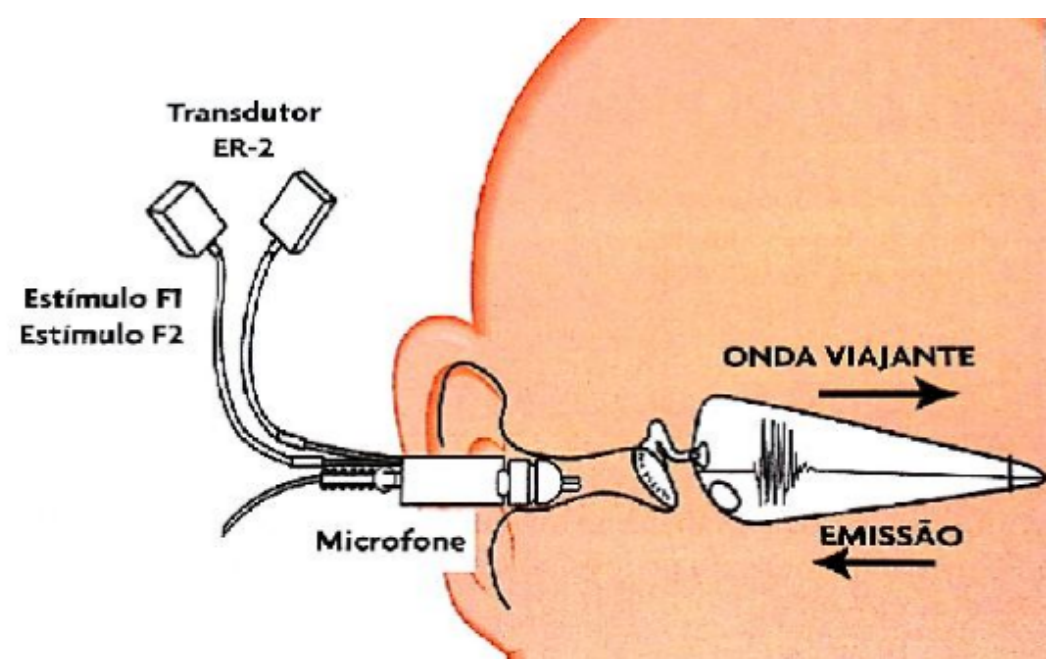

Figura 3. Sonda para evocar e registrar as EOAEPD

Fonte: Piza MRT, Cóser PL, Alvarenga KF. Eletrofisiologia da audição e emissões otoacústicas: princípios e aplicações clínicas. 2 ed; 2010.

As EOAEPD são consideradas presentes quando há relação Sinal/Ruído $(\mathrm{S} / \mathrm{R})$ de pelo menos 6dBNPS. Devido à possibilidade das EOAs demonstrarem o estado do funcionamento das CCE, este teste vem sendo adotado como procedimento de investigação auditiva em diversas situações clínicas: na triagem auditiva neonatal; no diagnóstico diferencial da perda auditiva neurossensorial; durante administração de ototóxicos e no monitoramento da audição em diferentes alterações auditivas (18).

As amplitudes das emissões otoacústicas transientes e por produto de distorção em 15 pacientes com PANSSI tiveram incrementos simultaneamente a recuperação dos limiares auditivos e foi sugerido que a função das CCE estão deterioradas quando os limiares estão elevados e se recuperam quando há uma melhora nos limiares auditivos (99).

As Emissões Otoacústicas Evocadas por Produto de Distorção (EOAEPD) são sensíveis a distúrbios cocleares. Em um estudo prospectivo com 10 pacientes, três com EOAEPD intactas no início da enfermidade, tiveram uma melhora média de $33 \mathrm{~dB}$ na média tonal de $500 \mathrm{~Hz}, 1000 \mathrm{~Hz}$ e $2000 \mathrm{~Hz}$ com a terapia (corticoterapia por via oral), enquanto que cinco dos sete pacientes com EOAEPD ausentes não tiveram melhora na audição. Os autores sugeriram que a presença de EOAEPD pode ser um fator prognóstico útil que se correlaciona positivamente com a recuperação da PANSS (100). 
Vários indicadores prognósticos têm sido sugerido para prever a melhora na PANSS. Em estudo para avaliar se os testes de EOAET e EOAEPD poderiam ser considerados como testes prognósticos confiáveis na PANSS em 20 pacientes com PANSS unilateral os autores ressaltaram que poderiam ser um indicador do estado funcional da orelha interna, mas não um teste prognóstico da PANSS. O tratamento consistiu em glicerol administrado por via intravenosa em intervalos de 3 horas por 4 dias. A ATL foi avaliada novamente 1 hora após a última administração de glicerol. Após a terapia, 12 pacientes (60\%) apresentaram uma melhora significativa na ATL com uma melhora média de $11 \mathrm{~dB}$. A relação entre a presença ou ausência de EOAs no pré tratamento e a modificação na ATL não foi significativa (101).

Em relação as EOAEPD como fator prognóstico na PANSSI, foram realizadas ATL e EOAEPD em 108 pacientes todos os dias por 7 dias, a cada duas semanas e mensalmente após a alta e os resultados mostraram que uma melhor amplitude das EOAEPD foi um bom indicador de prognóstico. A faixa etária mais jovem (<ou=40 anos), com melhor ATL inicial ( $<65 \mathrm{~dB}$ ) apresentou um melhor prognóstico (102).

Em 2008, foram investigados como os sintomas de plenitude auricular e zumbido e os resultados no teste de emissões otoacústicas evocadas (EOAE) mudaram em relação ao curso da recuperação de limiares na ATL na perda audtiva neurossensorial súbita em 16 pacientes, sendo 8 com PANSS e melhora auditiva (Grupo A) e oito pacientes com PANSS sem melhora auditiva (Grupo B). O estudo foi realizado até que não houvesse mais mudança nos limiares auditivos por mais de uma semana e a recuperação auditiva já não era mais esperada. Os sintomas só melhoraram no Grupo A mostrando uma relação significativa entre a melhora auditiva e a melhora da plenitude auricular, presença de zumbido, melhora da intensidade do zumbido e incômodo com o zumbido. Nenhum dos pacientes do Grupo A ou B apresentaram respostas nas EOAE no primeiro exame. No grupo A, as respostas das EOAE apareceram simultaneamente com a melhora dos limiares auditivos em cinco pacientes (63\%), e apareceram mais tarde do que a melhora auditiva nos outros três pacientes (37\%). Foi possível concluir que os pacientes com PANSS e melhora na audição (Grupo A) apresentaram tendência a ter respostas das EOAE e as sensações de plenitude auricular e zumbido melhorando quase simultaneamente, sendo que a melhora foi principalmente nas frequências baixas e médias, enquanto os pacientes com melhora auditiva pobre apresentaram tendência a ter EOAE ausentes e plenitude auricular persistente, assim como zumbido 
persistente (16).

Hoth (2006) examinaram audiogramas e EOAs de 25 pacientes com PANSS desde o primeiro dia até um máximo de 505 dias após a perda auditiva, realizando medições de três a nove sessões. Sendo um exame objetivo e mostrando a existência de mudanças sutis no funcionamento das CCE, o autor ressalta que as EOAEPD podem ser monitoradas em pacientes que sofreram uma PANSS. Nestes pacientes, pode ocorrer uma alteração do limiar de audição em intervalos de tempo observáveis e o acompanhamento das EOAs juntamente com audiogramas clínicos permite a avaliação da correlação entre as medidas objetivas e subjetivas da capacidade auditiva e oferece a possibilidade de comparar os resultados das primeiras EOAs com audiogramas posteriores ou audiogramas de início com as EOAs posteriores. Assim, o monitoramento das EOAEPD em pacientes com PANSSI durante e após o tratamento pode oferecer uma visão sobre o processo de recuperação da função coclear (103).

Amiridavan et al. (2006) também ressaltaram que a PANSS é uma condição desconcertante para os pacientes e há muitas controvérsias sobre sua etiologia, características audiológicas, fatores prognósticos e tratamento. Os autores realizaram estudo prospectivo com 53 pacientes com PANSS, divididos em dois grupos de tratamento: por via oral (corticoide + acyclovir) e outro grupo tratado com urographin intravenosa. Quinze pacientes $(28,3 \%)$ responderam bem, vinte $(37,7 \%)$ responderam parcialmente, e dezoito $(33,9 \%)$ tiveram pouca ou nenhuma resposta ao tratamento. Os autores recomendaram a realização das Emissões Otoacústicas Evocadas Transientes (EOAT) em todos os pacientes com PANSS (104).

Nemati et al. (2011) realizaram estudo prospectivo com o objetivo de identificar mudanças nos parâmetros das EOAs após o tratamento da PANSS com corticoide por via oral (prednisolona) e aciclovir. Foram acompanhados 26 pacientes com PANSSI que realizaram Audiometria Tonal Limiar, Timpanometria e pesquisa dos reflexos acústicos, Emissões Otoacústicas Transientes e por Produto de Distorção. Além de comparar os valores absolutos das EOAE no pré e pós tratamento, foram comparados os valores alterados (grupo estudo) com a orelha contralateral normal (grupo controle). Foram obtidos os seguintes valores absolutos no teste de Emissões Otoacústicas Evocadas por Produto de Distorção no pré e pós tratamento: DP1 $(-19.2 \mathrm{~dB} \pm 9.49 \mathrm{~dB})$ e relação Sinal/Ruído $(2.28 \mathrm{~dB} \pm 5.26 \mathrm{~dB})$ e no pós tratamento: DP1 $(-15.68 \mathrm{~dB} \pm 11.25 \mathrm{~dB})$ e relação Sinal/Ruído $(0.91 \mathrm{~dB} \pm 5.29 \mathrm{~dB})$. 
Em relação a orelha contralateral antes do tratamento foram obtidos os seguintes valores absolutos: DP1 $(-0.8 \mathrm{~dB} \pm 7.9 \mathrm{~dB})$ e relação Sinal/Ruído $(8.51 \mathrm{~dB} \pm 5.69 \mathrm{~dB})$. Para obter tais valores, os autores utilizaram os seguintes parâmetros: $f 1=70 d B N P S$, f2=60dBNPS; f2/f1=1.2; 2f1-f2 e avaliaram as frequências entre $500 \mathrm{~Hz}$ a $8000 \mathrm{~Hz}$ $(500,750,1000,1500,2000,3000,4000,6000$ e $8000 \mathrm{~Hz})$. Os 26 pacientes (idade média de 40,54 anos, 16 homens e 10 mulheres e orelha esquerda mais afetada que a orelha direita, mas sem diferença significante) após o tratamento foram divididos em: Grupo 1 (com melhora completa: >=30dB); Grupo 2 (melhora parcial: >=10dB e $<=30 \mathrm{~dB}$ e Grupo 3 (sem melhora: <=9dB), sendo que 12 sujeitos tiveram melhora completa e 8 tiveram melhora parcial, totalizando 20 sujeitos com recuperação da PANSS. Cabe ressaltar que a maioria dos sujeitos tinha perda auditiva de grau moderado $(n=10)$ seguido por perda auditiva de grau profundo $(n=7)$, perda auditiva de grau severo $(n=6)$ e perda auditiva de grau leve $(n=3)$. Após a análise dos resultados, os autores concluíram que o teste de emissões otoacústicas deve ser realizado nestes sujeitos por se tratar de método rápido, não invasivo e objetivo, com alta reprodutibilidade, alta estabilidade teste-reteste, bem como pode mostrar eventos subclínicos na cóclea que refletem a atividade das células ciliadas externas. Ressaltaram ainda a importância do uso das emissões otoacústicas evocadas como instrumento para monitorar os resultados do tratamento proposto (17).

Hyeon No et al. (2013) avaliaram a aplicabilidade do teste de EOAEPD em 35 pacientes com PANSS divididos em: grupo com perda auditiva leve $(<=40 \mathrm{~dB})$, moderada a moderadamente severa $(41-70 \mathrm{~dB})$ e severa $(>=71 \mathrm{~dB})$ de acordo com seus limiares auditivos iniciais e que foram submetidos a EOAEPD após 2 semanas do término do tratamento com corticoide por via oral e concluíram que o teste de EOAEPD foi um método objetivo eficiente e não invasivo e que pode ser usado para monitorar os efeitos do tratamento em pacientes com PANSS (105).

Shupak et al. (2014) avaliaram o papel das emissões otoacústicas evocadas (EOAE) na predição da PANSSI em quinze (15) pacientes acompanhados por até 3 meses. Foi realizada Audiometria Tonal Limiar, EOAET e EOAEPD. As médias dos limiares tonais das três frequências mais afetadas, a detecção e a relação Sinal/Ruído foram calculadas. Os principais desfechos do estudo foram a melhora auditiva, a sensibilidade e especificidade das medidas (106). 


\section{OBJETIVOS}

\subsection{OBJETIVO GERAL}

Analisar o zumbido e a audição em portadores de perda auditiva neurossensorial súbita idiopática submetidos à corticoterapia.

\subsection{OBJETIVOS ESPECÍFICOS}

Comparar o incômodo e a gravidade do zumbido subjetivo agudo no pré e pós tratamento com corticoide por via oral e com corticoide intratimpânico de resgate;

Comparar a média tetratonal da audiometria tonal limiar no pré e pós tratamento com corticoide por via oral e com corticoide intratimpânico de resgate;

Comparar a amplitude e a relação Sinal/Ruído das emissões otoacústicas evocadas por produto de distorção no pré e pós tratamento com corticoide por via oral e com corticoide intratimpânico de resgate. 


\section{MÉTODOS}

\subsection{Desenho e Tipo de estudo}

Estudo analítico, observacional, prospectivo e longitudinal em que foram analisadas as medidas das orelhas acometidas de sujeitos com zumbido subjetivo agudo e perda auditiva neurossensorial súbita idiopática, no pré e pós tratamento.

\subsection{Sujeitos}

Foram convidados a participar da pesquisa pacientes encaminhados por médico otorrinolaringologista com queixa de zumbido subjetivo agudo e perda auditiva neurossensorial súbita, atendidos no período de janeiro de 2014 a junho de 2015, no Instituto Brasiliense de Otorrinolaringologia (IBO), em Brasília-DF.

\subsubsection{Critérios de inclusão:}

- Zumbido subjetivo agudo;

- Perda auditiva neurossensorial súbita idiopática de 30dB (decibéis) em pelo menos 3 frequências consecutivas;

- Adultos de ambos os sexos;

- Idade entre 18 anos a 65 anos;

- Primeiro atendimento até 15 dias do início da perda auditiva neurossensorial súbita;

- Curva timpanométrica do tipo A (Jerger, 1970).

\subsubsection{Critérios de exclusão:}

- História de doenças da orelha média;

- Sinais de otite média aguda ou crônica;

- Presença de Timpanograma do tipo Ar, Ad, C ou B (Jerger, 1970);

- História de cirurgia otológica prévia;

- História de Síndrome de Ménière ou flutuação da audição; 
- Enfermidades sistêmicas como diabetes e/ou hipertensão arterial;

- História de trauma acústico;

- História de exposição a ruído ocupacional;

- Enfermidade neurológica;

- História de perda auditiva neurossensorial unilateral ou bilateral anterior ao episódio da perda auditiva neurossensorial súbita.

\subsection{Procedimentos}

4.3.1 Avaliação Clínica, Laboratorial e de Imagem

Os sujeitos realizaram exame clínico otorrinolaringológico, composto de otoscopia, orofaringoscopia e rinoscopia, bem como avaliação laboratorial e de imagem.

Em relação ao exame de imagem, os sujeitos realizaram ressonância magnética no início da enfermidade, bem como realizaram os seguintes exames laboratoriais: glicemia de jejum, creatinina, uréia, perfil lipídico, cardiolipina, hormônio tridotironina e hormônio tiroxina (T3, T4), hormônio estimulante da tireoide (TSH), proteína C reativa (PCR), sorologia para herpes simples, Venereal Disease Research Laboratory (VDRL), varicela zoster e rubéola.

\subsubsection{Termo de Consentimento Livre e Esclarecido (TCLE) e Anamnese}

Após a consulta inicial e realização da Anamnese (Apêndice A), o paciente assinava o Termo de Consentimento Livre e Esclarecido (Apêndice B).

O TCLE foi redigido em termos acessíveis a qualquer grupo sociocultural, sendo lido e explicado para os participantes que assinaram atestando sua vontade em participar da pesquisa. Nem todos os sujeitos convidados concordaram em participar da pesquisa.

Os procedimentos desta pesquisa ofereceram riscos mínimos à saúde dos participantes. 


\subsubsection{Escala Analógico-Visual (EAV) e Tinnitus Handicap Inventory (THI)}

4.3.3.1 A Escala Analógico-Visual (EAV) (Anexo I) bastante utilizada na avaliação da dor crônica, consiste em uma escala com pontuação de 0 a 10, em que o paciente subjetivamente classifica o incômodo do zumbido. A nota 0 corresponde a pouco incômodo com o zumbido e a nota 10 representa um incômodo muito grande. Por meio da Escala Analógico-Visual, pode-se pontuar com as notas 0, 1, 2, $3,4,5,6,7,8,9$ ou 10. Notas de 0 a 3 são consideradas como zumbido leve, de 4 a 7 como zumbido moderado e de 8 a 10 como zumbido severo $(4,28)$. Foi considerada melhora do incômodo do zumbido na Escala Analógico-Visual (EAV) quando, após o tratamento, houve melhora de dois pontos na nota em relação ao incômodo provocado pelo zumbido antes do tratamento (44).

4.3.3.2 O Tinnitus Handicap Inventory (THI) (Anexo I), desenvolvido por Newman et al. (1996), é um questionário de fácil interpretação e aplicação. Denominado Questionário de Gravidade do Zumbido (QGZ), é um instrumento validado internacionalmente e adaptado ao português brasileiro (35). É composto por 25 questões, divididas em três escalas: funcional, emocional e catastrófica. São três as opções de resposta para cada uma das questões, pontuadas da seguinte maneira: sim (4 pontos), às vezes (2 pontos) e não (nenhum ponto).

A escala funcional $(F)$ mede a interferência do zumbido em atividades mentais, sociais, ocupacionais e físicas e consiste em 11 questões, alcançando pontuação máxima de 44. A escala emocional (E) mede as respostas afetivas, como ansiedade, raiva e depressão, correspondendo a 9 questões e pode atingir pontuação máxima de 36 . A escala catastrófica $(C)$ quantifica o desespero e a incapacidade referida pelo paciente em lidar com o sintoma; representando 5 perguntas do inventário e pode atingir o máximo de 20 pontos. 
4.3.3.3 Classificação do zumbido pelo THI segundo Mc Combe et al. (2001)

Segundo os autores, somando-se os pontos obtidos no THI, o zumbido pode ser classificado como: desprezível (0 - 16), leve (18-36), moderado (38 - 56), severo (58 - 76) ou catastrófico $(78$ - 100) e considera-se como melhora da gravidade de sensação do zumbido a mudança de categoria após o tratamento.

\subsubsection{Medidas de Imitância Acústica}

Para assegurar a integridade da orelha externa e média em todos os participantes, antes dos procedimentos de aferição do limiar, todos foram submetidos à meatoscopia e timpanometria em ambas orelhas. Seguindo o critério adotado para seleção da amostra, todos os participantes apresentaram curva tipo ' $A$ ', indicando bom funcionamento do sistema tímpano-ossicular. Posteriormente, foram obtidos os limiares do reflexo acústico nas frequências de $500 \mathrm{~Hz}, 1000 \mathrm{~Hz}$, $2000 \mathrm{~Hz}$ e $4000 \mathrm{~Hz}$ em ambas orelhas.

\subsubsection{Aferição de limiares tonais}

Foi realizada por meio da Audiometria Tonal Limiar (ATL) com o paciente sentado dentro de uma cabine acústica e onde foram registrados os limiares tonais obtidos por condução aérea nas frequências de $250 \mathrm{~Hz}, 500 \mathrm{~Hz}, 1000 \mathrm{~Hz}, 2000 \mathrm{~Hz}$, $3000 \mathrm{~Hz}, 4000 \mathrm{~Hz}, 6000 \mathrm{~Hz}$ e $8000 \mathrm{~Hz}$ e por condução óssea nas frequências de $500 \mathrm{~Hz}, 1000 \mathrm{~Hz}, 2000 \mathrm{~Hz}$ e $4000 \mathrm{~Hz}$ com audiômetro clínico de dois canais Itera II Madsen ${ }^{\circledR}$. O fone padrão TDH 39 foi utilizado para aferição dos limiares tonais de $250 \mathrm{~Hz}$ a $8000 \mathrm{~Hz}$. Já os limiares ósseos foram obtidos por meio de um vibrador ósseo na mastóide. Os limiares tonais foram obtidos em ambas orelhas e o exame foi iniciado pela melhor orelha referida.

Foi utilizada a técnica descendente tanto com tom puro quanto com tom de frequência modulada (warble) devido à queixa de zumbido. Foram analisados os achados somente na orelha acometida, tendo em vista que todos os pacientes apresentaram perda auditiva neurossensorial unilateral. 
Para análise da recuperação auditiva, foi utilizada a proposta de Nemati et al. (2011), após a obtenção da média tetratonal $(500 \mathrm{~Hz}, 1000 \mathrm{~Hz}, 2000 \mathrm{~Hz}$ e $4000 \mathrm{~Hz})$ em três categorias:

A) Recuperação completa quando ocorreu melhora >=30dBNA na média tetratonal;

B) Recuperação parcial, quando ocorreu melhora $>=10 \mathrm{dBNA}$ e $<=30 \mathrm{dBNA}$ na média tetratonal;

C) Sem melhora quando ocorreu uma recuperação <=9dBNA na média tetratonal.

4.3.6 Limiar de Reconhecimento de Fala, Limiar de Detecção de Fala e Índice Percentual de Reconhecimento de Fala

O Limiar de Reconhecimento de Fala (LRF) foi realizado para confirmar os achados do limiar de tom puro. Foram utilizadas palavras trissilábicas e considerouse como resultado o valor obtido quando o sujeito repetiu corretamente duas de quatro palavras apresentadas (50\% das apresentações). Considerou-se que o LRF pode estar $10 \mathrm{~dB}$ acima da média tritonal de $500 \mathrm{~Hz}, 1000 \mathrm{~Hz}$ e $2000 \mathrm{~Hz}$ (108).

O Limiar de Deteção de Fala (LDF) foi utilizado na orelha acometida quando o LRF não pode ser aplicado, como nos casos de perda auditiva severa a profunda. Nesse teste o paciente necessita apenas detectar a emissão da sílaba "pa" sem necessariamente discriminá-la, devendo ser também compatível com os limiares audiométricos.

Para o Índice Percentual de Reconhecimento de Fala (IPRF), o sujeito foi orientado a repetir uma lista com 25 monossílabos em cada orelha. A intensidade foi mantida fixa, $40 \mathrm{~dB}$ acima da média tritonal $(500 \mathrm{~Hz}, 1000 \mathrm{~Hz}$ e $2000 \mathrm{~Hz})$. Caso o número de monossílabos repetidos corretamente fosse inferior a $88 \%$ (quatro palavras ou mais repetidas incorretamente), foi apresentada uma lista com 25 dissílabos, repetindo-se o mesmo procedimento adotado com as palavras monossilábicas. Todos foram realizados a viva voz. 
4.3.7 Aferição da amplitude e relação Sinal/Ruído (S/R) das Emissões Otoacústicas Evocadas por Produto de Distorção (EOAEPD)

O teste de emissões otoacústicas foi realizado em sala acusticamente tratada, com o objetivo de avaliar especificamente a funcionalidade das células ciliadas externas.

O equipamento de emissões otoacústicas, utilizado neste estudo, Otoread, Interacoustic $₫$, monitorou automaticamente o nível de ruído; a linearidade do estímulo, durante o teste; e o posicionamento adequado da sonda. Para indicar o momento, em que cada um desses aspectos tornou-se inadequado para a testagem, apareceram na tela, respectivamente, as mensagens "NOISY" e "NO SEAL". Para solucionar, a oliva foi trocada ou reposicionada, e a avaliação reiniciada.

As EOAEPD foram avaliadas por meio da apresentação simultânea de dois tons puros diferentes (F1 e F2), expressos pela razão de 1,22. Utilizou-se o parâmetro de intensidade $L=65 \mathrm{~dB}$ e $\mathrm{L}=55 \mathrm{~dB}$, sendo aferidas as condições cocleares nas bandas de frequências de $2000 \mathrm{~Hz}, 3000 \mathrm{~Hz}, 4000 \mathrm{~Hz}$ e $5000 \mathrm{~Hz}$, obtendo-se a amplitude e a relação Sinal/Ruído.

Optou-se por realizar e analisar o teste de EOAEPD, por ser um teste que permite avaliar separadamente cada banda de frequência, além das EOAs poderem estar presentes quando os limiares auditivos estiverem melhores que 45dBNA. As emissões otoacústicas evocadas transientes (EOAT), por sua vez, costumam estar ausentes quando os limiares excedem 20 a 30dBNA.

As análises das EOAEPD foram feitas por frequência, seguindo os critérios de amplitude (DP) maior que $-5 \mathrm{~dB}$ e relação Sinal/Ruído (S/R) maior que $6 \mathrm{~dB}$ (109, 110).

Os exames coletados foram impressos no momento do teste, isto permitiu a visualização dos parâmetros amplitude e relação Sinal/Ruído nas EOAEPD por banda de frequência separadamente (Figura 4). 


\section{OtoRead}

\section{TESTE EMISSAO OTO-ACUSTICA}

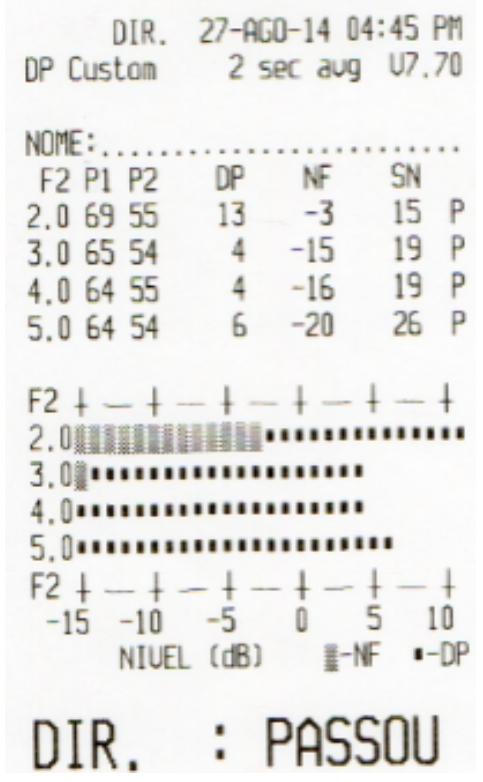

DP- Amplitude (dB)

$\mathrm{SN}$ - relação Sinal/Ruído $(\mathrm{dB})$

Figura 4 - Impresso demonstrativo dos registros das EOAEPD

\subsection{Propostas terapêuticas}

* Grupo Via Oral (GVO)- Predinisolona

* Grupo Resgate (GR)- Metilpredinisolona intratimpânica após corticoterapia por via oral

A corticoterapia foi realizada por médico Otorrinolaringologista da seguinte forma:

GVO- Prednisolona $1 \mathrm{mg} / \mathrm{Kg} / \mathrm{dia}$, por dez (10) dias, com redução gradativa a partir do $10^{\circ}$ dia e completa retirada ao final de três semanas.

GR- $40 \mathrm{mg} / \mathrm{ml}$ de Metilprednisolona intratimpânica, sendo três (3) injeções com intervalo de 48 horas entre elas.

Todos os pacientes foram tratados ambulatorialmente, não havendo necessidade de internação.

O procedimento da injeção intratimpânica foi realizado com uso de microscópio, no qual foi utilizado anestésico em spray diretamente no conduto auditivo externo e, posteriormente, com a cabeça posicionada $45^{\circ}$ em direção à orelha não acometida, aplicada a solução de metilprednisolona (aproximadamente 
0,5 ml). Foram realizados dois orifícios com a própria agulha de aplicação, um logo abaixo do umbo, para aplicar a medicação e outro na região póstero-superior para servir de orifício de escape, não havendo necessidade de tubo de ventilação. Após a aplicação, o indivíduo permaneceu por cerca de 45 minutos em posição supina, com a cabeça fletida $45^{\circ}$ para maximizar o efeito da solução utilizada (44).

4.5 Reavaliação do incômodo e gravidade do zumbido e dos achados audiológicos e eletroacústicos

A Escala Analógico-Visual (EAV), o Tinnitus Handicap Inventory (THI), a Audiometria Tonal Limiar (ATL) e o teste de Emissões Otoacústicas Evocadas por Produto de Distorção (EOAEPD) foram realizados novamente após 90 dias do último dia do tratamento aplicado, totalizando 3 meses de acompanhamento (15).

\subsection{Procedimentos Éticos}

Esta pesquisa foi aprovada pelo Comitê de Ética em Pesquisa (CEP) da Faculdade de Ciências da Saúde da Universidade de Brasília, processo 132/2012 (Anexo II).

\subsection{Análise dos resultados}

As médias das medidas foram comparadas após o tratamento comparandoas entre GVO e GR, usando-se um modelo de análise de covariância (ANCOVA).

No modelo ANCOVA, considerou-se como variável dependente as medidas obtidas após o tratamento, a modalidade de tratamento como variável independente e as medidas no pré tratamento como covariável.

Comparações de médias intra grupos foram realizadas com o emprego do teste $t$ de Student para amostras emparelhadas.

Considerou-se significativo $p<0,05$ e a análise foi realizada usando-se SAS v 9.4 (SAS Institute, Inc., 2012). 


\subsection{PLANO DE TRABALHO}

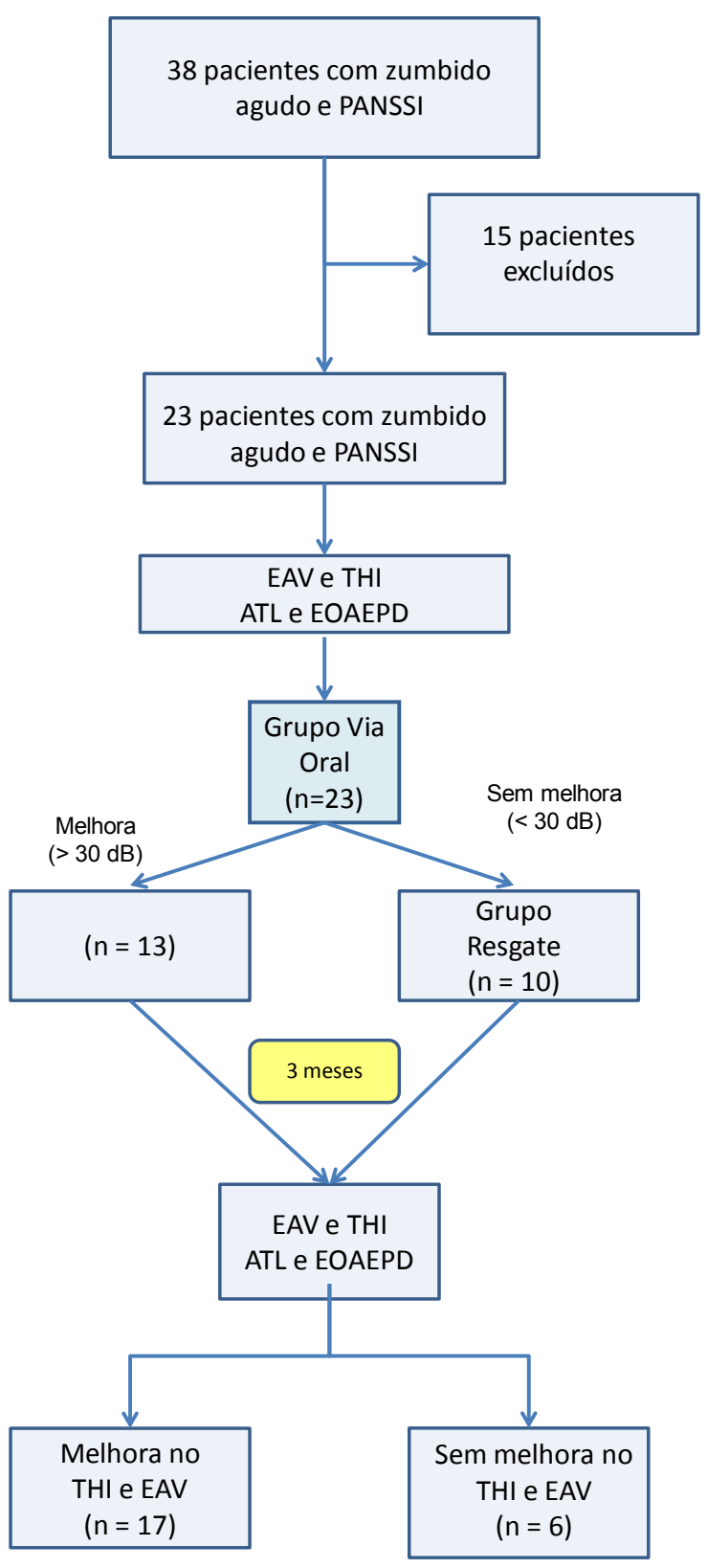




\section{RESULTADOS}

Este capítulo apresenta os achados das avaliações em relação ao zumbido na Escala Analógico-Visual (EAV), no Tinnitus Handicap Inventory (THI) e os achados em relação à audição na Audiometria Tonal Limiar (ATL) e nas Emissões Otoacústicas Evocadas por Produto de Distorção (EOAEPD), considerando os dados obtidos no pré e no pós tratamento (3 meses).

Foram avaliados 38 sujeitos com zumbido subjetivo agudo e perda auditiva neurossensorial súbita, atendidos no período de janeiro de 2014 a junho de 2015 . Destes, 15 sujeitos não preencheram os critérios de inclusão, dos quais: 2 relataram perda auditiva anterior ao episódio de perda auditiva neurossensorial súbita; 1 apresentou perda auditiva neurossensorial súbita bilateral; em 3 foi encontrada a etiologia da perda auditiva neurossensorial súbita; 2 não concordaram em participar da pesquisa; 2 não retornaram para o seguimento na data prevista e 5 apresentavam idade abaixo de 18 anos ou acima de 65 anos na data do episódio de perda auditiva neurossensorial súbita.

Foram incluídos 23 sujeitos com zumbido subjetivo agudo e perda auditiva neurossensorial súbita idiopática (PANSSI) unilateral, sendo 13 sujeitos do Grupo Via Oral (GVO), submetidos a corticoterapia sistêmica por via oral e 10 sujeitos do Grupo Resgate (GR), submetidos a corticoterapia intratimpânica como terapia de resgate.

O Grupo Via Oral (GVO) com 13 sujeitos era composto por 6 sujeitos do gênero feminino e 7 do gênero masculino, com idade média de 38,30 anos (18 a 65 anos) e o Grupo Resgate (GR) com 10 sujeitos, era composto por 7 sujeitos do gênero feminino e 3 do gênero masculino, com idade média de 47,40 anos (30 a 62 anos).

A orelha direita foi acometida em 47,82\% ( $n=11)$ dos sujeitos e a orelha esquerda, em $52,17 \%(n=12)$.

As características gerais dos grupos no pré tratamento, segundo idade, orelha acometida (direita ou esquerda), gênero e a variação do grau da perda auditiva no pré tratamento, podem ser observadas na Tabela 1, a seguir. 
Tabela 1. Características gerais dos grupos, segundo idade, orelha acometida, gênero e variação do grau da perda auditiva no pré tratamento

\begin{tabular}{|c|c|c|c|c|c|c|c|}
\hline \multirow[t]{2}{*}{ Grupo } & \multirow[t]{2}{*}{$\begin{array}{l}\text { Idade } \\
\text { (anos) }\end{array}$} & \multicolumn{2}{|c|}{$\begin{array}{c}\text { Orelha } \\
\text { acometida }\end{array}$} & \multicolumn{2}{|c|}{ Gênero } & \multirow{2}{*}{$\begin{array}{l}\text { Grau de } \\
\text { perda } \\
\text { auditiva } \\
\text { (média } \\
\text { tetratonal) }\end{array}$} & \multirow[t]{2}{*}{ Total } \\
\hline & & OD & $\mathrm{OE}$ & Masculino & Feminino & & \\
\hline GVO & 38,30 & 9 & 4 & 7 & 6 & $\begin{array}{l}\text { Moderada } \\
\text { a Profunda }\end{array}$ & 13 \\
\hline GR & 47,40 & 2 & 8 & 3 & 7 & $\begin{array}{l}\text { Moderada } \\
\text { a Profunda }\end{array}$ & 10 \\
\hline
\end{tabular}

Legenda: GVO- Grupo Via Oral, GR- Grupo Resgate, OD- orelha direita, OE- orelha esquerda

5.1 Resultados em relação ao zumbido na Escala Analógico-Visual (EAV)

Na EAV, o valor médio de incômodo no pré tratamento para o GVO foi 7,69 e no pós tratamento foi 5,30 .

O valor médio para o GR no pré tratamento foi 8,30 e 5,81 no pós tratamento, como pode ser observado na Tabela 2.

Tabela 2. Resultados na EAV no pré e pós tratamento, em ambos os grupos

\begin{tabular}{|c|c|c|c|c|c|}
\hline & \multicolumn{2}{|c|}{ Grupo - Média [IC 95\%] } & \multicolumn{3}{|c|}{ Comparações entre Grupos } \\
\hline Variável & $\begin{array}{c}\text { GVO } \\
(n=13)\end{array}$ & $\begin{array}{c}\text { GR } \\
(n=10)\end{array}$ & $\begin{array}{c}\not \neq \\
\text { GR X GVO } \\
{[\text { IC 95\%] }}\end{array}$ & $\begin{array}{c}\text { F- } \\
\text { valor } \\
\text { (df) }\end{array}$ & $\begin{array}{c}\text { p- } \\
\text { valor }\end{array}$ \\
\hline \multicolumn{6}{|l|}{ EAV } \\
\hline Pré tratamento & $\begin{array}{r}7,69[6,79 ; \\
8,59]\end{array}$ & $8,30[7,29 ; 9,31]$ & & & \\
\hline Pós tratamento & $\begin{array}{r}5,15[3,92 ; \\
6,38]\end{array}$ & $6,00[4,61 ; 7,39]$ & & & \\
\hline$\neq$ (Pré -Pós) & $\begin{array}{r}2,54[1,34 ; \\
3,74]^{\dagger}\end{array}$ & $2,30[0,95 ; 3,65]$ & & & \\
\hline $\begin{array}{l}\text { Pós tratamento } \\
\text { (ajustado) }^{\#}\end{array}$ & $\begin{array}{r}5,30[4,20 ; \\
6,39]\end{array}$ & $5,81[4,56 ; 7,06]$ & $\begin{array}{r}0,51[-1,17 \\
2,19]\end{array}$ & $\begin{array}{r}0,40 \\
(1,20)\end{array}$ & 0,5319 \\
\hline
\end{tabular}

Comparações intra grupos (Pré x Pós tratamento): ${ }^{\mp} p<.05 \mathrm{e}^{\dagger} p<.01$, foram calculados com o uso do teste t pareado.* $p$-valores para comparação entre grupos foram calculados com uso de ANCOVA com valores do baseline como covariável). \# médias ajustadas pelos valores do basal do modelo ANCOVA

Legendas: $\neq$ diferença, $X$ versus, GVO-Grupo Via Oral, GR-Grupo Resgate 
A seguir, na Figura 5, podem ser visualizadas as notas atribuídas pelos pacientes do GVO para o incômodo causado pelo zumbido na EAV.

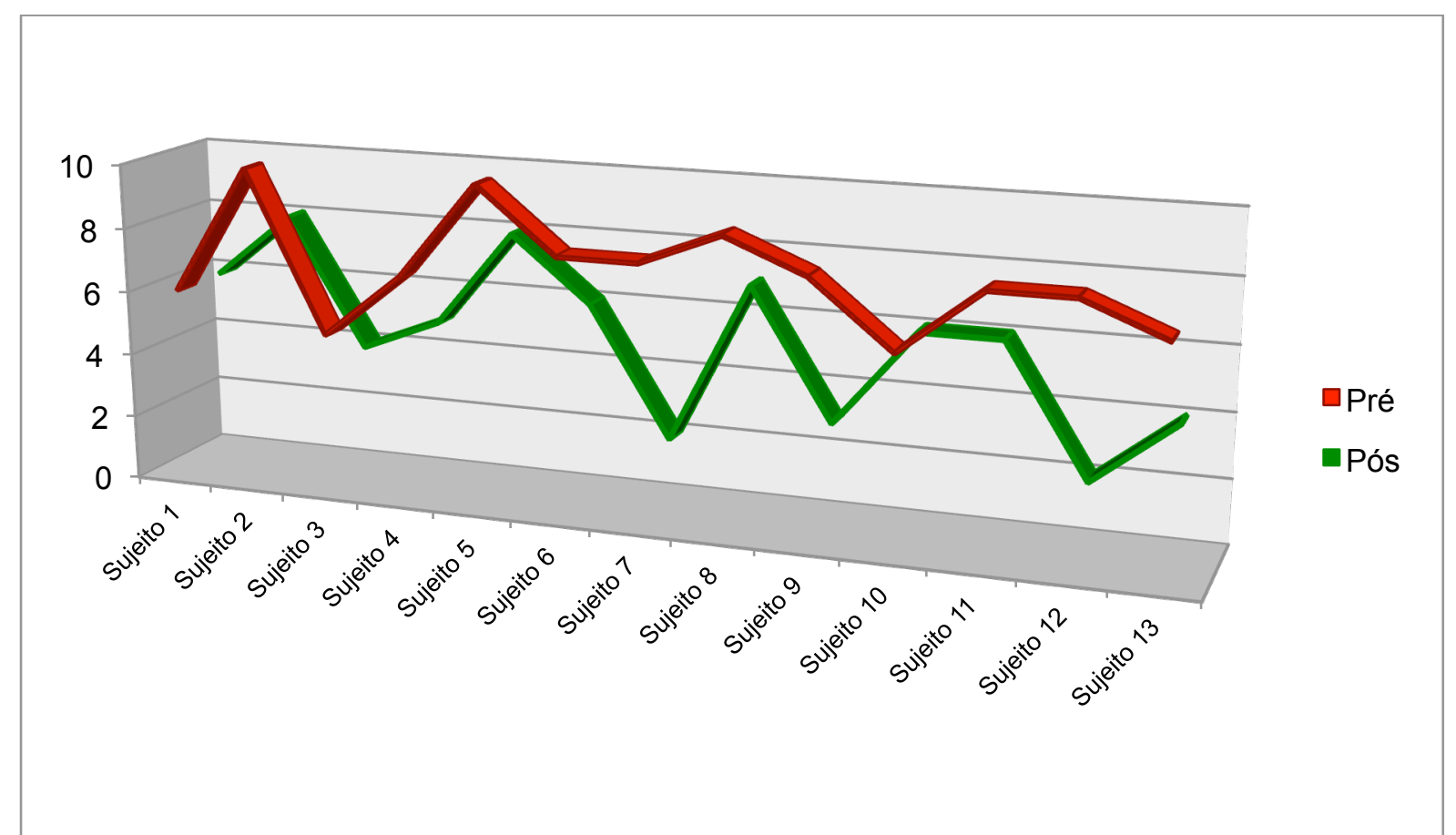

Figura 5. Distribuição das notas de incômodo atribuídas pelos pacientes do GVO na EAV pré e pós tratamento

No GVO pré tratamento, $61,53 \%(n=8)$ dos sujeitos atribuiu nota $=$ ou $>8$ na EAV, reduzindo para $15,38 \%(n=2)$ de sujeitos no pós tratamento apresentando nota = ou > 8 (zumbido com incômodo severo).

A nota individual atribuída pelos pacientes do GR para o incômodo causado pelo zumbido na EAV pode ser visualizada na Figura 6 , a seguir. 


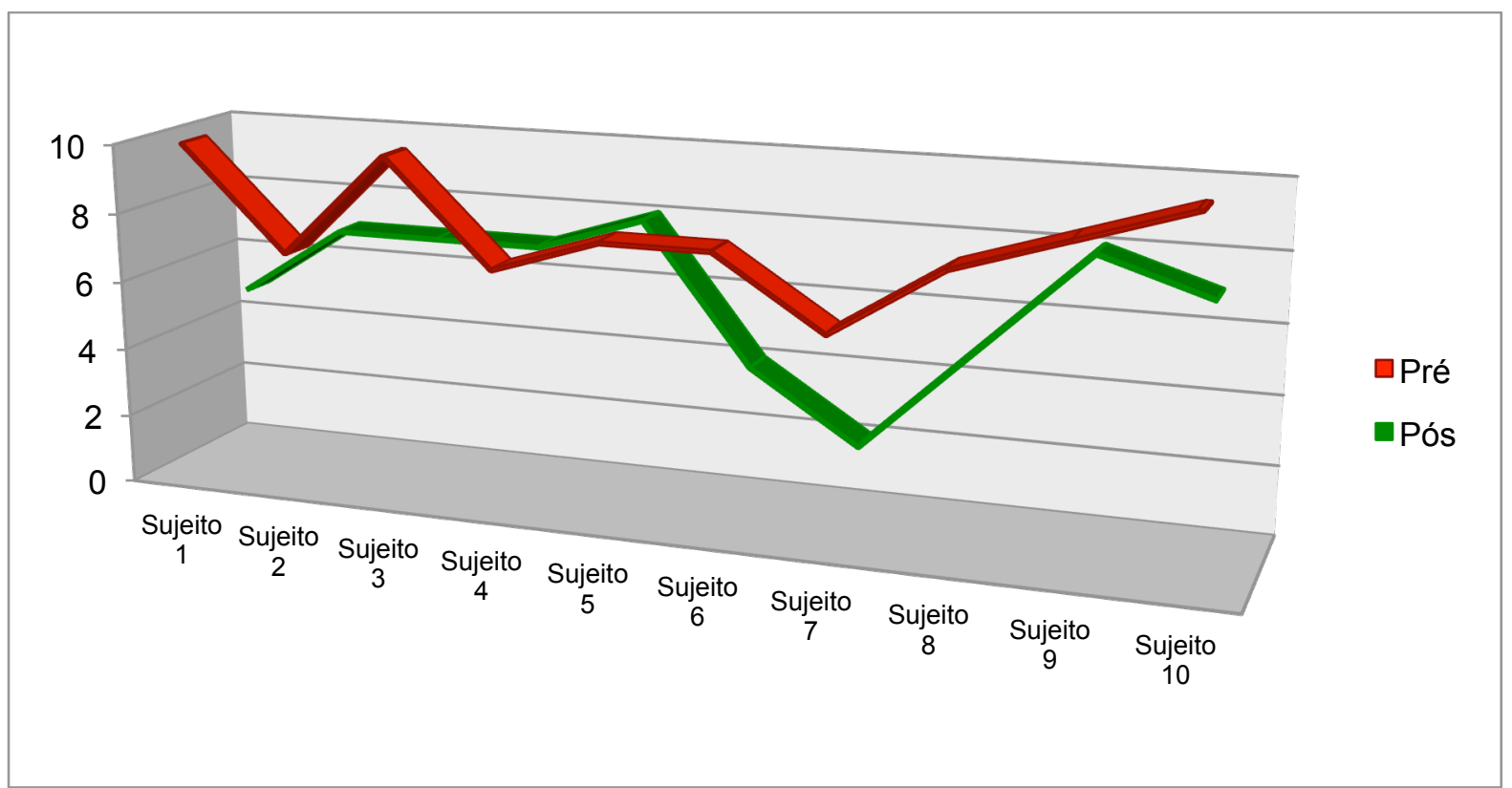

Figura 6. Distribuição das notas de incômodo atribuídas pelos pacientes do GR na EAV pré e pós tratamento

No GR, no pré tratamento, $70 \%(n=7)$ dos sujeitos atribuiu nota $=$ ou $>8$ na EAV, reduzindo para $20 \%(n=2)$ de sujeitos no pós tratamento apresentando nota $=$ ou > 8 (zumbido com incômodo severo).

$\mathrm{Na}$ Figura 7, a seguir, é possível visualizar o percentual de melhora em relação ao incômodo atribuído ao zumbido na EAV, conforme o critério de diminuição de dois pontos.

GVO

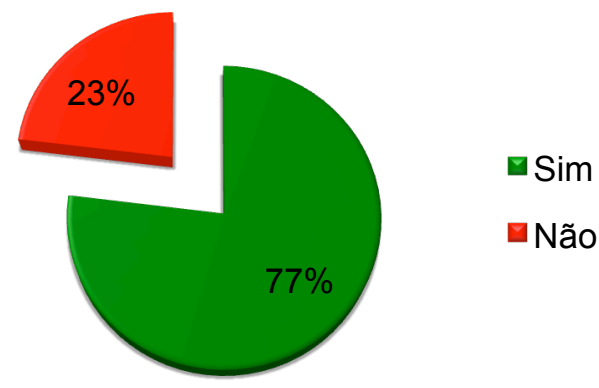

GR

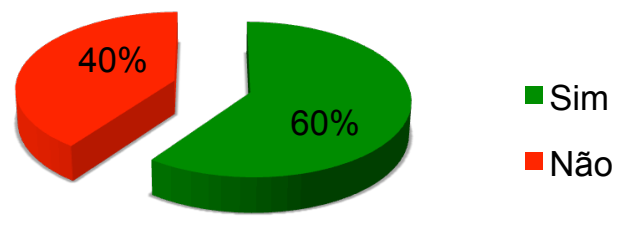

Figura 7. Percentual de diminuição do incômodo com o zumbido em ambos os grupos, na EAV pré e pós tratamento

Verifica-se que no GVO, $77 \%$ dos sujeitos apresentaram diminuição do incômodo com o zumbido após o tratamento e no GR, a redução foi de $60 \%$. 
5.2 Resultados em relação ao zumbido no Tinnitus Handicap Inventory (THI)

Para o Grupo Via Oral, as médias da pontuação do THI no pré tratamento foram: escala funcional: 35,23 pontos; escala emocional: 19,54 pontos; escala catastrófica: 10,00 pontos, que somadas, geraram uma média total de 64,77 pontos.

No pós tratamento, as médias foram: escala funcional: 23,31 pontos; escala emocional: 13,39 pontos; escala catastrófica: 7,80 pontos, que somadas, geraram uma média total de 45,90 pontos (Tabela 3 ).

Para o Grupo Resgate , as médias da pontuação do THI no pré tratamento foram: escala funcional: 34,60 pontos; escala emocional: 20,40 pontos; escala catastrófica: 17,20 pontos, que somadas, geraram uma média total de 72,20 pontos.

Após o tratamento as médias foram: escala funcional: 27,30 pontos; escala emocional: 14,20 pontos; escala catastrófica: 8,06 pontos, que somadas, geraram uma média total de 47,73 pontos (Tabela 3). 
Tabela 3. Resultados no THI no pré e pós tratamento, em ambos os grupos

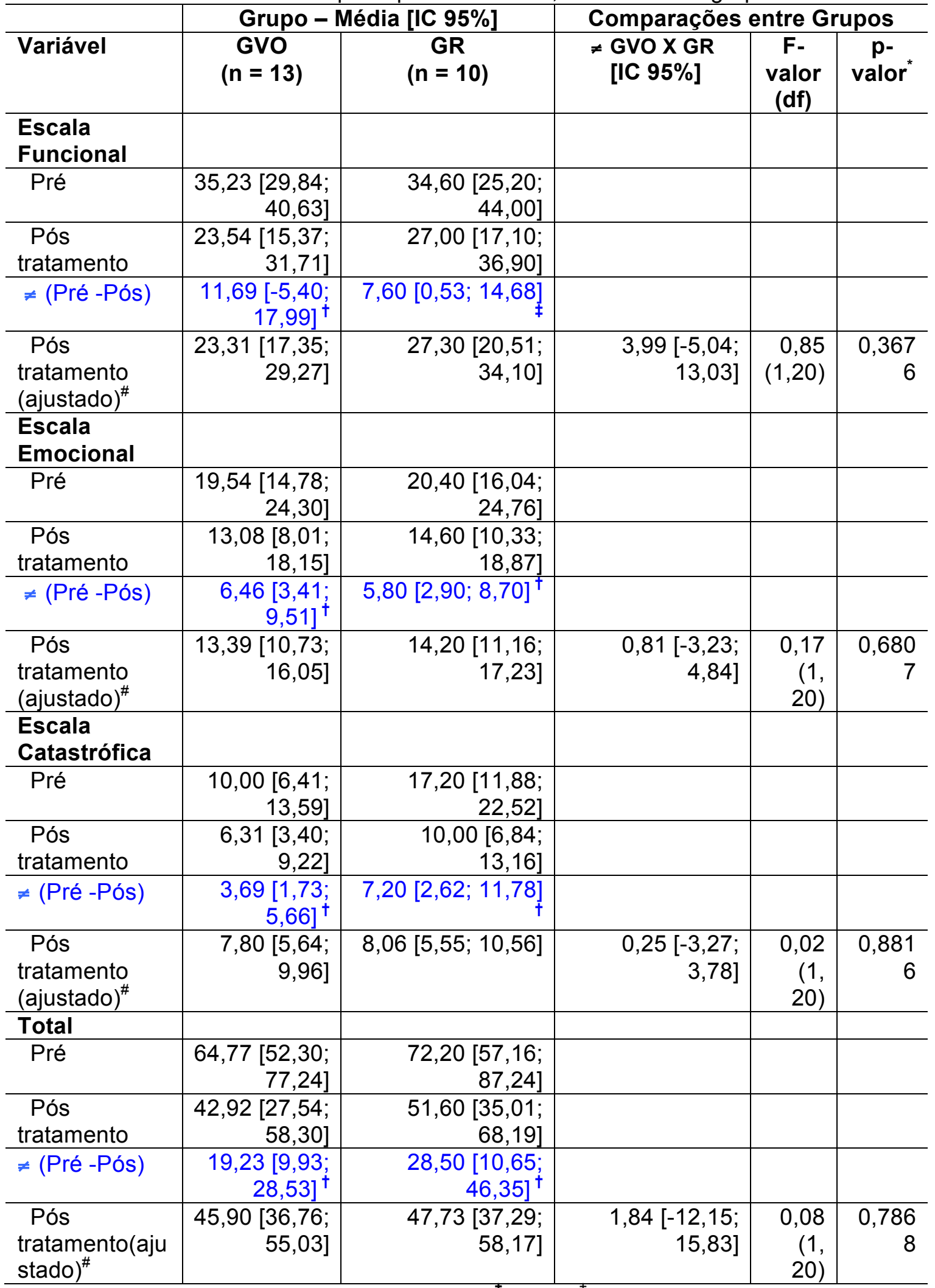

Comparações intra grupos (Pré x Pós tratamento): ${ }^{\ddagger} p<.05 \mathrm{e}^{\dagger} \mathrm{p}<.01$, foram calculados com o uso do teste t pareado. ${ }^{*}$-valores para comparação entre grupos foram calculados com uso de ANCOVA com valores do baseline como covariável). \# médias ajustadas pelos valores do basal do modelo ANCOVA

Legendas: $\neq$ diferença, X versus, GVO-Grupo Via Oral, GR-Grupo Resgate 
Ao utilizar o THI para identificar as características relacionadas ao zumbido no GVO, as médias da pontuação em cada escala, no pré e pós tratamento, podem ser visualizadas na Figura 8, a seguir.

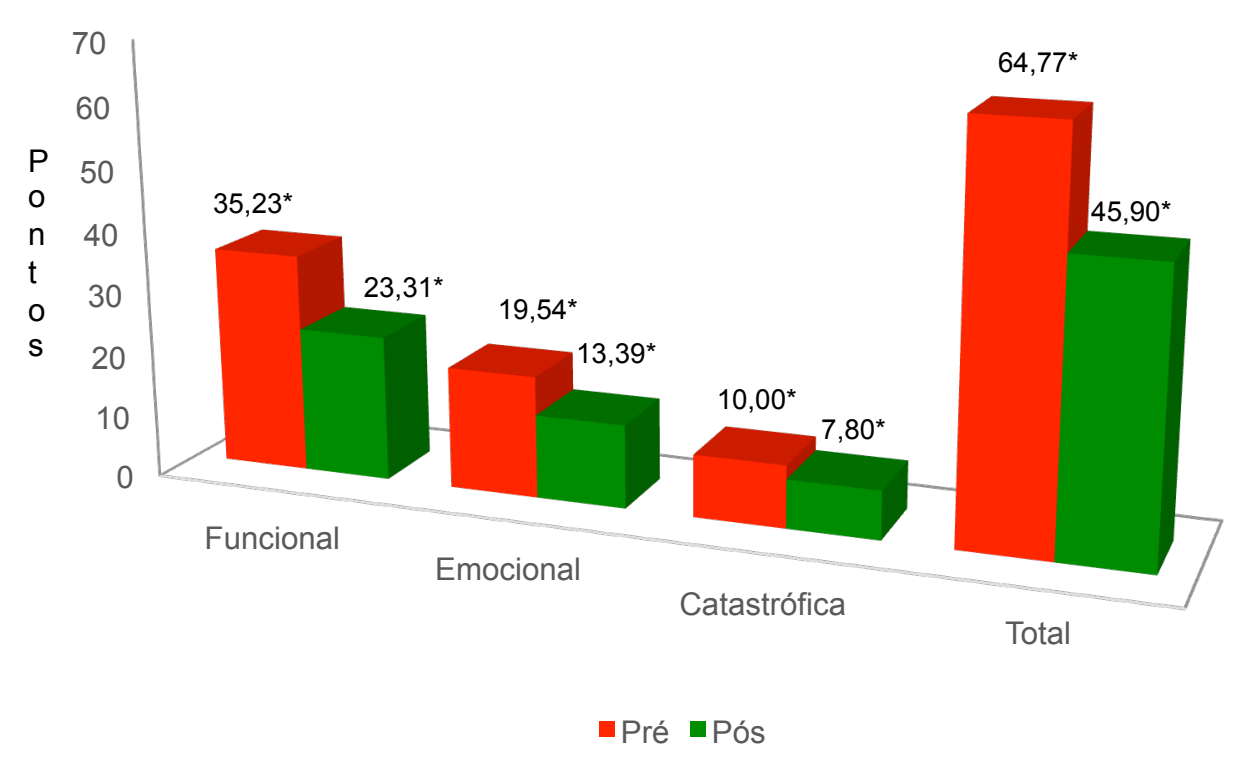

Figura 8. Distribuição das notas atribuídas pelos pacientes no THI, pré e pós tratamento, no GVO Legenda: * apresentou diferença estatisticamente significante

Verifica-se que a pontuação total no GVO foi de 64,77 pontos no pré tratamento e 45,90 pontos no pós tratamento.

Ao utilizar o THI para identificar as características relacionadas ao zumbido no GR, as médias da pontuação em cada escala, no pré e pós tratamento, podem ser visualizadas na Figura 9, a seguir. 


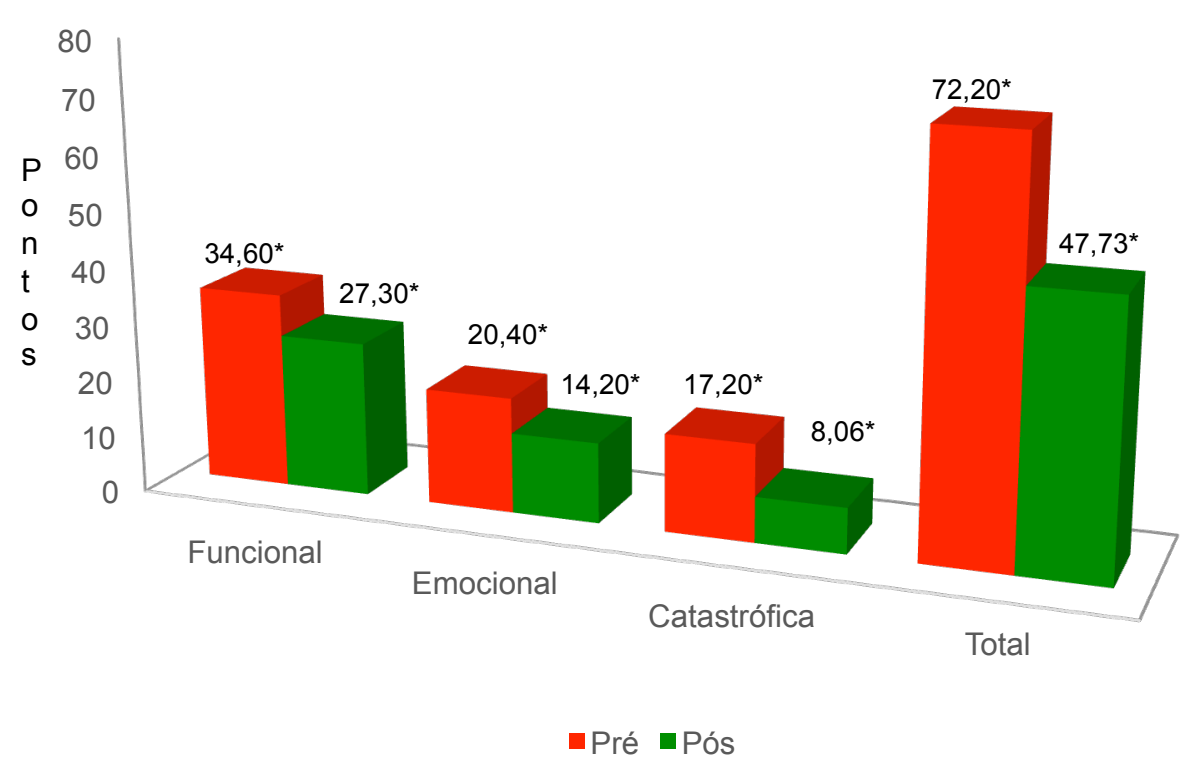

Figura 9. Distribuição das notas atribuídas pelos pacientes no THI, pré e pós tratamento, no GR Legenda: * apresentou diferença estatisticamente significante

Verifica-se que a pontuação total no GR foi de 72,20 pontos no pré tratamento sendo reduzida para 47,73 pontos no pós tratamento.

Os achados na EAV e no THI, ao comparar pré e pós tratamento, intra grupos, evidenciaram diferença estatisticamente significante (Tabelas 2 e 3, Figuras 10 e 11). 


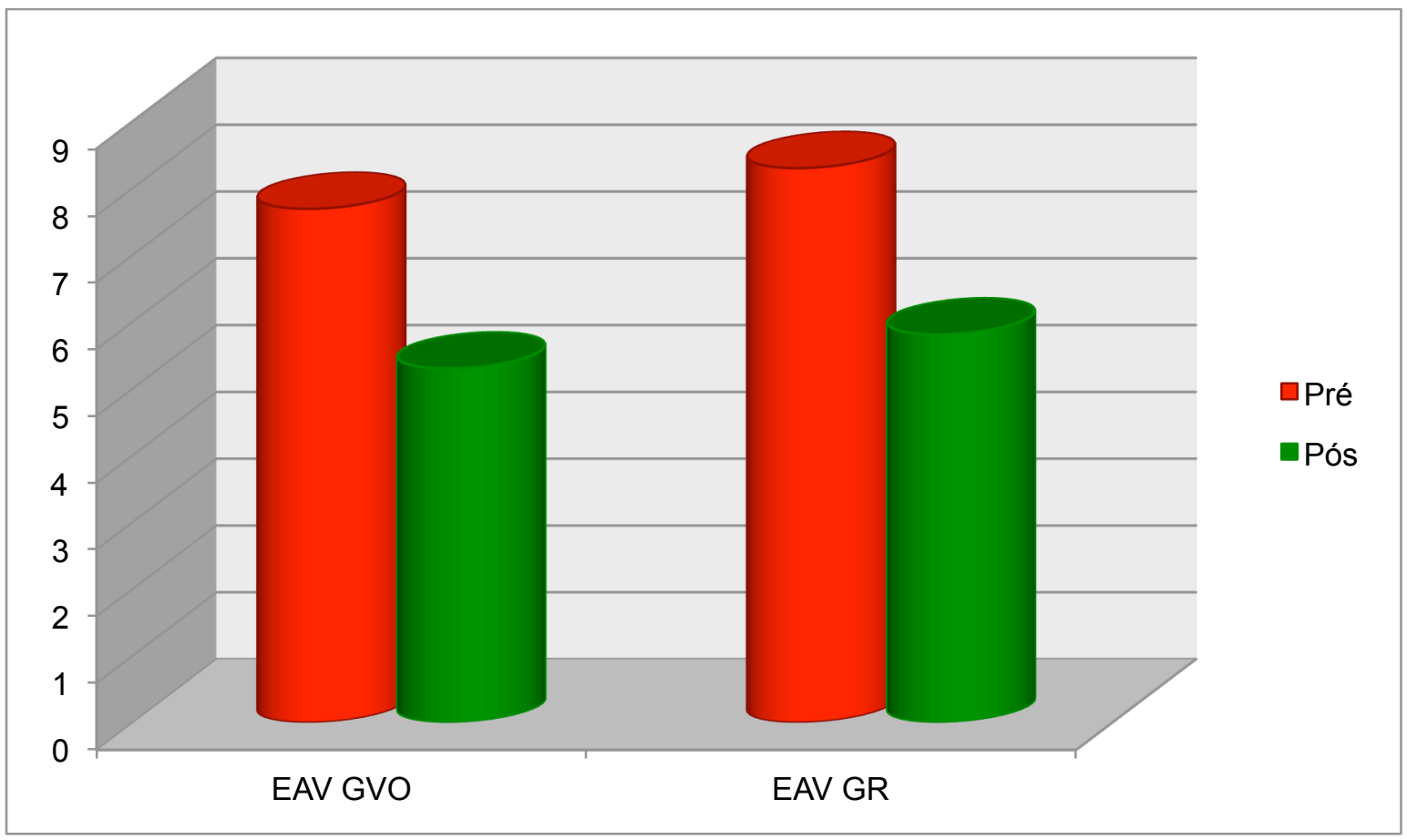

Figura 10- Comparação entre EAV, pré e pós tratamento

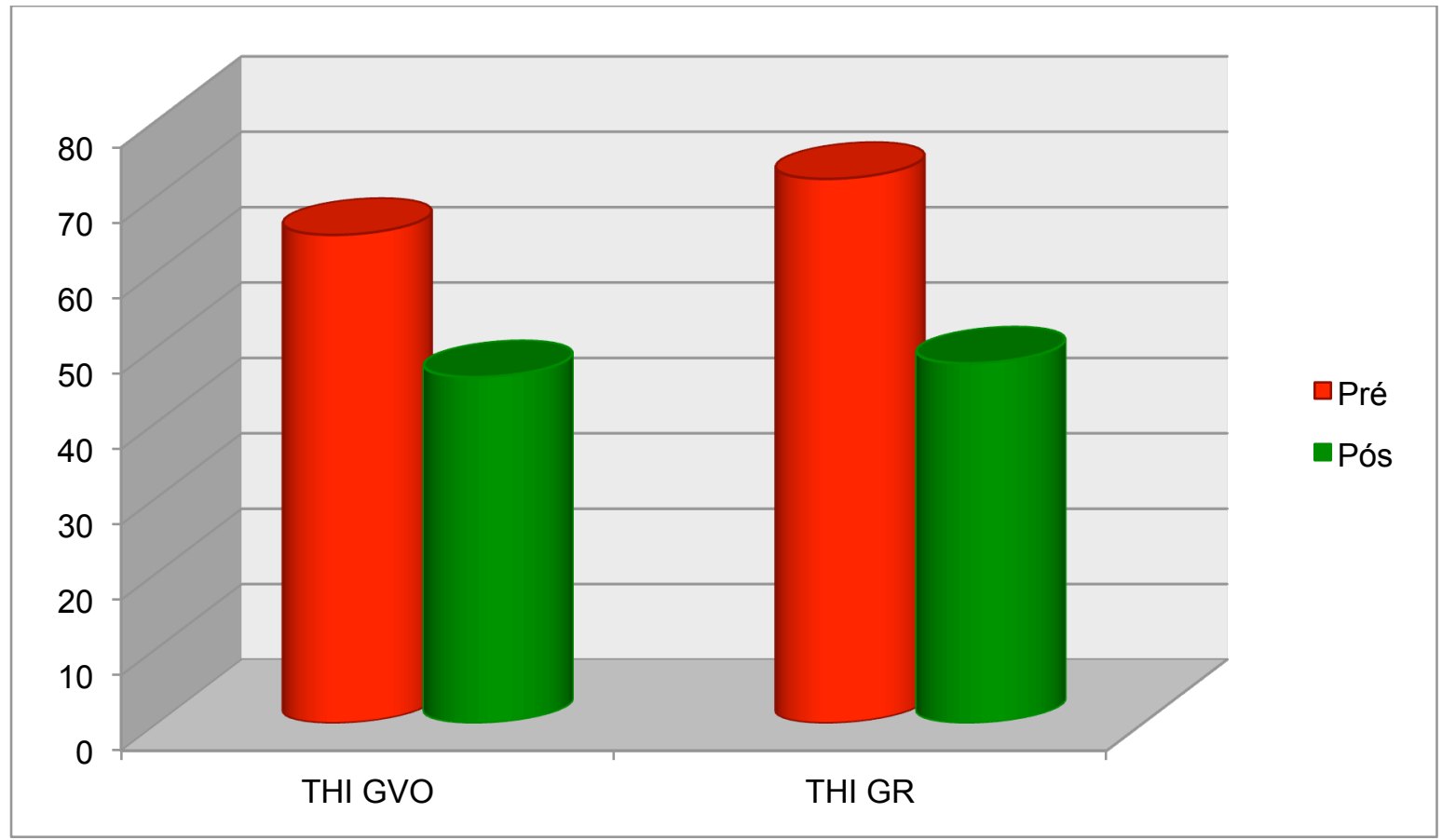

Figura 11 - Comparação entre THI, pré e pós tratamento 
Dados mais específicos dos achados do THI, conforme a classificação proposta por Mc Combe (2001) em relação a gravidade do zumbido, podem ser visualizadas nas Figuras 12 e 13, a seguir.

Verifica-se que no pré tratamento, após a aplicação do THI, para a maioria dos sujeitos do GVO, o zumbido foi classificado como moderado $(38,46 \%)$ ou severo $(38,46 \%)$ e no pós tratamento, foi classificado pela maioria $(38,46 \%)$ como zumbido leve (Figura 12).

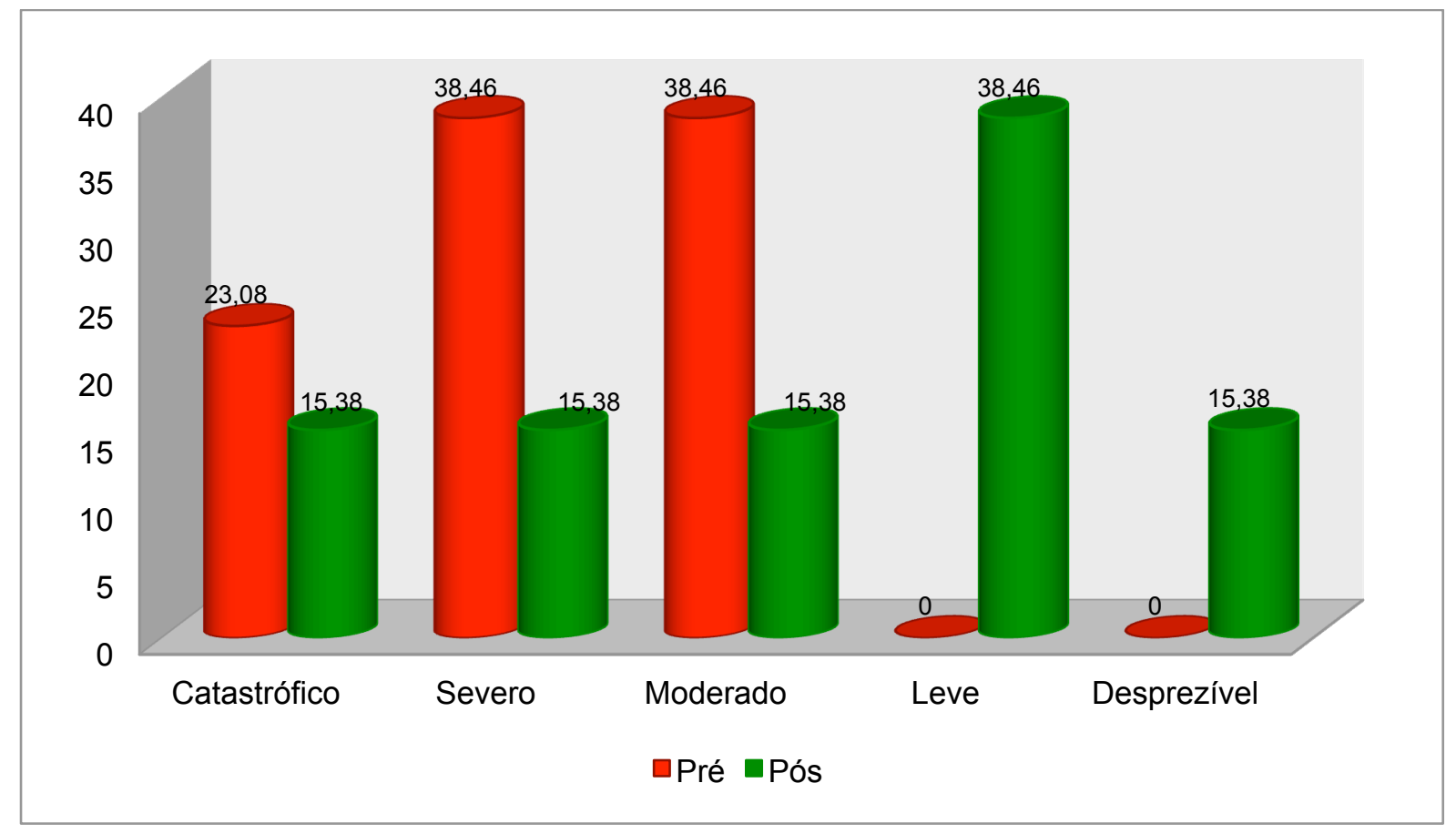

Figura 12. Classificação do zumbido segundo McCombe (2001) no pré e pós tratamento no GVO

Para o GR, no pré tratamento, o zumbido foi classificado pela maioria como sendo severo $(40 \%)$ e catastrófico $(40 \%)$ e no pós tratamento, a maioria $(30 \%)$ classificou o zumbido como sendo moderado (Figura 13). 


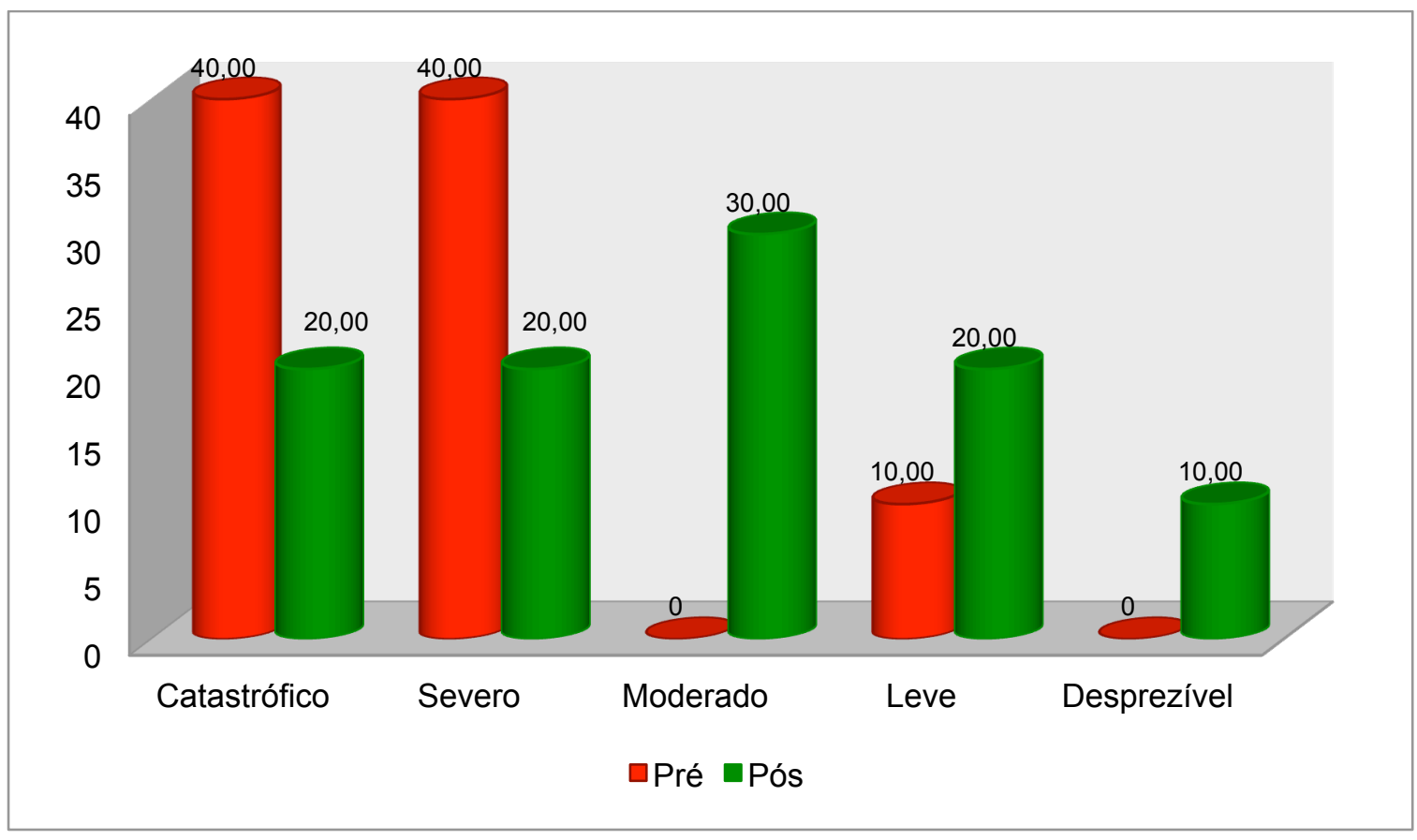

Figura 13. Classificação do zumbido segundo McCombe (2001) no pré e pós tratamento no GR

Assim, verifica-se que, no GVO, no pós tratamento, o zumbido foi classificado pela maioria como sendo leve $(38,46 \%)$ e no GR, como sendo moderado $(30,00 \%)$.

Evidenciou-se que ocorreu mudança de categoria no pós tratamento, em ambos os grupos.

Em relação a análise dos valores médios na Escala Analógico-Visual (EAV) e no Tinnitus Handicap Inventory (THI) entre os grupos, não foi observada diferença estatisticamente significativa, no pós tratamento entre as duas terapias consideradas.

Já na análise intra grupos: Os valores médios na EAV apresentaram uma redução significativa, em ambos os grupos, no pós tratamento em relação ao pré tratamento ( $p<0,05$, para todas as comparações). O mesmo ocorreu no THI. Ambas as terapias se mostraram equivalentes estatisticamente, apresentando uma redução significativa dos valores médios após tratamento. 
Quando observados os limiares auditivos (média tetratonal), no pré e pós tratamento, em ambos os grupos, verifica-se que a média no GVO, no pré tratamento era $74,23 \mathrm{~dB}$ (perda auditiva de grau severo) e foi reduzida para $59,69 \mathrm{~dB}$ (perda auditiva de grau moderado) no pós tratamento.

Para o GR no pré tratamento, a média tetratonal era $86,50 \mathrm{~dB}$ (perda auditiva de grau severo) e foi reduzida para $51,91 \mathrm{~dB}$ (perda auditiva de grau moderado) no pós tratamento, conforme Tabela 4 e Figura 14, a seguir.

Tabela 4. Resultados da média tetratonal obtida na Audiometria Tonal Limiar, em ambos os grupos

\begin{tabular}{|c|c|c|c|c|c|}
\hline \multirow{2}{*}{ Variável } & \multicolumn{2}{|c|}{ Grupo - Média [IC 95\%] } & \multicolumn{3}{|c|}{ Comparações entre Grupos } \\
\hline & $\begin{array}{c}\text { GVO } \\
(n=13)\end{array}$ & $\begin{array}{c}\text { GR } \\
(n=10)\end{array}$ & $\begin{array}{l}\neq \text { GVO X GR } \\
\text { [IC 95\%] }\end{array}$ & $\begin{array}{c}\text { F- } \\
\text { valor } \\
\text { (df) }\end{array}$ & $\begin{array}{c}\text { p- } \\
\text { valor }\end{array}$ \\
\hline \multicolumn{6}{|l|}{ Média Tetratonal } \\
\hline Pré & $\begin{array}{r}74,23 \\
{[58,25 ;} \\
90,21]\end{array}$ & $\begin{array}{r}86,50[72,49 \\
100,51]\end{array}$ & & & \\
\hline Pós tratamento & $\begin{array}{r}55,00 \\
{[36,17 ;} \\
73,83]\end{array}$ & $\begin{array}{r}58,00[39,90 ; \\
76,10]\end{array}$ & & & \\
\hline$\neq$ (Pré -Pós) & $\begin{array}{r}19,23 \\
{[9,93} \\
28,53]^{\dagger}\end{array}$ & $\begin{array}{r}28,50[10,65 \\
46,35]^{\dagger}\end{array}$ & & & \\
\hline $\begin{array}{l}\text { Pós tratamento } \\
\text { (ajustado) }^{\#}\end{array}$ & $\begin{array}{r}59,69 \\
{[47,74 ;} \\
71,63]\end{array}$ & $\begin{array}{r}51,91[38,22 ; \\
65,59]\end{array}$ & $\begin{array}{r}-7,78[-26,25 ; \\
10,69]\end{array}$ & $\begin{array}{r}0,77 \\
(1 \\
20)\end{array}$ & $\begin{array}{r}0,390 \\
2\end{array}$ \\
\hline
\end{tabular}

Comparações intra grupos (Pré x Pós tratamento): ${ }^{\ddagger} p<.05$ e ${ }^{\dagger} p<.01$, foram calculados com o uso do teste t pareado.* p-valores para comparação entre grupos foram calculados com uso de ANCOVA com valores do baseline como covariável). \# médias ajustadas pelos valores do basal do modelo ANCOVA

Legendas: $\neq$ diferença, $\mathrm{X}$ versus, GVO-Grupo Via Oral, GR-Grupo Resgate 


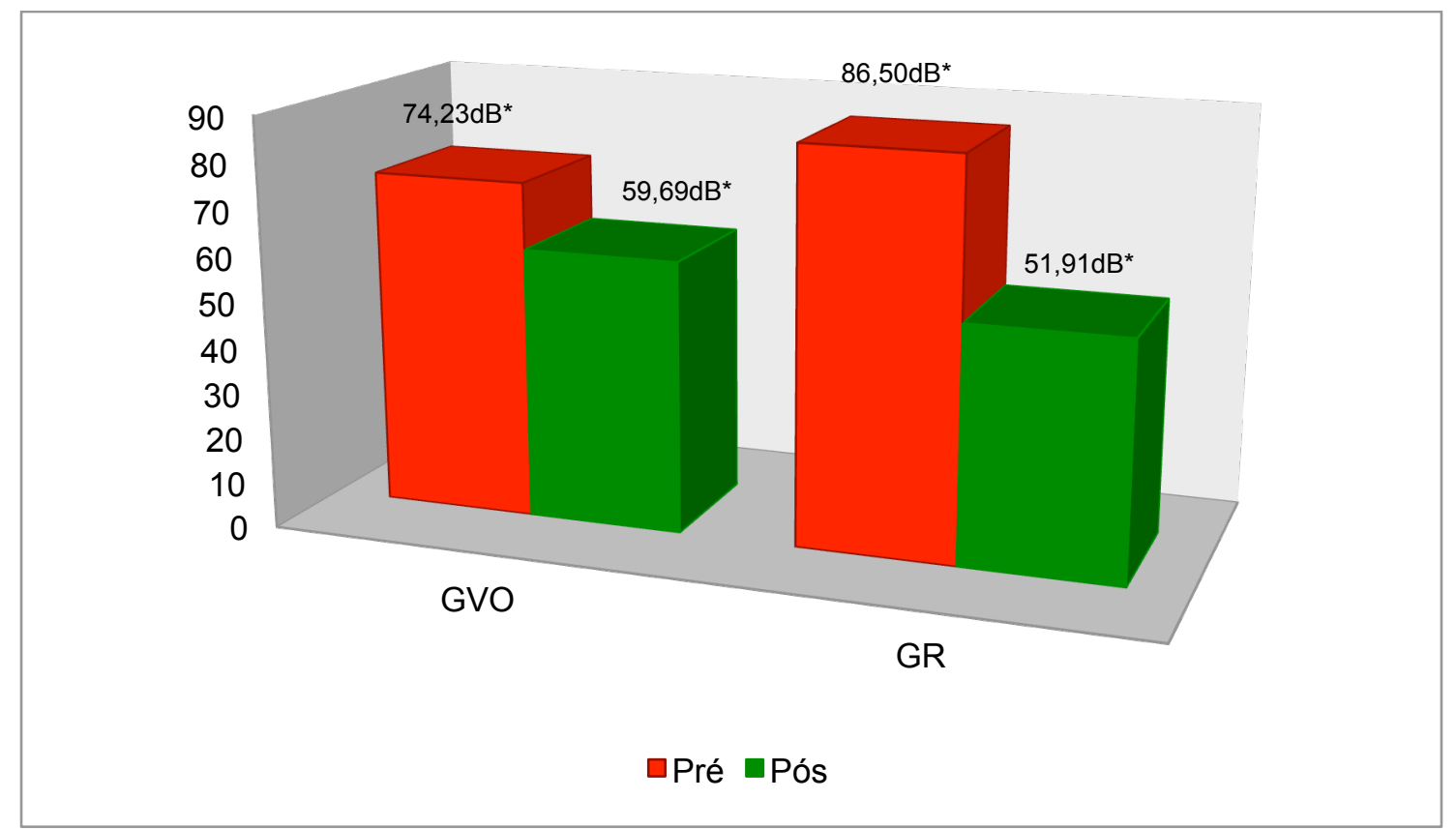

Fig 14. Média tetratonal, pré e pós tratamento, em ambos os grupos Legenda: * apresentou diferença estatisticamente significante

Em relação a taxa de recuperação, podemos observar o percentual de melhora, para ambos os grupos na Figura 15, a seguir.

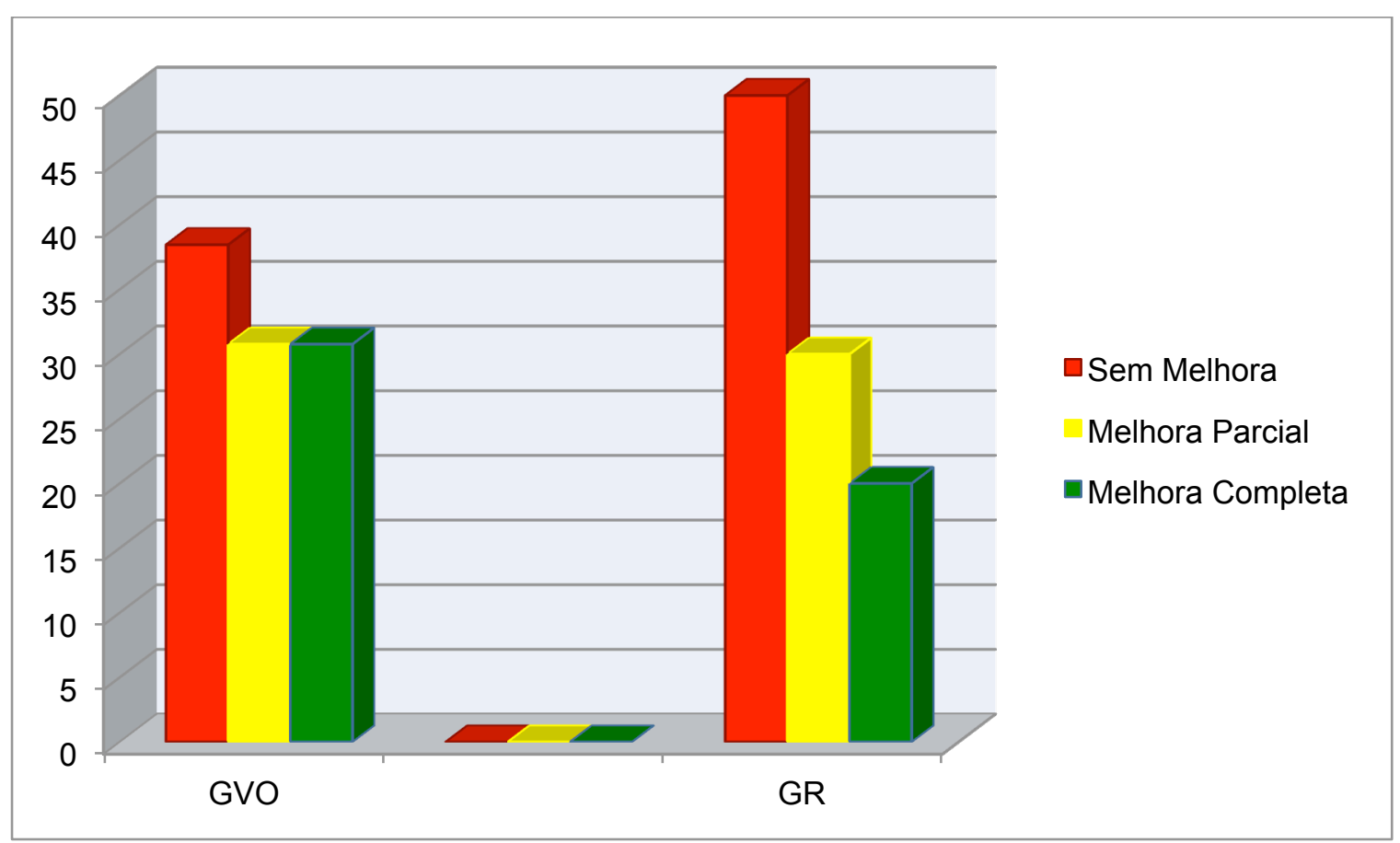

Fig 15. Taxa de recuperação auditiva na Audiometria Tonal Limiar, em ambos os grupos 
É possível verificar que no GVO, 30,77\% dos sujeitos apresentaram melhora completa da média tetratonal e $30,77 \%$ apresentaram melhora parcial, totalizando $61,54 \%$ de melhora.

Em relação ao GR, 20,00\% apresentou melhora completa da média tetratonal e $30,00 \%$ apresentou melhora parcial, totalizando $50,00 \%$ de melhora neste grupo.

Em relação a Audiometria Tonal Limiar (ATL), na análise entre os grupos não foi observada diferença significativa na média tetratonal, no pós tratamento entre as duas terapias consideradas. $\mathrm{Na}$ análise intra grupos, os valores médios dos Limiares Auditivos (média tetratonal) apresentaram uma diferença estatisticamente significativa, em ambos os grupos, no pós tratamento em relação ao pré tratamento ( $p<0,05$, para todas as comparações). Ambas as terapias se mostraram equivalentes sobre o aspecto estatístico apresentando uma redução significativa dos valores médios dos parâmetros após tratamento empregado. 
5.4 Resultados em relação as Emissões Otoacústicas Evocadas por Produto de Distorção (EOAEPD)

Os achados para a amplitude em $2000 \mathrm{~Hz}, 3000 \mathrm{~Hz}, 4000 \mathrm{~Hz}$ e $5000 \mathrm{~Hz}$, no GVO e no GR, podem ser visualizadas na Tabela 5 e Figura 16, a seguir.

Tabela 5. Resultados da amplitude das EOAEPD, em ambos os grupos

\begin{tabular}{|c|c|c|c|c|c|}
\hline \multirow{2}{*}{ Variável } & \multicolumn{2}{|c|}{ Grupo - Média [IC 95\%] } & \multicolumn{3}{|c|}{ Comparações entre Grupos } \\
\hline & $\begin{array}{c}\text { GVO } \\
(n=13)\end{array}$ & $\begin{array}{c}\text { GR } \\
(n=10)\end{array}$ & $\begin{array}{c}\neq \text { GVO X GR } \\
{[\text { IC 95\%] }}\end{array}$ & $\begin{array}{l}\text { F-valor } \\
\text { (df) }\end{array}$ & $\begin{array}{c}\text { p- } \\
\text { valor }\end{array}$ \\
\hline \multicolumn{6}{|l|}{ Amplitude $2000 \mathrm{~Hz}$} \\
\hline Pré & $\begin{array}{r}-10,08[-12,86 ;-- \\
7,29]\end{array}$ & $\begin{array}{r}-12,30[-15,10 ;- \\
9,50]\end{array}$ & & & \\
\hline Pós tratamento & $-1,69[-6,09 ; 2,71]$ & $\begin{array}{r}-3,90[-8,91 ; \\
1,11] \\
\end{array}$ & & & \\
\hline F (Pré -Pós) & $\begin{array}{r}-8,38[-11,84 ;- \\
4,93]^{\dagger}\end{array}$ & $\begin{array}{r}-8,40[-13,66 ;- \\
3.14]^{\dagger}\end{array}$ & & & \\
\hline Pós tratamento (ajustado) & $-2,42[-6,26 ; 1,42]$ & $\begin{array}{r}-2,95[-7,35 ; \\
1,44]\end{array}$ & $-0,54[-6,47 ; 5,40]$ & $\begin{array}{r}0,04(1 \\
20) \\
\end{array}$ & 0,8527 \\
\hline \multicolumn{6}{|l|}{ Amplitude $3000 \mathrm{~Hz}$} \\
\hline Pré & $\begin{array}{r}-9,77[-13,02 ;- \\
6,52]\end{array}$ & $\begin{array}{r}-12,00[-13,91 ;- \\
10,09] \\
\end{array}$ & & & \\
\hline Pós tratamento & $-1,85[-6,05 ; 2,35]$ & $\begin{array}{r}-7,10[-13,87 ;- \\
0,33]\end{array}$ & & & \\
\hline$\neq$ (Pré -Pós) & $\begin{array}{r}-7,92[-11,64 ;- \\
4,21]^{\dagger}\end{array}$ & $\begin{array}{r}-4,90[-10,92 ; \\
1,12]\end{array}$ & & & \\
\hline Pós tratamento (ajustado) & $-2,68[-7,00 ; 1,64]$ & $\begin{array}{r}-6,02[-10,97 ;- \\
1,07]\end{array}$ & $-3,34[-10,01 ; 3,33]$ & $\begin{array}{r}1,09(1 \\
20) \\
\end{array}$ & 0,3091 \\
\hline \multicolumn{6}{|l|}{ Amplitude $4000 \mathrm{~Hz}$} \\
\hline Pré & $\begin{array}{r}-10,92[-14,87 ;- \\
6,97] \\
\end{array}$ & $\begin{array}{r}-11,30[-12,20 ;- \\
10,40]\end{array}$ & & & \\
\hline Pós tratamento & $\begin{array}{r}-5,08[-10,73 \\
0,58] \\
\end{array}$ & $\begin{array}{r}-6,10[-12,88 ; \\
0,68] \\
\end{array}$ & & & \\
\hline F (Pré -Pós) & $-5,85[-9,39 ;-2,31]$ & $\begin{array}{r}-5,20[-11,95 ; \\
1,55]\end{array}$ & & & \\
\hline Pós tratamento (ajustado) & $-5,26[-9,75 ;-0,76]$ & $\begin{array}{r}-5,86[-10,99 ;- \\
0,74]\end{array}$ & $-0,60[-7,42 ; 6,22]$ & $\begin{array}{r}0,03(1 \\
20) \\
\end{array}$ & 0,8554 \\
\hline \multicolumn{6}{|l|}{ Amplitude $5000 \mathrm{~Hz}$} \\
\hline Pré & $\begin{array}{r}-10,69[-14,65 ;- \\
6,73]\end{array}$ & $\begin{array}{r}-12,60[-14,94 ;- \\
10,26]\end{array}$ & & & \\
\hline Pós tratamento & $-2,85[-7,71 ; 2,02]$ & $\begin{array}{r}-4,40[-9,28 \\
0,48] \\
\end{array}$ & & & \\
\hline F (Pré -Pós) & $\begin{array}{r}-7,85[-12,32 ;-- \\
3,37]^{\dagger}\end{array}$ & $\begin{array}{r}-8,20[-12,95 ;- \\
3,44]^{\dagger}\end{array}$ & & & \\
\hline Pós tratamento(ajustado) & $-3,36[-7,40 ; 0,69]$ & $\begin{array}{r}-3,74[-8,36 ; \\
0,89] \\
\end{array}$ & $-0,38[-6,58 ; 5,81]$ & $\begin{array}{r}0,02 \\
(1,20)\end{array}$ & 0,8994 \\
\hline
\end{tabular}

Comparações intra grupos (Pré x Pós tratamento): ${ }^{\mp} p<.05 \mathrm{e}^{\dagger} \mathrm{p}<.01$, foram calculados com o uso do teste $t$ pareado.* $p$-valores para comparação entre grupos foram calculados com uso de ANCOVA com valores do baseline como covariável). \# médias ajustadas pelos valores do basal do modelo ANCOVA

Legendas: = diferença, X versus, GVO-Grupo Via Oral, GR-Grupo Resgate 


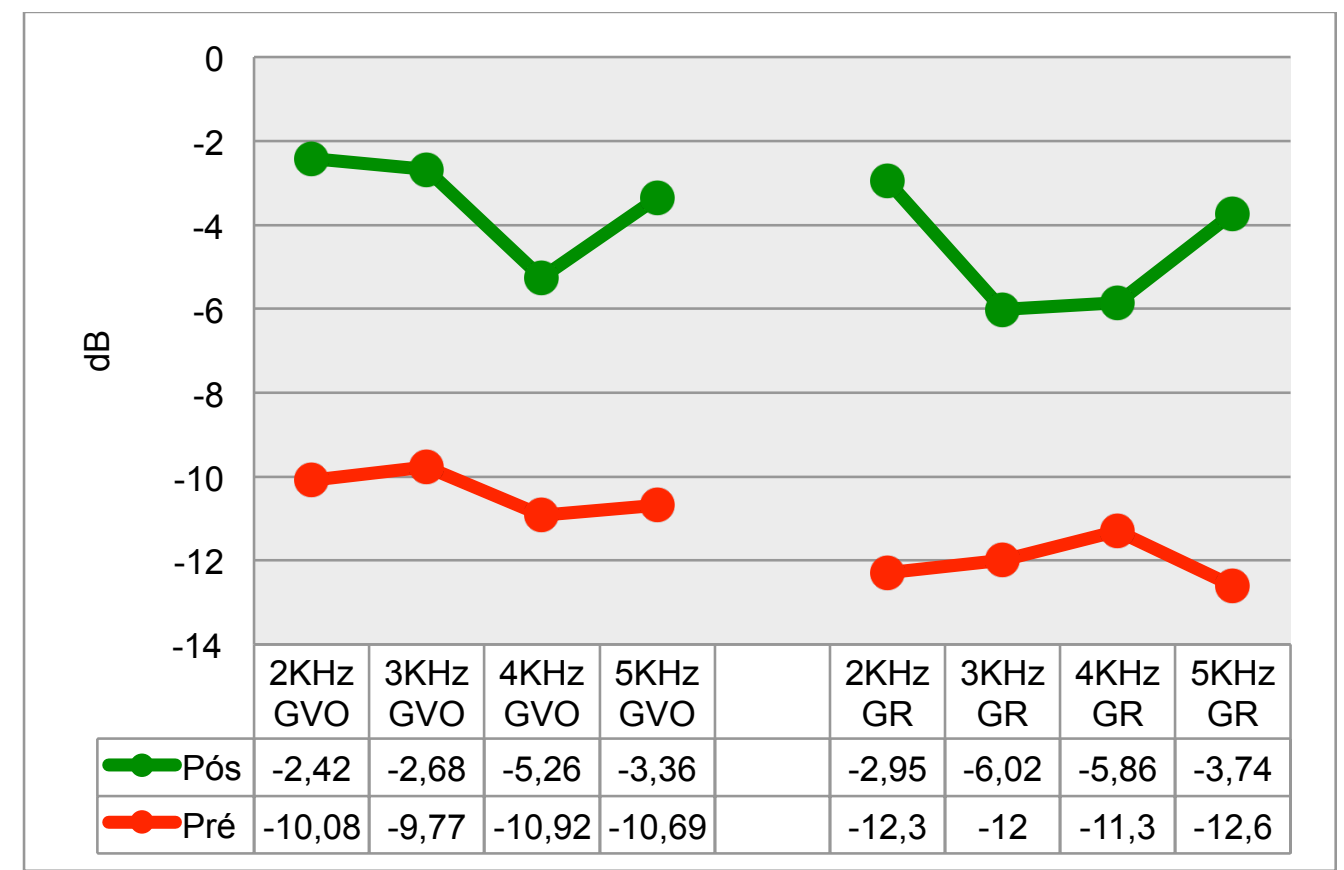

Figura 16. Medidas de amplitude pré e pós tratamento em ambos os grupos

Em ambos os grupos, as EOAEPD eram ausentes no pré tratamento. No pós tratamento, em ambos os grupos, ocorreu melhora com diferença estatisticamente significante para a maioria das bandas de frequência. No GVO em $2000 \mathrm{~Hz}, 3000 \mathrm{~Hz}$, $4000 \mathrm{~Hz}$ e $5000 \mathrm{~Hz}$ e no GR nas frequências de $2000 \mathrm{~Hz}$ e $5000 \mathrm{~Hz}$.

Quanto aos achados para a relação Sinal/Ruído (S/R) em $2000 \mathrm{~Hz}, 3000 \mathrm{~Hz}$, $4000 \mathrm{~Hz}$ e $5000 \mathrm{~Hz}$, no GVO e GR, podem ser visualizados na Tabela 6 e Figura 17, a seguir. 
Tabela 6. Resultados da relação Sinal/Ruído das EOAEPD, em ambos os grupos

\begin{tabular}{|c|c|c|c|c|c|}
\hline \multirow{2}{*}{ Variável } & \multicolumn{2}{|c|}{ Grupo - Média [IC 95\%] } & \multicolumn{3}{|c|}{ Comparações entre Grupos } \\
\hline & $\begin{array}{c}\text { GVO } \\
(n=13)\end{array}$ & $\begin{array}{c}\text { GR } \\
(n=10)\end{array}$ & $\begin{array}{c}{ }_{7} \text { GVO X GR } \\
\text { [IC 95\%] }\end{array}$ & $\begin{array}{c}\text { F- } \\
\text { valor } \\
\text { (df) }\end{array}$ & $\begin{array}{c}\text { p- } \\
\text { valor }\end{array}$ \\
\hline \multicolumn{6}{|l|}{$\begin{array}{l}\text { Relação S/R } \\
2000 \mathrm{~Hz}\end{array}$} \\
\hline Pré & $\begin{array}{r}2,77[0,90 ; \\
4,63]\end{array}$ & $1,30[-1,12 ; 1,88]$ & & & \\
\hline Pós tratamento & $\begin{array}{r}8,38[3,67 ; \\
13,10] \\
\end{array}$ & $7,10[1,98 ; 12,22]$ & & & \\
\hline$\neq$ (Pré-Pós) & $\begin{array}{r}-5,61[- \\
9,96 ;- \\
1,27]^{\ddagger}\end{array}$ & $\begin{array}{r}-7,10[-13,18 ; \\
1,02]^{\dagger}\end{array}$ & & & \\
\hline $\begin{array}{l}\text { Pós tratamento } \\
\text { (ajustado) }\end{array}$ & $\begin{array}{r}8,06[3,38 ; \\
12,73] \\
\end{array}$ & $7,53[2,12 ; 12,93]$ & $-0,53[-8,05 ; 6,99]$ & $\begin{array}{r}0,02 \\
(1,20) \\
\end{array}$ & 0,8849 \\
\hline \multicolumn{6}{|l|}{$\begin{array}{l}\text { Relação S/R } \\
3000 \mathrm{~Hz}\end{array}$} \\
\hline Pré & $\begin{array}{r}2,23[- \\
0,14 ; 4,60]\end{array}$ & $0,50[-0,58 ; 1,58]$ & & & \\
\hline Pós tratamento & $\begin{array}{r}8,69[4,13 ; \\
13,26] \\
\end{array}$ & $7,10[1,98 ; 12,22]$ & & & \\
\hline$\neq$ (Pré -Pós) & $\begin{array}{r}-6,46[- \\
11,18 ;- \\
1,74]^{\ddagger}\end{array}$ & $-5,10[-10,30 ; 0,10]$ & & & \\
\hline $\begin{array}{l}\text { Pós tratamento } \\
\text { (ajustado) }^{\#}\end{array}$ & $\begin{array}{r}8,52[4,17 ; \\
12,86]\end{array}$ & $5,83[0,85 ; 10,81]$ & $-2,69[-9,42 ; 4,05]$ & $\begin{array}{r}0,69 \\
(1,20)\end{array}$ & 0,4150 \\
\hline \multicolumn{6}{|l|}{$\begin{array}{l}\text { Relação S/R } \\
4000 \mathrm{~Hz}\end{array}$} \\
\hline Pré & $\begin{array}{r}1,20[- \\
1,40 ; 3,11] \\
\end{array}$ & $1,00[-0,22 ; 2,22]$ & & & \\
\hline Pós tratamento & $\begin{array}{r}7,85[3,03 ; \\
12,67]\end{array}$ & $4,30[-0,19 ; 8,79]$ & & & \\
\hline$\neq$ (Pré -Pós) & $\begin{array}{r}-7,85\left[^{-}\right. \\
11,61 ;- \\
4,08]^{\dagger}\end{array}$ & $-3,30[-8,69 ; 2,09]$ & & & \\
\hline $\begin{array}{l}\text { Pós tratamento } \\
\text { (ajustado) }\end{array}$ & $\begin{array}{r}8,15[4,16 ; \\
12,15]\end{array}$ & $3,90[-0,66 ; 8,46]$ & $-4,25[-10,34 ; 1,83]$ & $\begin{array}{r}2,13 \\
(1,20) \\
\end{array}$ & 0,1604 \\
\hline \multicolumn{6}{|l|}{$\begin{array}{l}\text { Relação S/R } \\
5000 \mathrm{~Hz}\end{array}$} \\
\hline Pré & $\begin{array}{r}1,23[- \\
1,90 ; 4,36] \\
\end{array}$ & $-0,70[-2,70 ; 1,30]$ & & & \\
\hline Pós tratamento & $\begin{array}{r}8,08[3,46 ; \\
12,70]\end{array}$ & $4,50[1,30 ; 7,70]$ & & & \\
\hline$\neq$ (Pré -Pós) & $\begin{array}{r}-6,85\left[^{-}\right. \\
11,41 ;{ }^{-} \\
2,28]^{\dagger}\end{array}$ & $-5,20[-8,02 ;-2,38]$ & & & \\
\hline $\begin{array}{l}\text { Pós tratamento } \\
\text { (ajustado) }\end{array}$ & $\begin{array}{r}7,59[4,01 ; \\
11,18]\end{array}$ & $5,13[1,02 ; 9,23]$ & $-2,47[-7,99 ; 3,05]$ & $\begin{array}{r}0,87 \\
(1,20) \\
\end{array}$ & 0,3623 \\
\hline
\end{tabular}

Comparações intra grupos (Pré x Pós tratamento): ${ }^{\ddagger} p<.05 \mathrm{e}^{\dagger} \mathrm{p}<.01$, foram calculados com o uso do teste t pareado. ${ }^{*}$-valores para comparação entre grupos foram calculados com uso de ANCOVA com valores do baseline como covariável). \# médias ajustadas pelos valores do basal do modelo ANCOVA

Legendas: $\neq$ diferença, $\mathrm{X}$ versus, GVO-Grupo Via Oral, GR-Grupo Resgate 


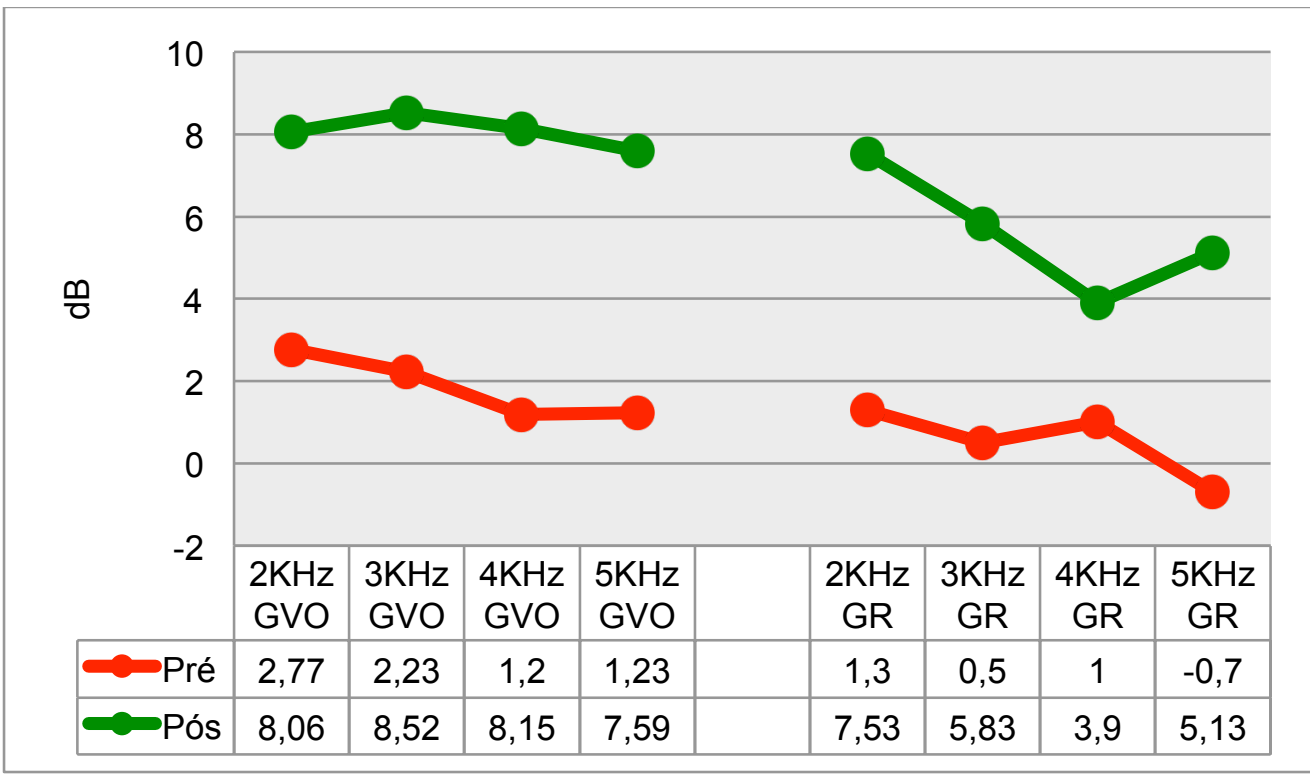

Figura 17. Medidas da relação Sinal/Ruído pré e pós tratamento em ambos os grupos

Em ambos os grupos, as medidas da relação Sinal/Ruído eram menores que $6 \mathrm{~dB}$, no pré tratamento. No pós tratamento, tanto no GVO, quanto no GR, ocorreu melhora estatisticamente significante na maioria das frequências.

No GVO ocorreu melhora nas frequências de $2000 \mathrm{~Hz}, 3000 \mathrm{~Hz}, 4000 \mathrm{~Hz}$ e $5000 \mathrm{~Hz}$ e no GR na frequência de $2000 \mathrm{~Hz}$ e $5000 \mathrm{~Hz}$.

Considerando os dois parâmetros analisados (amplitude e relação sinal/ruído), os 13 sujeitos do GVO não tinham presença de Emissões Otoacústicas Evocadas por Produto de Distorção no pré tratamento e $7(53,84 \%)$ apresentaram presença no pós tratamento.

Já no GR, dos 10 sujeitos que inicialmente não tinham presença de Emissões Otoacústicas por Produto de Distorção, 3 (30\%) passaram a apresentar no pós tratamento, considerando os dois parâmetros analisados. 
Em relação as Emissões Otoacústicas Evocadas por Produto de Distorção (EOAEPD):

a) Análise entre grupos:

Não foi observada diferença significativa nos valores médios de amplitude $(2000 \mathrm{~Hz}, 3000 \mathrm{~Hz}, 4000 \mathrm{~Hz}$ e $5000 \mathrm{~Hz})$, no pós tratamento entre as duas terapias ( $p=0,8527, p=0,3091, p=0,8554$ e $p=0,8994$, respectivamente).

Não foi observada diferença significativa nos valores médios da relação Sinal/Ruído $(2000 \mathrm{~Hz}, 3000 \mathrm{~Hz}, 4000 \mathrm{~Hz}$ e $5000 \mathrm{~Hz})$, no pós tratamento entre as duas terapias ( $p=0,8849, p=0,4150, p=0,1604$ e $p=0,3623$, respectivamente).

b) Análise intra grupos:

Os valores médios de amplitude apresentaram uma redução significativa, no GVO, no pós tratamento em relação ao pré ( $p<0,01$, para todas as comparações).

Os valores médios da relação Sinal/Ruído (S/R) apresentaram uma redução significativa, no GVO, no pós tratamento em relação ao pré ( $p<0,05$, para todas as comparações).

Os valores médios de amplitude no GR, apresentaram uma redução significativa, no pós tratamento em relação ao pré $(p<0,01$, para $2000 \mathrm{~Hz}$ e $5000 \mathrm{~Hz})$.

Os valores médios de relação Sinal/Ruído apresentaram uma redução significativa, no GR, no pós tratamento em relação ao pré $(p<0,01$, para $2000 \mathrm{~Hz}$ e $5000 \mathrm{~Hz})$.

Ambas as terapias se mostraram equivalentes sobre o aspecto estatístico apresentando uma redução significativa dos valores médios dos parâmetros após tratamento empregado, para maioria das comparações. 


\section{DISCUSSÃo}

No presente estudo, foi possível comparar o incômodo e a gravidade do zumbido subjetivo agudo pré e pós tratamento por meio do Tinnitus Handicap Inventory (THI) e da Escala Analógico-Visual (EAV), bem como comparar a média tetratonal obtida na Audiometria Tonal Limiar (ATL) e a amplitude e relação Sinal/Ruído (S/R) das Emissões Otoacústicas Evocadas por Produto de Distorção (EOAEPD). Ressalta-se que os instrumentos utilizados para caracterizar o zumbido subjetivo agudo no presente estudo são instrumentos amplamente utilizados em estudos que avaliaram o zumbido subjetivo $(9,19,28,29,31-35,38,39,42,44,49$, $50,57)$.

Na Escala Analógico-Visual (EAV) de incômodo, o Grupo Via Oral $(n=13)$, obteve uma média de 7,69 pontos no pré tratamento (zumbido com incômodo moderado) e na aplicação após três meses do tratamento, o resultado obtido foi de 5,30 pontos (zumbido com incômodo moderado). Ficou evidenciada a diminuição de dois pontos (44), no entanto, não ocorreu mudança na classificação $(4,28)$. Ainda assim, a percepção em relação ao incômodo com o zumbido, melhorou significativamente (Tabela 2).

Já em relação ao Grupo Resgate $(n=10)$, que foi submetido a uma segunda opção terapêutica, devido à falha no tratamento inicial, os valores médios obtidos inicialmente foram 8,30 pontos (zumbido com incômodo severo), e no pós tratamento foi obtida a média de 5,81 pontos (zumbido com incômodo moderado). Ao contrário do resultado do Grupo Via Oral, no Grupo Resgate, ocorreu além da diminuição de dois pontos, a mudança na classificação do incômodo em relação ao zumbido (incômodo severo para incômodo moderado).

Ficou demonstrado que a EAV, ainda que seja um método simples e de fácil aplicação $(28,44)$, se mostrou eficaz e confiável para demonstrar a percepção em relação ao incômodo causado pelo zumbido no pré e pós tratamento. Cabe ressaltar que a EAV pode ser influenciada por aspectos culturais, intelectuais e psicológicos, assim como o THI que é um método mais completo de avaliação, especialmente no que tange aos aspectos psicológicos e cotidianos do zumbido (36).

Desta forma, os dois métodos sendo utilizados conjuntamente, propiciam resultados mais confiáveis $(29,33)$. 
Em relação ao THI, ainda que de forma mais complexa, é possível de ser aplicado na prática clínica diária, permitindo uma abordagem de vários aspectos do zumbido na qualidade de vida do paciente, tendo também validade e confiabilidade, possibilitando avaliar as reações funcionais ao zumbido como dificuldade de concentração e tendências anti-sociais; reações emocionais ao zumbido, como raiva, frustração, irritabilidade e depressão e finalmente, reações catastróficas ao zumbido como desespero, sensação de "doença grave" e perda de controle (34).

Os achados do presente estudo permitiram demonstrar que o THI foi sensível em demonstrar melhora do zumbido em relação às três escalas (reações) avaliadas, quais sejam: funcional, emocional e catastrófica, assim como em relação a pontuação total, onde foi constatada diferença estatisticamente significante ao comparar o pré e pós tratamento (Tabela 3).

No presente estudo, o Grupo Via Oral $(n=13)$ apresentou uma pontuação total inicial de 64,77 pontos, sendo classificado como zumbido severo. Após 3 meses, o instrumento foi novamente aplicado e a pontuação total foi 45,90 pontos, sendo classificado como zumbido moderado. Constata-se que este instrumento foi mais sensível do que a EAV para este grupo.

O mesmo ocorreu no Grupo Resgate $(n=10)$ em que a pontuação total no pré tratamento foi 72,20 pontos (zumbido severo) e no pós tratamento foi 47,73 pontos (zumbido moderado). Desta forma, foi possível constatar diferença significativa da pontuação total no pré e pós tratamento. O mesmo ocorreu ao serem analisadas cada escala (reação) separadamente.

Importante ressaltar que, ainda que tenha ocorrido diminuição da pontuação total, bem como de cada escala avaliada separadamente, configurando portanto, mudança na classificação de zumbido severo para zumbido moderado, em ambos os grupos, o zumbido continuou presente o que pode ser explicado pelo fato destes sujeitos, em sua maioria, permanecerem com um determinado grau de perda auditiva, mesmo após o tratamento. Tal constatação reforça o descrito por Fukuda (1998) que evidencia que o zumbido possui um impacto relevante na qualidade de vida e no equilíbrio emocional dos sujeitos acometidos por tal sintoma (26), principalmente se não ocorre remissão total deste sintoma.

Tendo em vista os resultados obtidos, ressaltamos a importância da aplicação conjunta de ambos os instrumentos de avaliação do zumbido, pois os mesmos se complementam e possibilitam verificar o incômodo e a gravidade do zumbido, além 
de quantificar e qualificar as reações diante do sintoma, inclusive hipotetizando a respeito da influência do zumbido nos aspectos emocionais destes sujeitos, o que requer, uma abordagem multidisciplinar (90).

Wang et al. (2014), assim como no presente estudo, aplicaram ambos os instrumentos e verificaram que os escores do THI e da EAV foram reduzidos significativamente após injeção de corticoide intratimpânico no tratamento do zumbido agudo. No entanto, cabe ressaltar que seus pacientes apresentavam diversos tipos de patologias otológicas e, dentre elas, a perda auditiva neurossensorial súbita (19).

No presente estudo, em que os 23 pacientes apresentavam perda auditiva neurossensorial súbita idiopática, verificamos que ambas as terapias foram igualmente eficazes em reduzir o incômodo e a gravidade do zumbido, tendo havido diferença estatisticamente significativa ao comparar o pré e pós tratamento (Tabelas 2 e 3$)$.

Em relação ao zumbido, conforme An et al. (2014), ocorreu remissão deste sintoma em $37,7 \%$ dos pacientes no prazo de 3 meses, tendo sido significativamente maior nos pacientes com sintomas que duraram 2 semanas ou menos, sendo possível concluir que a duração dos sintomas afetou a taxa de recuperação para o zumbido subjetivo agudo (50).

Nossos achados se assemelham aos descritos acima, provavelmente devido ao curto espaço de tempo decorrido entre o início do sintoma e o início do tratamento, ou seja, ambos os tratamentos foram realizados o mais precocemente possível.

Também foi possível verificar, no presente estudo, diferença estatisticamente significativa ao comparar os achados na Audiometria Tonal Limiar (ATL) e nos achados eletroacústicos (EOAEPD) no pré e pós tratamento.

Em relação aos achados audiológicos, o presente estudo demonstrou que a melhora auditiva ocorreu simultaneamente a melhora em relação ao zumbido, concordantes com Wang et al. (2014).

A Audiometria Tonal Limiar foi um dos métodos de avaliação auditiva escolhidos no presente estudo por ser um método amplamente utilizado tanto para o diagnóstico diferencial quanto para o monitoramento auditivo em pacientes submetidos a tratamento medicamentoso $(13-15,17,20,53,57,76)$. No presente estudo, optou-se por comparar a média tetratonal $(13,14,17,19)$, diferindo de 
outros estudos $(61,74)$ que utilizaram a média tritonal e consideraram como melhora auditiva o ganho de $20 \mathrm{~dB}$ em pacientes tratados adicionalmente com aplicação de corticoide intratimpânico (44).

Optou-se por comparar a média tetratonal para a análise do ganho obtido em decibeis na Audiometria Tonal Limiar devido ao fato de que maioria dos sujeitos $(n=20)$ apresentou perda auditiva em todas as frequências testadas $(250 \mathrm{~Hz}$ a $8000 \mathrm{~Hz}$ ) seguida de perda auditiva nas frequências agudas. Acredita-se que a média tetratonal expressou de forma mais fidedigna o impacto da perda auditiva nestes sujeitos.

Optou-se ainda por considerar a recuperação auditiva baseada na proposta de Nematti et al. (2011) que considera como melhora absoluta ou completa quando ocorre melhora de $30 \mathrm{~dB}$ na média tetratonal, tendo em vista o conceito de perda auditiva neurossensorial súbita ser definida como uma perda auditiva súbita de pelo menos $30 \mathrm{~dB}$ em três frequências consecutivas e por considerar ser um método mais criterioso para determinar a melhora auditiva. Assim, baseado na média tetratonal, verificou-se recuperação auditiva (melhora parcial ou melhora completa) em 61,54\% dos sujeitos submetidos ao tratamento com corticoide por via oral e $50 \%$ dos sujeitos após a aplicação adicional de corticoide intratimpânico.

No presente estudo, verificou-se diferença estatisticamente significativa intra grupo, porém não entre os grupos. Ressalta-se o fato de que foi considerado como recuperação auditiva completa uma melhora de $30 \mathrm{~dB}$, sendo um critério mais exigente do que estudos anteriormente publicados $(15,20,53,76)$.

Em outro estudo, o ganho médio na média tetratonal do grupo tratado com corticoide sistêmico foi de $15 \mathrm{~dB}$ e no grupo resgate de $11 \mathrm{~dB}$, demonstrando que não houve melhora significativa em comparação com os pacientes tratados com a terapia padrão (71), enquanto em outro estudo foi encontrada diferença estatisticamente significativa com a aplicação adicional de corticoide intratimpânico (72).

Diversos autores encontraram melhores resultados auditivos no grupo que realizou a terapia combinada em comparação com aqueles tratados somente com corticoide por via oral $(73,75,79)$. No entanto, nestes estudos, o sucesso do tratamento foi considerado quando ocorria recuperação de $10 \mathrm{~dB}$ na média tritonal, diferindo do presente estudo em que, como referido anteriormente, foi considerado como recuperação completa, uma melhora de $30 \mathrm{~dB}$ na média tetratonal e como 
recuperação parcial, uma melhora entre $10 \mathrm{~dB}$ e $30 \mathrm{~dB}$.

Alguns estudos encontraram resultados positivos da aplicação de corticoide intratimpânico para o zumbido subjetivo crônico $(46,47)$ enquanto outros autores não encontraram diferença estatisticamente significante para o zumbido crônico (44), o que difere dos achados do presente estudo, em que foi demonstrada recuperação auditiva e do zumbido tanto no GVO quanto no GR, possivelmente por tratar-se de zumbido agudo.

Em consonância com os achados do presente estudo, Cesarini et al. (2002) e Yoshida et al. (2012) referiram que os melhores resultados com o tratamento intratimpânico para o zumbido foram obtidos quando o tratamento foi iniciado no prazo de até 3 meses do início do sintoma. Desta forma, quanto mais curto for o período entre o início da perda auditiva neurossensorial súbita e o início do tratamento com corticoide intratimpânico, maior a possibilidade de melhora em relação ao incômodo e a gravidade do zumbido.

Em acréscimo, autores descreveram que $32,5 \%$ dos sujeitos submetidos à aplicação de corticoide intratimpânico apresentaram recuperação auditiva completa e 67,5\% apresentaram recuperação parcial (40). Achados semelhantes em relação à recuperação parcial $(60,77 \%)$ foram obtidos no presente estudo. Entretanto, verificou-se uma taxa de recuperação auditiva completa melhor (50,77\%). Cabe ressaltar que o método terapêutico utilizado no estudo descrito anteriormente, foi substancialmente diferente do presente estudo, tendo sido realizada corticoterapia intravenosa associada à pentoxifilina.

Stachler et al. (2012) e Choi et al. (2013) recomendaram que o tempo de seguimento (follow-up) na perda auditiva neurossensorial súbita seja de pelo menos três meses $(15,21)$, o que está de acordo com o presente estudo. Ao realizar seguimento por seis meses, não foram observadas mudanças auditivas significativas ao comparar o terceiro mês e o sexto mês de acompanhamento (21).

Diversos autores recomendaram a terapia intratimpânica como adjuvante na perda auditiva neurossensorial súbita e uma opção possível no tratamento do zumbido para um determinado grupo de pacientes $(21,44,94)$. Os achados do presente estudo permitem que concordemos com os respectivos autores.

Ressalta-se o fato de que ainda que se tenham grupos o mais homogêneo possível no presente estudo, verifica-se que pequenas diferenças entre os sujeitos podem interferir no sucesso do tratamento escolhido, como por exemplo, o aspecto 
emocional, evidenciado principalmente nos métodos subjetivos de avaliação do incômodo e da gravidade do zumbido.

As diferenças individuais nas características clínicas entre os pacientes com zumbido e/ou perda auditiva neurossensorial súbita, impedem uma abordagem única no que diz respeito principalmente, a uma única linha de tratamento $(3,7,8,11,12$, 22, 23, 25-27, 37, 41, 43, 48, 51, 52, 54, 56, 59, 60, 62, 67-69, 78, 80-87, 91-93, 95).

Ressalta-se que no presente estudo, ambos os grupos analisados não apresentaram diferença significativa em relação a faixa etária, o gênero e a orelha acometida. Verificou-se que a orelha esquerda foi sutilmente mais acometida no grupo que foi submetido ao tratamento de resgate, bem como este grupo teve uma média de idade em termos absolutos, ligeiramente maior.

Ao examinar variáveis como gênero, idade e lateralidade em relação à recuperação após o início da perda auditiva neurossensorial súbita, verifica-se que os resultados obtidos no presente estudo são semelhantes aos de Raymundo et al. (2010) no qual os sujeitos submetidos à terapia de resgate foram aqueles em que a terapia por via oral foi insuficiente na obtenção de melhora auditiva, principalmente nos sujeitos com idade mais avançada.

Michiba et al. (2013) avaliaram sujeitos com PANSS que obtiveram melhora auditiva, mas permaneceram com zumbido residual. Verifica-se que, conforme os resultados obtidos neste estudo, audição e zumbido melhoraram simultaneamente. Ressalta-se que os dados subjetivos (EAV, THI e ATL) apresentaram melhores resultados em comparação com os achados eletroacústicos, o que pode ser explicado principalmente pelos aspectos emocionais envolvidos nestes métodos de avaliação, ainda que a ATL tenha objetividade em resultados numéricos absolutos.

Em relação à escolha da metilprednisolona, esta apresentou melhor atividade em orelha interna (70). A eficácia da injecção intratimpânica de dexametasona para o zumbido subjetivo foi de $37,5 \%$ (48) e da prednisolona, de 48,6\% (13).

Neste estudo, optou-se pela corticoterapia intratimpânica com metilprednisolona como terapia de resgate após falha do corticoide por via oral e encontramos dados que mostraram que esta associação foi particularmente eficaz em relação ao zumbido.

Rah et al. (2014) ressaltam que é significativa a correlação entre o grau de recuperação auditiva e a melhora subjetiva do zumbido após o tratamento (20). Nossos resultados permitem que concordemos com os respectivos autores. 
Em relação à avaliação objetiva da audição, o teste de emissões otoacústicas evocadas trata-se de método objetivo, rápido e indolor que não sofre influência dos aspectos emocionais geralmente associados à presença do zumbido, sendo um complemento valioso no follow-up auditivo (18, 96, 98, 99, 104-106). Tendo em vista sua objetividade, foi realizado nos sujeitos do presente estudo.

No Grupo Via Oral, nenhum sujeito apresentou presença de EOAEPD no pré tratamento. No pós tratamento, 53,84\% $(n=7)$ apresentaram presença de EOAEPD, considerando-se os dois parâmetros analisados. No GR, 30\% (n=3) apresentou presença de EOAEPD no pós tratamento.

Em 2008, Ishida et al. haviam descrito que em alguns pacientes o aparecimento das EOAs ocorreram simultaneamente com a melhora dos limiares auditivos e em outros pacientes, as EOAs apareceram mais tarde do que a melhora auditiva (16). No Grupo Via Oral, ocorreu diferença estatisticamente significativa no pré e pós tratamento, nos dois parâmetros analisados, em todas as frequências e no Grupo Resgate ocorreu melhora tanto na amplitude, quanto na relação sinal/ruído, tendo sido estatisticamente significativa nas frequências de $2000 \mathrm{~Hz}$ e $5000 \mathrm{~Hz}$ (Tabelas 5 e 6 ).

Há estudos que demonstraram um papel prognóstico das emissões otoacústicas na perda auditiva neurossensorial súbita $(16,100)$ e outros discordantes (101, 103). Schweinfurth et al. (1997) utilizaram as EOAEPD em pacientes com perda auditiva neurossensorial súbita e relataram que as EOAEPD haviam sido detectadas em três dos cinco pacientes cuja audição melhorou significativamente e sugeriram que a presença de EOAEPD poderiam ser um fator de prognóstico útil que se correlacionou positivamente com a recuperação da PANSS (100). Foi relatado um aumento significativo na amplitude das EOAEPD entre os pacientes que recuperaram a audição (102). Nossos achados foram concordantes com o estudo descrito.

A detecção das emissões otoacústicas durante os primeiros quinze dias após o início do tratamento, mesmo sem melhora da audição, pode sugerir que haveria uma melhor detecção das emissões otoacústicas três meses após, devido à alta sensibilidade do teste para detectar mudanças na atividade das células ciliadas externas (106).

Em relação aos fatores da perda auditiva neurossensorial súbita que podem predizer um prognóstico favorável, estes ainda são controversos na literatura (10, 
$45,58,71,88,89)$. Apenas dois fatores foram significativamente associados com a melhora da audição: presença do zumbido e a configuração da curva audiométrica ascendente $(88,89)$.

No presente estudo, foram avaliados pacientes com perda auditiva neurossensorial súbita idiopática e zumbido necessariamente agudo e foi possível demonstrar que os corticoides foram igualmente eficazes para estes pacientes. Provavelmente, o curto espaço de tempo entre o início do tratamento foi o fator determinante para prever efetividade da terapia com corticoide.

O presente estudo apresenta algumas limitações que devem ser consideradas: ausência de um grupo controle, pois isso provavelmente não seria correto do ponto de vista ético, pois este grupo teria que ser composto por pacientes que falharam na terapia por via oral e não seriam tratados com corticoide intratimpânico de resgate. Além disso, seria provável que estes pacientes não apresentassem melhora sem receber um tratamento de resgate após ter falhado na terapia com corticoide por via oral. Outro ponto a ser considerado é que o número de pacientes em estudos de perda auditiva neurossensorial súbita geralmente é reduzido. Ressalta-se ainda que estudos preliminares tiveram um número de pacientes similar ao do presente estudo.

Assim, para que os resultados obtidos no presente estudo possam se confirmar e serem generalizados, sugere-se a realização de estudos multicêntricos, tornando possível ampliar o número de sujeitos.

Finalmente, diante dos achados do presente estudo, questiona-se: por que os corticoides seriam mais eficazes no tratamento do zumbido agudo e não para tratar o zumbido crônico? Acredita-se que o início do zumbido ocorra quase sempre na cóclea e posteriormente, a lesão da cóclea provoca alterações nas vias auditivas centrais, fazendo com que em alguns pacientes este sintoma seja permanente e extremamente irritante, até mesmo incapacitante.

Ambos, corticoide por via oral e corticoide intratimpânico foram igualmente eficazes em nosso estudo. A aplicação de corticoide intratimpânico melhorou o zumbido ainda mais em pacientes que não responderam bem ao tratamento com corticoide por via oral. Provavelmente, a maior concentração de corticoide em fluidos da orelha interna após a injeção intratimpânica explica este resultado (64-66). 


\section{CONCLUSÃO}

O incômodo e a gravidade do zumbido subjetivo agudo associado à perda auditiva neurossensorial súbita idiopática após o tratamento com corticoide diminuiu em ambos os grupos avaliados, de forma estatisticamente significante.

A média tetratonal na Audiometria Tonal Limiar após o tratamento apresentou melhora em 61,54\% no Grupo Via Oral e 50\% no Grupo Resgate.

A análise das Emissões Otoacústicas Evocadas por Produto de Distorção apontou que, após o tratamento, 53,84\% dos sujeitos apresentaram presença de EOAEPD no Grupo Via Oral e 30\% no Grupo Resgate. 


\section{REFERÊNCIAS BIBLIOGRÁFICAS}

1. Jastreboff PJ. Phanton auditory perception (tinnitus): mechanisms of generation and perception. Neurosci Res. 1990;8(4):221-54.

2. Jastreboff PJ, Hanzell WP. A neurophysiological approach to tinnitus: clinical implications. Br J Audiol. 1993;27(1):7-17.

3. Sanchez TG, Bento RF, Minitti A, Câmara J. Zumbido: características e epidemiologia. Experiência do Hospital das Clínicas da Faculdade de Medicina da Universidade de São Paulo. Braz J Otorhinolaryngol. 1997;63(3):229-35.

4. Sanchez TG, Pedalini MEB, Bento RF. Aplicação da Terapia de Retreinamento do Zumbido (TRT) em hospital público. Arch Otolaryngol. 2002;6(1):29-38.

5. Bauer CA. Mechanisms of tinnitus generation. Curr Opin Otolaryngol Head Neck Surg. 2004;12(5):413-7.

6. Attias J, Urbach D, Gold S, Shemesh Z. Auditory event related potentials in chronic tinnitus patients with noise induced hearing loss. Hear Res. 1993;71(12):106-13.

7. Holdefer L, Oliveira CACP, Venosa AR. Sucesso no tratamento do zumbido com terapia em grupo. Braz J Otorhinolaryngol. 2010;76(1):102-6.

8. Ferrari GMS, Sanchez TG. O que é zumbido? In: Samelli AG. Zumbido: avaliação, diagnóstico e reabilitação. São Paulo: Lovise; 2004. p.17-22.

9. Dias A, Cordeiro R, Corrente JE. O incômodo causado pelo zumbido medido pelo Questionário de Gravidade do Zumbido. Rev Saúde Pública. 2006;40(4):706-11.

10. Maia RA, Cahali S. Surdez Súbita. Braz J Otorhinolaryngol. 2004;70(2):238-48. 
11. Penido NO, Ramos HVL, Barros FA, Cruz OLM, et al. Fatores clínicos, etiológicos e evolutivos da audição na surdez súbita. Braz J Otorhinolaryngol. 2005;71(5):633-8.

12. Rauch SD. Idiopathic Sudden Sensorineural Hearing Loss. N Engl J Med. 2008;359(8):833-40

13. Rauch SD, Halpin CF, Antonielle PJ, Babu S, et al. Oral vs intratympanic corticosteroid therapy for idiopathic sudden sensorineural hearing loss. JAMA. 2011;305(20):2071-9.

14. Halpin CF, Shi H, Reda D, Antonelli PJ, et al. Audiology in the sudden hearing loss: Clinical Trial. Otol Neurotol. 2012;33(6):907-11.

15. Stachler RJ, Chandrasekhar SS, Archer SM, Rosenfeld RM, et al. Clinical practice guideline: sudden hearing loss. Otolaryngol Head Neck Surg. 2012;146 (Suppl 3):S1-35.

16. Ishida IM, Sugiura M, Teranishi M, Katayama N, et al. Otoacoustics emissions, ear fullness and tinnitus in the recovery course of sudden deafness. Auris Nasus Larinx. 2008;35:41-6.

17. Nemati S, Naghavi SE, Kazemnejad E, Banan R. Otoacoustic Emissions in Sudden Sensorineural Hearing Loss: Changes of Measures with Treatment. Iranian J Otorhinolaringol. 2011;23(1):37-44.

18. Nodarse EM. Empleo de las emisiones otoacusticas para el pesquisaje del deficit auditivo. Rev Habanera Cienc Méd. 2006;5(1).

19. Wang P, Qiu Z, Chen L, Gan X, et al. Tinnitus assessment by THI and VAS in patients with sudden sensorineural hearing loss. Lin Chung Er Bi Yan Hou Tou Jing Wai Ke Za Zhi. 2014;28(22):1777-9. 
20. Rah YC, Park KT, Yi YJ, Seok J, et al. Successful treatment of sudden sensorineural hearing loss assures improvement of accompanying tinnitus. Laryngoscope. 2014; 125:1433-7.

21. Choi SJ, Lee JB, Lim HJ, In SM, et al. Intratympanic dexamethasone injection for refractory tinnitus: prospective placebo-controlled study. Laryngoscope. 2013;123(11):2817-22.

22. Heyning PV, Muehlmeir G, Cox T, Lisowska G, et al. Efficacy and safety of AM101 in the treatment of acute inner ear tinnitus a double-blind, randomized, placebocontrolled phase II study. Otol Neurotol. 2014;35:589-97.

23. Muehlmeir G, Biesinger $E$, Maier $H$. Safety of intratympanic injection of AM-101 in patients with acute inner ear tinnitus. Audiol Neurotol. 2011;16:388-97.

24. Tzaneva L, Sarov A, Damianova V. Audiological problems in patients with tinnitus exposed to noise and vibrations. Central European Journal of Public Health, 2002; 8(4): 233-5.

25. Shulman A. Introduction: Classification and Definition of Tinnitus. In: Kitahara, M. Tinnitus: Pathophysyiology and Management. IGAKU-SHOIN, Tokyo, p.1-6, 1988.

26. Fukuda Y. Zumbido e suas correlações otoneurológicas. In: Ganança MM. Vertigem tem cura? $1^{\text {a }}$ ed. São Paulo:1998, vol.1, p.171-6.

27. Azevedo AA, Figueiredo RR. Atualização em zumbido. Braz J Otorhinolaringol. $2004 ; 70(1): 27-40$.

28. Oiticica J, Bittar RSM. Tinnitus prevalence in the city of São Paulo. Braz J Otorhinolaryngol. 2015;81(2):167-76.

29. Figueiredo RR, Azevedo AA, Oliveira PM. Análise da correlação entre a escala visual-análoga e o Tinnitus Handicap Inventory na avaliação de pacientes com zumbido. Braz J Otorhinolaryngol. 2009;75(1):76-9. 
30. Kaltenbach JA, Afman CE. Hyperactivity in the dorsal cochlear nucleus after intense sound exposure and its resemblance to tone-evoked activity: a physiological model for tinnitus. Hear Res. 2000;140(1-2):165-72.

31. Sakata E, Itoh A, Itoh Y. Treatment of cochlear-tinnitus with dexamethasone infusion into the tympanic cavity. Int. Tinnitus J. 1996; 2:129-35.

32. Valente JPP, Pinheiro LAM, Carvalho GM, Guimarães AC, et al. Evaluation of factors related to the tinnitus disturbance. Int Tinnitus J. 2012;17(1):21-5.

33. Azevedo AA, Mello PO, Siqueira AG, Figueiredo RR. Análise crítica dos métodos de mensuração do zumbido. 2007;73(3):418-23.

34. Newman CW, Jacobson GP, Spitzer JB. Development of the Tinnitus Handicap Inventory. Arch Otolaryngol Head Neck Surg. 1996;122(2):143-8.

35. McCombe A, Baguley D, Coles R, McKenna L, et al. Guidelines for the grading of tinnitus severity: the results of a working group commissioned by the British Association of Otolaryngologists, Head and Neck Surgeons. Clin Otolaryngol Allied Sci. 2001;26:388-93.

36. Ferreira PEA, Cunha F, Onishi ET, Branco-Barreiro FCA, et al. Tinnitus handicap inventory: adaptação cultural para o Português Brasileiro. Pró-Fono Rev Atual Cient. 2005;17(3):303-10.

37. McNeill C, Távora-Vieira D, Alnafjan F, Searchfield GD, et al. Tinnitus pitch, masking, and the effectiveness of hearing aids for tinnitus therapy. Int $\mathrm{J}$ Audiol. 2012;51(12):914-9.

38. Ramos A, Polo R, Masgoret E, Artiles O, et al. Cochlear implant in patients with sudden unilateral sensorineural hearing loss and associated tinnitus. Acta Otorrinolaringol Esp. 2012;63(1):15-20. 
39. Macías AR, González JCF, Manrique M, Morera C, et al. Cochlear Implants as a Treatment Option for Unilateral Hearing Loss, Severe Tinnitus and Hyperacusis. Audiol Neurotol. 2015;20(suppl 1):60-6.

40. Artal R, Hernandéz R, Royo J, Vallés H. Sordera Súbita: Estudo retrospectivo sobre 40 casos ingressados em nuestro hospital. Rev. Otorrinolaringol. Cir. Cabeza Cuello. 2012; 72;39-48.

41. Meyer T. Intratympanic treatment for tinnitus: A review. Noise Health. 2013; 15(63):83-90.

42. Suckfuell M, Lisowska G, Domka W, Kabacinska A, et al. Efficacy and safety of AM-111 in the treatment of acute sensorineural hearing loss: a double-blind, randomized, placebo-controlled phase II study. Otol Neurotol. 2014;35(8):1317-26.

43. Folmer RL, Theodoroff SM, Casiana L, Shi Y, et al. Repetitive Transcranial Magnetic Stimulation Treatment for Chronic Tinnitus: A Randomized Clinical Trial. JAMA Otolaryngol Head Neck Surg. 2015; 141(8):716-22.

44. Araujo MFS, Oliveira CA, Bahmad Jr F. Intratympanic dexamethasone injections as a treatment for severe, disabling tinnitus. Does it work? Head Neck Surg. 2005; 131:113-7.

45. Sakata T, Esaki Y, Yamano T, Sueta N, Nakagawa T. A comparison between the feeling of ear fullness and tinnitus in acute sensorineural hearing loss. Int. J Audiol. 2008; 47(3):134-40.

46. Shulman A, Goldstein B. Intratympanic drug therapy with steroids for tinnitus control. Int Tinnitus J. 2000;6:10-20.

47. Cesarani A, Capobianco S, Soi D, Giuliano DA, et al. Intratympanic dexamethasone treatment for control of subjective idiophatic tinnitus: our clinical experience. Int Tinnitus J. 2002;8:111-3. 
48. She W, Dai $Y, D u ~ X$, Chen F, et al. Treatment of subjective tinnitus: a comparative clinical study of intratympanic steroid injection vs. oral carbamazepine. Med Sci Monit. 2009;15:35-9.

49. Yoshida T, Teranishi M, Iwata $T$, Otake $H$, et al. Intratympanic injection of dexamethasone for treatment of tinnitus in patients with sudden sensorineural hearing loss. Audiol Research. 2012; 2(1):4-7.

50. An YH, Kyu KK, Kwak MY, Yoon SW, et al. Prognostic factors for the outcomes of intratympanic dexamethasone in the treatment of acute subjective tinnitus. Otol Neurotol. 2014; 35:1330-7.

51. Banerjee A, Parnes LS. Intratympanic corticosteroids for sudden idiopathic sensorineural hearing loss. Otol Neurotol. 2005;26:878-81.

52. Merchant SN, Adams JC, Nadol JB Jr. Pathology and pathophysiology of idiopathic sudden sensorineural hearing loss. Otol Neurotol. 2005;26:151-60.

53. Raymundo IT; Bahmad Jr F; Filho JB; Pinheiro TGN, et al. Metilprednisolona intratimpânica como terapia de resgate na surdez neurossensorial súbita. Braz J Otorhinolaryngol. 2010;76(4):499-509.

54. Bittar RSM, Zeratti FE, Domingues EC, Ramalho JRO, et al. Surdez súbita: Experiência terapêutica de dez anos. Arch Int Otorrinolaringol. 2007;11(3):300-4.

55. Velasquez JCI, Ramirez JA, Navarro U. Corticoides Intratimpanicos en la hipoacusia neurosensorial súbita idiopática. Rev Otorrinolaringol Cir Cabeza Cuello. 2007; 35(3):93-8.

56. Nascentes SM, Paulo EAOH, Andrade EC, Silva AL, et al. Surdez súbita unilateral como manifestação de schwannoma vestibular: relato de caso. Braz J Otorhinolaryngol. 2007;73(5):713-6. 
57. Piñones JS, Villarreal I, Chillerón RG, Trinidad RRC et al. Intratympanic methylprednisolone for sudden sensorineural hearing loss: comprehensive re examination of the model. J Otolaryngol ENT Res. 2015;3(2):00060.

58. Lazarini PR, Camargo ACK. Surdez súbita idiopática: aspectos etiológicos e fisiopatogênicos. Braz J Otorhinolaryngol. 2006;72(4):554-61.

59. Cho CS, Choi YJ. Prognostic factors in sudden sensorineural hearing loss: a retrospective study using interaction effects. Braz $\mathrm{J}$ Otorhinolaryngol. 2013;79(4):466-70.

60. Bogaz EA, Maranhão ASA, Inoue DP, Suzuki FAB, et al. Variables with prognostic value in the onset of idiopathic sudden sensorineural hearing loss. Braz J Otorhinolaringol. 2015;81(5):520-6.

61. Dispenza F, De Stefano A, Constantino C, Marchese D, et al. Sudden sensorineural hearing loss: results of intratympanic steroids as salvage treatment. Am J Otolaryngol. 2013; 34(4):296-300.

62. Wilson WR, Byl FM, Laird N. The efficacy of steroids in the treatment of idiopathic sudden hearing loss: a double blind clinical study. Arch Otolaryngol. 1980;106:772-6.

63. Schuknecht HF. Ablation therapy for the relief of Meniere's disease. Laryngoscope. 1956;66:859-70.

64. Chandrasekhar SS, Rubinstein RY, Kwartler JA, Gatz M, et al. Dexamethasone pharmacokinetics in the inner ear: comparison of route of administration and use of facilitating agents. Otolaryngol Head Neck Surg. 2000;122:521-8.

65. Bachman G, Su J, Zumegen C, Wittekindt C, et al. Permeability of the round window membrane for prednisolone-21-hydrogen succinate. Prednisolone content of the perilymph after local administration vs. systemic injection. HNO. 2001;49:538-42. 
66. Slattery WH, Fisher LM, Iqbal Z, Friedman RA, et al. Intratympanic steroid for the treatment of sudden hearing loss. Otolaryngol Head Neck Surg. 2005;133:251-9.

67. Silverstein H, Choo D, Rosenberg SI, Kuhn J, et al. Intratympanic steroid treatment of inner ear disease and tinnitus (preliminary report). Ear Nose Throat J. 1996;75:468-71.

68. Gianoli GJ, Li JC. Transtympanic steroids for treatment of sudden hearing loss. Otolaryngol Head Neck Surg. 2001;125:142-6.

69. Lefebvre PP, Staecker H. Steroid perfusion of the inner ear for sudden sensorineural hearing loss after failure of conventional therapy: a pilot study. Acta Otolaryngol. 2002;122:698-702.

70. Parnes LS, Sun AH, Freeman DJ. Corticosteroid pharmacokinetics in the inner ear fluids: an animal study followed by clinical application. Laryngoscope. 1999; 109:1-17.

71. Lauterman J, Sudhoff H, Junker R. Transtympanic corticoid therapy for acute profound loss. Eur Arch Otorhinolaryngol. 2005:1-9.

72. Xenellis J, Papadimitriou N, Nikolopoulos T, Maragoudakis P, et al. Intratympanic steroid treatment in idiopathic sudden sensorineural hearing loss: a control study. Otolaryngol Head Neck Surg. 2006;134(6):940-5.

73. Arslan N, Oguz H, Demircik M, Safak MA, et al. Combined intratympanic and systemic use of steroids for idiopathic sudden sensorineural hearing loss. Otol Neurotol. 2011;32(3):393-7.

74. Wycherly BJ, Thompkins JJ, Kim HJ. Early posttreatment audiometry underestimates hearing recovery after intratympanic steroid treatment of sudden sensorineural hearing loss. Int J Otolaryngol. 2011.

75. Koltsidopoulos $P$, Bibas $A$, Sismanis $A$, Tzonou $A$, et al. Intratympanic and sistemic steroids for sudden hearing loss. Otol Neurotol. 2013;34:771-6. 
76. Yang $\mathrm{CH}$, Wu RW, Hwang CF. Comparison of intratympanic steroid Injection, hyperbaric oxygen and combination therapy in refractory sudden sensorineural hearing loss. Otol Neurotol. 2013;34:1411-6.

77. Wei BP, Stathopoulos D, O'Leary S. Steroids for idiopathic sudden sensorineural hearing loss. Cochrane Database Syst Rev. 2013.

78. Baysal E, Tunç O, Baglam T, Durucu C, et al. Systemic steroid versus combined systemic and intratympanic steroid treatment for sudden sensorineural hearing loss. J Craniofac Surg. 2013;24:432-4.

79. Gungodan O, Pinar E, Imre A, Ozturkcan S, et al. Therapeutic efficacy of the combination of intratympanic methylprednisolone and oral steroid for idiopathic sudden deafness. Otolaryngol Head Neck Surg. 2013;149(5):753-8.

80. Plontke S, Lowenheim $\mathrm{H}$, Preyer $\mathrm{S}$, et al. Outcomes research analysis of continuous intratympanic glucocorticoid delivery in patients with acute severe to profound hearing loss: basis for planning randomized controlled trials. Acta Otolaryngol. 2005;125:830-9.

81. Dallal I, Bruschini L, Nacci A, Bruschini P, et al. Transtympanic steroids as a salvage therapy in sudden hearing loss: preliminary results. ORL. 2006;68(5):185-90.

82. Choung YH, Park K, Shin YR, Cho MJ. Intratympanic dexamethasone injection for refractory sudden sensorineural hearing loss. Laryngoscope. 2006;116:747-52.

83. Chen Y, Wen L, Hu P, Qiu J, et al. Endoscopic intratympanic methylprednisolone injection for treatment of refractory sudden sensorineural hearing loss and one case in pregnancy. J Otolaryngol Head Neck Surg. 2010;39(6):640-5. 
84. Moon IS, Lee JD, Kim J, Hong SJ, et al. Intratympanic dexamethasone is an effective method as a salvage treatment in refractory sudden hearing loss. Otol Neurotol. 2011;32(9):1432-6.

85. Lee JB, Choi SJ, Park K, Park HY, et al. The efficiency of intratympanic dexamethasone injection as a sequential treatment after initial systemic steroid therapy for sudden sensorineural hearing loss. Eur Arch Otorhinolaryngol. 2011;268(6):833-9.

86. Seggas I, Koltsidopoulos $P$, Bibas A, Tzonou A, et al. Intratympanic steroids therapy for sudden hearing loss: a review of the literature. Otol Neurotol. 2010;32:2935.

87. Garavello W, Galluzzi F, Gaini RM, Zanetti D. Intratympanic steroids treatment for sudden deafness: a meta-analysis of randomized controlled trials. Otol Neurotol. 2012;33:724-9.

88. Ben-David J, Luntz M, Magamsa I, Fradis M, et al. Tinnitus as a prognostic sign in idiopathic sudden sensorineural hearing loss. Int Tinnitus J. 2001;7(1):62-4.

89. Hikita-Hatanabe N, Kitahara T, Horii A, Kawashima T, et al. Tinnitus as a prognostic factor of sudden deafness. Acta Oto-Laryngol. 2010;130:79-83.

90. Carlsson PI, Hall M, Lind KJ, Danermark B. Quality of life, psychosocial consequences, and audiological rehabilitation after sudden sensorineural hearing loss. Int J Audiol. 2011;50(2):139-44.

91. Barreto MASC, Silva IBO, Oliveira CACP, Bahmad Jr. F. Intratympanic corticotherapy and tinnitus control after sudden hearing loss. Int Tinnitus J. 2012,17(2):186-93.

92. Michiba T, Kitahara T, Hikita-Watanabe N, Fukushima M, et al. Residual tinnitus after the medical treatment of sudden deafness. Auris Nasus Larynx. 2013;40:162-6. 
93. Lee JB, Choi SJ. Potential Benefits of Combination Therapy as Primary Treatment for Sudden Sensorineural Hearing Loss. Otolaryngol Head Neck Surg. 2016;154(2):328-34.

94. Lavigne P, Lavigne F, Saliba I. Intratympanic corticosteroids injections: a systematic review of literature. Eur Arch Otorhinolaryngol. 2015;23:1-8.

95. Suckfull M. Perspectives on the pathophysiology and treatment of sudden idiopathic sensorineural hearing loss. Dtdch Arztebl Int. 2009;106(41):669-76.

96. Oiticica J, Bittar RSM, Castro CC, Grasel S, et al. Contribution of audiovestibular tests to the topographic diagnosis of sudden deafness. Int Arch Otorhinolaryngol. 2013;17(3):305-14.

97. Gattaz G, Ruggieri M, Bogar P. Estudo das Emissões Otoacusticas em adultos jovens audiologicamente normais. Braz J Otorhinolaryngol. 1994; 60(1):15-8.

98. Massaro CAM. Emissões Otoacústicas. In: Aquino AMCM (org).Processamento Auditivo: Eletrofisiologia e Psicoacústica. Lovise, 2002. p.41-61.

99. Nakamura M, Yamasoba T, Kaga K. Changes in otoacoustic emissions in patients with idiopathic sudden deafness. Audiol. 1997;36:121-35.

100. Schweinfurth JM, Cacace AT, Parnes SM. Clinical Applications of Otoacoustic Emissions in Sudden Hearing Loss. Laryngoscope. 1997; 107:1457-63.

101. Canale A, Lacilla M, Giordano C, De Sanctis A, et al. The prognostic value of the otoacoustic emission test in low frequency sudden hearing loss. Eur Arch Otorhinolaryngol. 2005;262:208-12.

102. Chao TK, Chen THH. Distortion Product Otoacoustic Emissions as a Prognostic Factor for Idiopathic Sudden Sensorineural Hearing Loss. Audiol Neurotol. 2006;11:331-8. 
103. Hoth S. On a possible prognostic value of otoacoustic emissions: A study on patients with sudden hearing loss. Eur Arch of Otorhinolaryngol. 2006; 262(3):217224.

104. Amiridavan M, Nemati S, Hashemi SM, Jamshidi M, et al. Otoacoustic emissions and auditory brainstem responses in patients with sudden sensorineural hearing loss. Do otoacoustic emissions have a prognostic value? Journal of Research in Medical Sciences. 2006;11(4):263-9.

105. Hyeon No Y, Choi G, Park CW, Kwon JH, et al. Clinical usefulness of otoacoustic emission sum in sudden sensorineural hearing loss patients. Korean $\mathrm{J}$ Otorhinolaringol Head Neck Surg. 2013;56:212-6.

106. Shupak A, Zeidan R, Shemesh R. Otoacoustic Emissions in the Prediction of Sudden Sensorineural Hearing Loss Outcome. Otol Neurotol. 2014; 10:1-7.

107. Jerger J. Clinical experience with impedance audiometry. Arch Otolaryngol. 1970;92(4):311-24.

108. Menegotto IH, Costa MJ. Avaliação da percepção de fala na avaliação audiológica convencional. In: Boéchat EM, Menezes PL, Couto CM, Frizzo ACF, et al. Tratado de Audiologia. São Paulo: Santos, cap.9.2015.p.67-75.

109. Lonsbury-Martin BL, Martin GK, Telischi FF. Emissões Otoacústicas na prática clínica. In: Musiek FE, Rintelmann WF. Perpectivas Atuais em Avaliação Auditiva. São Paulo: Manole, cap.6. 2001. p.163-192.

110. OTOREAD. OPERATION MANUAL - Standard \& Clinical. Interacoustic - ver. 11/2005. OTOREAD.

111. Piza MRT, Cóser PL, Alvarenga KF. Eletrofisiologia da audição e emissões otoacústicas: princípios e aplicações clínicas. 2 ed; 2010. p.120. 


\title{
ANEXO I
}

\section{Aprovação no Comitê de Ética}

\author{
Parecer Consubstanciado \\ Projeto: $132 / 12$ \\ Data $11 / 09 / 2012$ \\ Projeto: Doutorado - Monique Antunes de Souza Chelminki Barreto, Orientador: Dr. \\ Fayez Bahmad Júnior \\ Análise da Eficácia da Corticoterapia intratimpânica e corticoterapia via oral em \\ pacientes com surdez.
}

\section{PARECER}

\section{Apresentação / Sumário do Projeto}

$\mathrm{O}$ estudo se propõe a analisar a eficácia de diferentes modalidades terapêuticas em pacientes com surdez neurossensorial súbita. Pretende realizar avaliação auditiva por meio da Audiometria Tonal Limiar, Audiometria Vocal, Imitanciometria, Emissões Otoacústicas Evocadas e Potenciais Evocados antes do tratamento proposto (Metilpredinisolona via oral e/ou intratimpânica) e posteriormente, por um período de 18 meses de acompanhamento. Além das avaliações auditivas, pretende-se ainda acompanhar a queixa de zumbido por meio de instrumentos validados (Questionário e Escala Análogo Visual). Visa avaliar 40 indivíduos no Instituto Brasiliense de Otorrinolaringologia.

Despesas: $\mathrm{R} \$ 58.220,00$ (cinquenta e oito mil, duzentos e vinte reais). Todas as despesas serão de responsabilidade da pesquisadora e orientador. O transporte dos sujeitos para realização das etapas do estudo será custeado pela pesquisadora assim como demais ônus. Os exames não serão cobrados e os resultados serão entregues aos sujeitos participantes. Pretende-se patrocínio para a aquisição ou a oferta da medicação proposta para o estudo. Na impossibilidade deste, os custos serão arcados pela pesquisadora e orientador.

\section{Objetivo Geral:}

Analisar a eficácia de diferentes modalidades terapêuticas em pacientes com surdez neurossensorial súbita.

\section{Objetivos Específicos:}

* Analisar as medidas psicoacústicas e eletrofisiológicas em pacientes com surdez neurossensorial súbita submetidos a diferentes modalidades terapêuticas;

* Verificar a incidência de alterações na função das células ciliadas externas em pacientes com surdez neurossensorial súbita submetidos a diferentes modalidades terapêuticas;

* Verificar a incidência de alterações nas vias auditivas centrais em pacientes com surdez neurossensorial súbita submetidos a diferentes modalidades terapêuticas;

* Mensurar o impacto do zumbido na qualidade de vida de pacientes com surdez neurossensorial súbita submetidos a diferentes modalidades terapêuticas.

Para todas as análises, serão realizadas comparações entre o grupo controle (GC) e os grupos de estudo (G1, G2, G3).

Avaliação dos riscos e benefícios/metodologia:

- Instituição: Instituto Brasiliense de Otorrinolaringologia, Brasília, DF

- Número de sujeitos da pesquisa: 40 pacientes, A amostra será composta por sujeitos que apresentarem o diagnóstico de surdez neurossensorial súbita no período de referência de 18 meses de coleta.

- Critérios de inclusão e exclusão: adultos com perda auditiva neurossensorial igual ou maior que $30 \mathrm{~dB}$ NPS (decibél nível de pressão sonora) em pelo menos três frequências consecutivas, com instalação súbita ou no máximo em 72 horas, com idade mínima de 18 anos, de ambos os sexos, que não tenha sido submetido a cirurgia otológica prévia; que não apresente sinais de otite média aguda ou crônica; sem história de Síndrome de Ménière ou flutuação da audição. 
O estudo será do tipo Ensaio Clínico Prospectivo, randomizado, cego, placebo-controlado em que os sujeitos serão alocados em quatro grupos aleatoriamente, conforme a modalidade terapêutica aplicada: Modalidade Terapêutica:

* G1-corticoterapia via oral (VO) $(\mathrm{n}=10)$

* G2-corticoterapia via oral (VO)+ corticoterapia intratimpânica (IT) (n=10)

* G3-corticoterapia via oral (VO) + solução salina intratimpânica (IT) (n=10)

* GC-sujeitos que procuram o tratamento após 30 dias da instalação da surdez neurossensorial súbita, sem tratamento $(\mathrm{n}=10)$

A corticoterapia será realizada por médico Otorrinolaringologista da seguinte forma:

Via oral: Metilprednisolona $1 \mathrm{mg} / \mathrm{Kg} /$ dia, por quatorze (14) dias, com redução gradativa após cinco (5) dias e completa retirada ao final de três semanas.

Via intratimpânica: $40 \mathrm{mg} / \mathrm{ml}$ de Metilprednisolona, sendo quatro (4) injeções com intervalo de 48 horas entre elas.

Todos os pacientes serão tratados ambulatorialmente, não havendo necessidade de internação. O procedimento da corticoterapia intratimpânica será realizado com uso de microscópio, onde será utilizado anestésico em spray diretamente no conduto auditivo externo e, posteriormente, com a cabeça posicionada $45^{\circ}$ em direção a orelha não afetada, aplicado a solução de metilprednisolona (aproximadamente $0,5 \mathrm{ml}$ ). Serão realizados dois orifícios com a própria agulha de aplicação, um logo abaixo do umbo, para aplicar a medicação e outro na região póstero-superior para servir de orifício de escape, não havendo necessidade de tubo de ventilação. Após a aplicação, o indivíduo deverá permanecer por 45 minutos em posição supina, com a cabeça fletida $45^{\circ}$ para maximizar o efeito da solução utilizada.

A coleta de dados será realizada da seguinte forma:

3.4.1. Questionário Tinnitus Handicap Inventory (THI) (Anexo I)

3.4.2. Escala Análogo - Visual (EAV) (Anexo II)

3.4.3. Exames realizados no início da enfermidade, aos 7 dias, 14 dias, 30 dias, 90 dias, 120 dias e 180 dias, totalizando 6 meses de acompanhamento (Bahmad et al., 2010).

A) Meatoscopia para avaliar presença de cerume que poderia prejudicar o resultado dos exames

B) Audiometria Tonal Limiar utilizando Audiômetro Equinox Suite, Interacoustic, apresentando tons puros de $250 \mathrm{~Hz}$ a $8000 \mathrm{~Hz}$, de intensidade máxima de $120 \mathrm{~dB}$, para avaliar os limiares auditivos, por via aérea e via óssea.

C) Audiometria Vocal: índice percentual de reconhecimento de fala (IPRF) e limiar de recepção de fala (LRF) com o Audiômetro Equinox Suite.

D) Imitanciometria utilizando o equipamento AT 235, Interacoustic, com o objetivo de avaliar as condições da orelha média.

E) Emissões Otoacústicas Evocadas Transiente e por Produto de Distorção (EOAET e EOAEPD): realizado com o equipamento Eclipse EP-25, Interacoustic, conectado ao computador, com o objetivo de avaliar o funcionamento das células ciliadas externas;

F) Potenciais Evocados Auditivos de Tronco Encefálico (PEATE/BERA): realizado com o equipamento Eclipse EP-25, Interacoustic, conectado ao computador, com o objetivo de avaliar a integridade das vias auditivas centrais.

A avaliação da recuperação auditiva será realizada através:

a) taxa de melhora, que mensura o ganho auditivo em percentual e usa o lado contralateral como referência. Os limiares auditivos serão calculados utilizando-se a média das frequências de 250,500 , $1000,2000,4000$ e $8000 \mathrm{~Hz}$ e as taxas de melhora acima de $90 \%$ serão definidas como recuperação total; entre $21 \%$ e $89 \%$ como recuperação parcial (entre 51 e $89 \%$ considerada boa e entre 21 e $50 \%$ considerada regular e finalmente, se a taxa de melhora for inferior a $20 \%$, será considerado como falha 
terapêutica (Shiraishi et al. 1993).

Taxa de melhora $(\%)=$ Limiar inicial - Limiar final X 100. Limiar inicial - Limiar do ouvido contralateral;

b) melhora de $20 \mathrm{~dB}$ nas frequências de $500 \mathrm{~Hz}, 1000 \mathrm{~Hz}$ e $2000 \mathrm{~Hz}$ ou $20 \%$ de melhora da discriminação auditiva (Índice Percentual de Reconhecimento de Fala) (Bahmad et al., 2010).

Documentos analisados:

1.

2. Folha de rosto

3. Termo de responsabilidade e compromisso dos pesquisadores

4. Termo de concordância do Instituto Brasiliense de Otorrinolaringologia, pelo Diretor Dr. Fayez Bahmad Júnior

5. Projeto de pesquisa

6. Questionário THI (Tinnitus Handicap Inventory) brasileiro

7. Escala visual análoga (EVA)

8. TCLE

9. Cronograma: Início em 2013 e término em 2016

10. Currículo dos pesquisadores

Conclusão

O projeto atende as especificações da Resolução 196/96 e suas complementares

Recomendação

Aprovação 
ANEXO II: QUESTIONÁRIO TINNITUS HANDICAP INVENTORY E ESCALA VISUAL ANALÓGICA

Nome:

Data de Nascimento / / Escolaridade

Gênero Masc. Fem

Data:

\begin{tabular}{|c|c|c|c|c|}
\hline & Tinnitus Handicap Inventory (THI) & Sim & $\begin{array}{l}\text { As } \\
\text { vezes }\end{array}$ & Não \\
\hline 1 & Devido ao seu zumbido é difícil se concentrar? & & & \\
\hline 2 & $\begin{array}{l}\text { O volume (intensidade) do seu zumbido faz com que seja } \\
\text { difícil escutar as pessoas? }\end{array}$ & & & \\
\hline 3 & O seu zumbido deixa você nervoso? & & & \\
\hline 4 & O seu zumbido deixa você confuso? & & & \\
\hline 5 & Devido ao seu zumbido, você se sente desesperado? & & & \\
\hline 6 & Você se queixa muito do seu zumbido? & & & \\
\hline 7 & $\begin{array}{l}\text { Devido ao seu zumbido, você tem dificuldade para pegar } \\
\text { no sono à noite? }\end{array}$ & & & \\
\hline 8 & $\begin{array}{l}\text { Você sente como se não pudesse se livrar do seu } \\
\text { zumbido? }\end{array}$ & & & \\
\hline 9 & $\begin{array}{l}\text { O seu zumbido interfere na sua capacidade de } \\
\text { aproveitar atividades sociais (tais como sair para jantar, } \\
\text { ir ao cinema)? }\end{array}$ & & & \\
\hline 10 & Devido ao seu zumbido, você se sente frustrado? & & & \\
\hline 11 & $\begin{array}{l}\text { Devido ao seu zumbido, você pensa que tem uma doença } \\
\text { grave? }\end{array}$ & & & \\
\hline 12 & O seu zumbido torna difícil aproveitar a vida? & & & \\
\hline 13 & $\begin{array}{l}\text { O seu zumbido interfere nas suas tarefas no serviço e em } \\
\text { casa? }\end{array}$ & & & \\
\hline 14 & $\begin{array}{l}\text { Devido ao seu zumbido, você se sente frequentemente } \\
\text { irritado? }\end{array}$ & & & \\
\hline 15 & Devido ao seu zumbido, você acha difícil ler? & & & \\
\hline 16 & O seu zumbido deixa você chateado? & & & \\
\hline 17 & $\begin{array}{l}\text { Você sente que o seu zumbido atrapalha o seu } \\
\text { relacionamento com a sua família e amigos? }\end{array}$ & & & \\
\hline 18 & $\begin{array}{l}\text { Você acha difícil tirar a sua atenção do zumbido e se } \\
\text { concentrar em outra coisa? }\end{array}$ & & & \\
\hline 19 & Você sente que não tem controle sobre o seu zumbido? & & & \\
\hline 20 & $\begin{array}{l}\text { Devido ao seu zumbido, você se sente frequentemente } \\
\text { cansado? }\end{array}$ & & & \\
\hline 21 & $\begin{array}{l}\text { Devido ao seu zumbido, você se sente frequentemente } \\
\text { deprimido? }\end{array}$ & & & \\
\hline 22 & O seu zumbido faz com que você sinta ansioso? & & & \\
\hline 23 & Você sente que não pode mais suportar o seu zumbido? & & & \\
\hline 24 & O seu zumbido piora quando você está estressado? & & & \\
\hline 25 & O seu zumbido faz com que você se sinta inseguro? & & & \\
\hline
\end{tabular}

Escala Visual Analógica (EVA)

$\begin{array}{lllllllllll}0 & 1 & 2 & 3 & 4 & 5 & 6 & 7 & 8 & 9 & 10\end{array}$

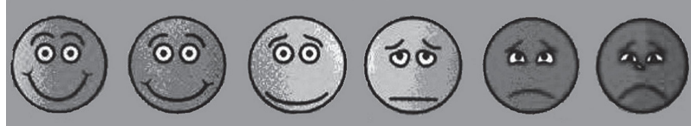




\section{APÊNDICE A}

\section{ANAMNESE}

IDENTIFICAÇÃO:

Nome:

Idade: Sexo: Raça: Profissão Tel: Data:

Endereço:

HISTÓRIA:
1) Tempo de Zumbido:
a) $<3$ meses
c) 6-9 meses
e) $12-15$ meses
b) 3-6 meses
d) 9-12 meses
e) 15-18 meses

2) Localização:

a) O.D. / O.E. / ambos b) lado pior: D / E / / cabeça não

3) Tipo:

$\begin{array}{ll}\text { a) único / múltiplo } & \text { c) pulsátil / clique }\end{array}$

b) flutuação de volume d) objetivo

e) descrição:

4) Evolução:

a) súbito / progressivo

b) constante /

a) manhã / noite

intermitente

5) Fatores de piora:

b) barulho / silêncio

c) álcool / cigarro

e) exercício

a) rádio / TV / fundo

d) nervosismo

f) jejum

6) Fatores de melhora:

b) medicamentos

7) Interferência:
a) sono
c) Emotional
b) concentração
d) Social

8) Hipoacusia:

a) D / E / bilateral / não c) ambiente ruidoso

c) rot. cervical: ( ) ipsi ( ) contra
b) progressiva / estável / flutuante
d) plenitude D / E / bilateral

e) hiperacusia / fonofobia / recrutamento

9) Efeito do barulho:
a) nenhum
b) melhora

f) proteção auricular
a) vertigem / instabilidade
c) piora com

10) Tonturas:
b) minutos / horas / dias

c) piora (minutos / horas / dias)

11) Cirurgia otológica prévia
12) Cefaléia:
a) não
b) sim:
13) ATM:
a) dor
c) bruxismo
b) estalos
d) não
14) Hábitos:
a) tabagismo / elitismo b) café / chocolate
c) doces
15) Queixa Principal:
a) zumbido
b) surdez
c) outra:
16) Queixas
secundárias:
a) zumbido
b) surdez
c) vertigem
d) plenitude auricular e) outras: 


\section{APÊNDICE B}

\section{TERMO DE CONSENTIMENTO LIVRE E ESCLARECIDO-TCLE}

O (A) senhor (a) está sendo convidado (a) a participar da pesquisa intitulada "CARACTERIZAÇÃO DO ZUMBIDO SUBJETIVO AGUDO EM PORTADORES DE PERDA AUDITIVA NEUROSSENSORIAL SÚBITA IDIOPÁTICA".

Tal pesquisa justifica-se pela necessidade de promover a saúde auditiva dos sujeitos com zumbido agudo e perda auditiva súbita. Serão realizadas uma entrevista, testes auditivos não invasivos, rápidos e indolores, quais sejam audiometria tonal limiar, audiometria vocal e Teste de Emissões Otoacústicas Evocadas. Será ofertada a terapia por meio da ingestão de corticoide via oral (predinisolona) e/ou aplicação de metilprednisolona intratimpânica.

Os procedimentos são ambulatoriais, a medicação é de fácil administração e pode ser utilizada logo após o diagnóstico, relativamente sem dor, com possibilidade de ser utilizada em pacientes com contra-indicação ao uso de corticoide por via oral (exemplo: imunocomprometidos, tuberculose, diabetes), são altas concentrações da medicação diretamente na orelha e os efeitos adversos são raros (Raymundo et al., 2010).

A sua participação nesta pesquisa é voluntária.

O desconforto se deve ao tempo dispensado na entrevista e realização dos exames, que é cerca de 2 horas, bem como decorrentes da aplicação da medicação que pode apresentar os seguintes riscos: dor de ouvido e vertigem (menos de $1 \%$ dos casos). Tais sintomas são de fácil controle com uso de analgésicos como dipirona e paracetamol (Raymundo et al., 2010).

Informo que o $\mathrm{Sr}(\mathrm{a})$ tem a garantia de acesso, em qualquer etapa do estudo, sobre qualquer esclarecimento de eventuais dúvidas e é garantida a liberdade da retirada deste consentimento a qualquer momento e deixar de participar da pesquisa, sem qualquer tipo de penalidade, recebendo os resultados até o momento em que participar

Nos comprometemos a utilizar os dados coletados somente para pesquisa, e os resultados serão veiculados através de artigos científicos, em revistas especializadas e/ou em encontros científicos e congressos, sem nunca tornar 
possível a sua identificação, assegurando desta forma, o sigilo e a privacidade dos seus dados.

Não existirão despesas ou compensações pessoais para o participante em qualquer fase do estudo. Também não há compensação financeira relacionada à sua participação.

Se o(a) Senhor(a) tiver qualquer dúvida em relação à pesquisa, por favor telefone para: Fga. Monique Antunes de Souza Chelminski Barreto, telefone (61) 8203-0599 ou no telefone (61) 3542-8017 ou ainda no Instituto Brasiliense de Otorrinolaringologia, telefone: (61) 3328-6009.

Este projeto foi Aprovado pelo Comitê de Ética em Pesquisa da Faculdade de Ciências da Saúde da Universidade de Brasília. As dúvidas com relação à assinatura do TCLE ou os direitos do sujeito da pesquisa podem ser obtidos através do telefone: (61) 3107-1947.

Este documento foi elaborado em duas vias, uma ficará com o pesquisador responsável e a outra com o sujeito da pesquisa.

Brasília, de $2014 / 2015$.

\begin{tabular}{ll}
\hline Nome da pesquisadora responsável & Assinatura \\
\hline Nome do participante & Assinatura
\end{tabular}

Comitê de Ética em Pesquisa com Seres Humanos da Faculdade de Ciências da Saúde da Universidade de Brasília

cepfs@unb.br 